
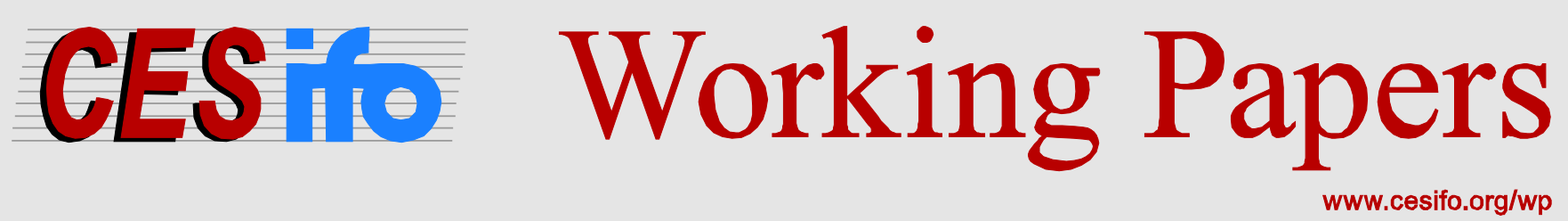

\title{
Heterogeneous Economic Integration Agreement Effects
}

\author{
Scott L. Baier \\ Jeffrey H. Bergstrand \\ Matthew W. Clance
}

CESIFO WORKING PAPER NO. 5488

Category 8: Trade Policy

August 2015

An electronic version of the paper may be downloaded

- from the SSRN website:

- from the RePEc website:

- from the CESifo website:

wWw.SSRN.com

www.RePEc.org

www.CESifo-group.org/wp 


\title{
Heterogeneous Economic Integration Agreement Effects
}

\begin{abstract}
Gravity equations have been used for more than 50 years to estimate ex post the partial effects of trade costs on international trade flows, and the well-known - and traditionally presumed exogenous - "trade-cost elasticity" plays a central role in computing general equilibrium tradeflow and welfare effects of trade-cost changes. This paper addresses theoretically and empirically the influence of variable and fixed export costs in explaining the likely heterogeneity in the trade-cost elasticity. We offer four potential contributions. First, for motivation, we show empirically that the heterogeneity in various economic integration agreements' (EIAs') partial effects on trade flows far exceeds that explained simply by variation in depth of the trade liberalization. Second, we use standard Armington- and Melitz-type general equilibrium trade models to motivate theoretically the roles of variable trade costs and of fixed and variable export costs, respectively, for explaining (endogenous) heterogeneous partial effects of changes in ad valorem tariff rates on trade flows, as well as on intensive and extensive product margins (with or without network effects and with an untruncated Pareto distribution in the Melitz model). Third, we show empirically that the heterogeneity in EIAs' partial effects on the intensive margin is explained well just by distance and adjacency, capturing variable natural trade costs; however, the heterogeneity in EIAs' partial effects on the extensive margin is explained empirically by distance and adjacency, as well as several other cultural and institutional variables, capturing variable and fixed export costs. Fourth, we show that such estimated heterogeneous effects can predict 83-94 percent of economic welfare effects of EIAs and can potentially predict ex ante a potential EIA's partial trade-flow effect and general equilibrium welfare effect.
\end{abstract}

JEL-Code: F100, F120, F130, F140, F150.

Keywords: international trade, economic integration agreements, gravity equation.

Scott L. Baier

John E. Walker Department of Economics

Clemson University

USA - Clemson, SC 29634

Jeffrey H. Bergstrand

sbaier@clemson.edu

University of Notre Dame

USA - Notre Dame, IN 46556

bergstrand.1@nd.edu

Matthew W. Clance

Department of Economics University of Pretoria

South Africa - Hatfield 0028

mwclance@gmail.com 
"The welfare effects in this class of model are linked to the change in the share of trade that takes place inside a country.... Intuitively, because the initial flows are so small, even doubling trade with ex-colonies will result in very tiny changes in the share of expenditure that is spent locally. In contrast, adding even a few percentage points of trade with a major partner will be much more important for welfare." (Head and Mayer, "Gravity Equations," Handbook of International Economics, vol. 4, 2014; bold added)

\section{Introduction}

The "gravity equation" has been used for more than 50 years since Tinbergen (1962) to explain statistically ex post the cross-sectional and panel variation of bilateral international (aggregate goods) trade flows and the partial effects of economic integration agreements (EIAs) on such flows. However, the link between these ex post estimates and the welfare gains from trade liberalization has been - at best - tenuous. This paper addresses this shortcoming, picking up to a large extent where Helpman, Melitz, and Rubinstein (2008) left off. While fixed export costs and firm heterogeneity are now recognized as important to explain intensive margin, extensive margin, and aggregate trade flow levels, we show that such factors are also important to explain quantitatively the size of partial effects of EIAs (and, in general, trade liberalizations) on intensive margin, extensive margin and aggregate trade flow levels and to approximate the (general equilibrium) welfare effects of EIAs.

Typically, the trade flow from one country to another in a gravity equation is explained using the exporting and importing countries' gross domestic products (GDPs), bilateral distance, and an array of other explanatory variables, including dummy variables for EIAs. In fact, one focus of Tinbergen (1962) was to examine the partial effect of preferential trade agreements on trade flows. While Tinbergen (1962) is typically cited as the first published gravity-equation study of trade flows, researchers using the international trade gravity equation have seldom explored some of the novel contributions - and anomalies - of this seminal study. For instance, Tinbergen's first specifications included dummy variables for common membership in the British Commonwealth and for common membership in the Belgium-Netherlands-Luxembourg (BENELUX) economic union. Allowing the two agreements to have heterogeneous (partial) effects, Tinbergen found trivial impacts of these agreements on members' trade. However, in a later specification using a single dummy for membership in any preferential trade agreement, Tinbergen found that common membership increased trade for the typical pair by more than 100 percent. This completely overlooked contrasting result is just one of several motivations for our paper exploring determinants of the heterogeneity in EIAs' partial effects.

Of course, hundreds of gravity-equation analyses have been published (and many more completed) in the last 50 years with thousands of estimates of (like Tinbergen (1962)) the bilateral trade impacts of common membership in some form of EIA. ${ }^{1}$ Cipollina and Salvatici (2010) conducted a meta analysis of estimates of the (partial) effects of EIAs on trade flows and found a mean (median) effect of 0.59 (0.38), implying an increase of 80 (46) percent. The effects range from -9.01

\footnotetext{
${ }^{1}$ We use the term economic integration agreement to broadly capture any of one-way or two-way preferential trade agreements, free trade agreements, customs unions, common markets, or economic unions.
} 
to 15.41 including outliers. Once fixed or random effects are introduced, the minimum estimate is 0.01 and the maximum estimate is 1.52. Similarly, Head and Mayer (2014) in a meta analysis found mean (median) estimates of 0.59 (0.47) and considerable partial effect heterogeneity. The vast heterogeneity in EIAs' estimated trade-flow effects motivated Anderson and van Wincoop (2004) to note:

"Implausibly strong regularity (common coefficients) conditions are often implicitly imposed on the trade cost function [in gravity equations]. For example, the effect of membership in a customs union or a monetary union on trade costs is often assumed to be uniform for all members. (p. 711)

This paper has four goals. First, using a random coefficients econometric analysis we demonstrate that - not only is there considerable heterogeneity in EIAs' (partial) impacts on trade but - the heterogeneous EIA effects far exceed what can be explained by the degree of trade liberalization of such agreements. It is well known that every economic integration agreement is unique in terms of the degree of trade liberalization, e.g., degree of decline in $\tau_{i j t}$ (where $\tau_{i j t}$ is an ad valorem measure of tariffs and nontariff barriers of country $j$ on country $i$ 's goods in year $t$ ). However, it is also well known that empirical ad valorem measures of bilateral tariff rates are subject to measurement error; ad valorem measures of nontariff barriers (also lowered by EIAs) are likely worse. Yet the reduction of nontariff barriers has been taking center stage in recent important proposed EIAs, such as the Transatlantic Trade and Investment Partnership (TTIP), cf., Berden, Francois, Tamminen, Thelle, and Wymenga (2010) and Francois, Manchin, Norberg, Pindyuk, and Tornberger (2013). Moreover, as Anderson and van Wincoop (2004) note, "Particularly egregious is the paucity of good data on policy barriers" (p. 693). ${ }^{2}$ Consequently, recent advances in gravity-equation modeling have turned to panel data methodologies to find unbiased and precise empirical estimates of the "average treatment effects" of EIAs on trade flows to avoid the measurement-error issues associated with crude estimates of $\tau_{i j t}$, cf., Baier and Bergstrand (2007), Anderson and Yotov (2011), and Eicher, Henn, and Papageorgiou (2012). In particular, Baier, Bergstrand, and Feng (2014), or BBF, found economically plausible, unbiased, and precise estimates of the average treatment effects of one-way preferential, two-way preferential, free, and "deeper" trade agreements. In section 2, we extend the methodology in BBF to show that the heterogeneity in EIAs' partial effects on trade far exceeds that from the degree of liberalization, suggesting the need to search for other factors to explain the heterogeneity in EIA (partial) effects. Preliminary empirical evidence from Baier, Bergstrand, and Clance (2015) suggests that EIA dummies' coefficient estimates are systematically related to various observable bilateral trade-cost proxies.

Second, motivated by the empirical random coefficients analysis, we use Armington- and Melitztype general equilibrium models to explain theoretically why trade-cost elasticities are likely endogenous and related to the levels of country-pairs' variable export costs and fixed and variable export costs, respectively (and do not necessarily depend on externalities or the underlying distribution

\footnotetext{
${ }^{2}$ See Anderson and van Wincoop (2004), section 2 for a poignant and thorough description of the inadequacy of data on tariffs and non-tariff measures for trade economists.
} 
of productivities in the Melitz model). Only four recent studies (to the authors' knowledge) have argued that trade-cost elasticities are theoretically endogenous. Helpman, Melitz, and Rubinstein (2008), or HMR, was the first to generate a rationale for heterogeneous trade impacts of a given percent change in trade costs using constant elasticity of substitution (CES) utility. With heterogeneous firms, HMR argued that a given percent change in trade costs would cause some countries to start trading (via the extensive margin); the trade-cost elasticity becomes endogenous to the specific country-pair $i j$ as determined by the probability of positive exports for pair $i j\left(\rho_{i j}\right)$. Their empirical exercise showed that the distance elasticity varied and tended to decrease (in absolute terms) with the per capita income of the country-pair; however, they did not explore the explicit relationship of this heterogeneity to variable trade costs relative to fixed trade costs, nor fixed policy trade costs relative to fixed non-policy trade costs. Krautheim (2012) picked up on the relevance of the extensive margin with CES preferences for influencing the trade-cost elasticity by introducing network effects. In his baseline model, network effects (spillovers) "magnify" the trade-cost elasticity, but do not endogenize it. In his paper's last section, consideration of an additively separable fixed export cost potentially endogenizes his trade-cost elasticity; however, he does not derive closed-form solutions for the endogenous trade-cost-elasticity case. More recently, Melitz and Redding (2015) detailed the importance of "small deviations" from the parameter restrictions in Arkolakis, Costinot, and Rodriguez-Clare (2012), or ACR, to demonstrate that trade-cost elasticities are potentially endogenous. In particular, Melitz and Redding (2015) show that a simple distinction between untruncated and truncated Pareto productivity distributions can cause the difference between exogenous and endogenous trade-cost elasticities. With a truncated Pareto productivity distribution, the trade-cost elasticity is sensitive to the share of exporters in the domestic market (and the cutoff productivity), a function of the specific country-pair's fixed export costs; in the case of an untruncated Pareto distribution, their trade-cost elasticity is exogenous. While all three papers focus on extensive margin effects for endogenizing the trade-cost elasticity, all maintain the intensive-margin trade-cost elasticity to be constant (under CES preferences). Only Novy (2013) conjectured theoretically an endogenous trade-cost elasticity by assuming (non-CES) transcendental logarithmic (or translog) preferences; however, his empirical work used aggregate trade flows, rather than intensive margins, for evidence.

This paper extends this literature theoretically. In section 3, we show in the context of a simple Armington model with constant-elasticity-of-substitution preferences how tariff removals' effects on trade (at the intensive margin) - that is, the "trade-cost" elasticity - can be sensitive to the levels of ad valorem bilateral variable export costs between two countries by assuming the more empirically plausible trade-cost function of Hummels and Skiba (2004) and Anderson and van Wincoop (2004). In section 4, we extend the Melitz-type model in Krautheim (2012) to motivate how the interactions of exogenous factors influencing fixed export costs (such as bilateral distance as well as bilateral dummy variables capturing institutional (policy) and cultural (non-policy) characteristics) with endogenous fixed export costs associated with "network effects" can additionally explain theoretically the sensitivity of the elasticity of the extensive margin of trade flows with respect to variable tariff rate levels and with respect to fixed export costs (even with an untruncated Pareto productivity 
distribution). We derive novel closed-form solutions for the relationships between (additively separable) exogenous fixed export costs, endogenous network fixed export costs, productivity cutoffs, and extensive margins of trade with CES preferences and for the relationships between policy-based fixed export costs, non-policy based fixed export costs, productivity cutoffs, and extensive margins of trade.

Third, guided by these theoretical results, we show empirically that the heterogeneity in EIAs' effects can be explained well by (exogenous) observable factors commonly used to explain these variable and fixed export costs. In section 5, we use our theory to motivate the relationships between HMR's "geographic, institutional, and cultural" variables and the variation in EIAs' effects on the intensive and extensive margins. Specifically, we show that distance and adjacency - influencing variable transport costs - explain well the heterogeneity in EIA partial effects on the intensive (product) margin. Moreover, distance, adjacency, and typical gravity dummy variables reflecting common institutional and cultural country characteristics - capturing (policy and non-policy, respectively) fixed export costs - explain well the heterogeneity in EIA partial effects on the extensive (product) margin. To the best of our knowledge, only two studies have estimated heterogeneous EIA effects using interaction terms like here to avoid the dilemma of a multitude of individual dummies that yield econometrically weak coefficient estimates. Vicard (2011) investigated empirically interactions of numerous economic variables with EIA dummies, but the study was not guided by theory and so interaction effects lacked economic interpretation. Cheong, Kwak, and Tang (2015) examined empirically interactions of EIA dummies with measures of GDP size and similarity and found significant effects, but this study also lacked theoretical guidance. Also, both of those studies looked only at aggregate trade flows. Our study is unique by offering theoretical guidance from Armington and Melitz models to understand the roles of variable trade costs and of fixed and variable export costs, respectively - with or without network externalities and with an untruncated Pareto distribution for explaining heterogeneous EIA effects, for explaining differential EIA effects - quantitatively and qualitatively - on intensive and extensive (product) margins, and for controlling for various degrees of EIA liberalization (as raised in Kohl, Brakman, and Garretsen (2014)). ${ }^{3}$

Since our theory suggests that EIAs' effects may be influenced by factors influencing both the intensive and extensive margins of trade, Section 6 employs the Hummels and Klenow (2005) productmargin-decomposition methodology to explore empirically how distance and other factors influence such margins' EIA effects. We show that various factors influence EIAs' effects on intensive and extensive margins of trade differently, quantitatively and qualitatively. This section also provides a robustness analysis of our main results to lagged terms-of-trade effects, nontradable goods' "cutoffs," and interaction effects by type of EIA. ${ }^{4}$

\footnotetext{
${ }^{3}$ We intentionally use an untruncated Pareto distribution for productivities to distinguish the economic channels explaining our endogenous trade-cost elasticities from those channels addressed in Melitz and Redding (2015).

${ }^{4}$ It is important to note that, although we focus on heterogeneous partial effects of EIA dummies, our analysis holds in principle for ad valorem tariff rates as well, such as in Baier and Bergstrand (2001). Our focus empirically on heterogeneous EIA dummy coefficients, rather than heterogeneous tariff-rate elasticities, is due to the "paucity" of high quality ad valorem tariff-rate (and nontariff-rate) data and the empirical prominence of EIA dummies in the literature. Nevertheless, our theory will be cast with a focus on heterogeneous partial tariff-rate elasticities. We leave for future research applying the methodology in this paper to the case where high quality ad valorem measures of bilateral tariff and nontariff barriers are available.
} 
Fourth, we address directly our introductory quote and show that the our approach to gravityequation modeling now makes more plausible ex ante use of gravity equations for predicting the partial effects of future EIAs and their likely welfare effects. Studies such as Baier and Bergstrand (2007), or BB, and BBF can help policymakers predict future partial (and then general) equilibrium effects of a planned EIA; BB (BBF) predicts the average effect without (with) regard to type of EIA. However, those predicted partial effect estimates are homogeneous across country-pairs (based on average treatment effects). In section 7 , we show that estimating quantitatively the sensitivity of estimated partial effects to geographic, institutional, and cultural characteristics enables gravity equations to more precisely inform policy makers ex ante of pair-specific predicted impacts of EIAs - accounting for both heterogeneous general and partial equilibrium effects. We will show that the heterogeneity of EIA partial effects helps to explain the likely welfare gains and predictability of EIAs, as well as the timing of EIAs. For instance, we will show that 83-94 percent of the welfare gain for country $j$ of an EIA with country $i$ can be explained by the heterogeneous partial trade elasticity along with the share of country $j$ 's imports from country $i$, consistent with the introductory quote. Put succinctly, previous gravity equations allowing for heterogeneous partial effects of EIAs on trade have been limited not just by weak estimates (to be discussed shortly), but allowed only ex post evaluation. Our paper suggests a methodology for generating robust and precise partial effect estimates that can also be used potentially for ex ante trade and welfare analysis, which we demonstrate in Section 8 for the the proposed Transatlantic Trade and Investment Partnership (TTIP). ${ }^{5}$ Section 9 provides conclusions.

\section{Empirical Motivation for the Theory}

In this section, we demonstrate that there is considerable heterogeneity in the (partial) effects of EIAs, independent of the depth of the EIA, using a random coefficients econometric approach. First, we address econometrically how the most recent panel approach to estimate gravity can be extended to allow for random coefficient estimates to illustrate the large heterogeneity of EIA effects - even after accounting for the depth of EIA. The second section discusses the data and presents the results.

\subsection{Heterogeneous Partial EIA Effects}

Most of the trade-policy liberalizations in the past 25 years have been bilateral (and plurilateral) EIAs, such as free trade agreements. However, typically EIAs are broad agreements reaching beyond elimination of ad valorem tariff rates (which are variable trade costs). They have also lowered fixed export costs. ${ }^{6}$ For instance, see Horn, Mavroidis, and Sapir (2010) on the numerous non-

\footnotetext{
${ }^{5}$ It should also be noted that traditional ex ante computable general equilibrium models typically use trade-cost elasticities previously estimated from empirical specifications assuming homogeneous average partial effects. We also address in section 7 that our heterogeneous trade-cost elasticities violate macro restriction R3 in Arkolakis, Costinot, and Rodriguez-Clare (2012) so that welfare cannot be measured solely by the share of domestic output absorbed domestically and an exogenous trade-cost elasticity.

${ }^{6}$ Consequently, later in the paper, we will distinguish bilateral fixed export costs associated with "policy," denoted $F_{i j t}^{X P}$, from bilateral fixed export costs associated with "non-policy," or "natural," factors, denoted $F_{i j t}^{X N}$.
} 
tariff-rate provisions covered in an anatomy of European Union and United States' preferential trade agreements. Thus, EIA liberalizations likely lower $\tau_{i j t}$ and $F_{i j t}^{X P}$. Moreover, as noted in the introduction, empirical ad valorem measures of bilateral tariff rates are subject to measurement error; ad valorem-equivalent measures of nontariff barriers (also lowered by EIAs) are worse. This measurement issue further complicates estimation of the trade-cost elasticity.

Consequently, researchers using gravity equations have turned instead to panel data methodologies with dummy variables to find unbiased and precise empirical estimates of the "average treatment effects" of EIAs on trade flows, cf., BB, Anderson and Yotov (2011), Eicher, Henn, and Papageorgiou (2012), and Head and Mayer (2014). For instance, BB showed that unbiased and precise estimates of EIAs on bilateral trade flows could be captured using the gravity-equation specification below using ordinary least squares (OLS): ${ }^{7}$

$$
\ln X_{i j t}=\alpha+\eta_{i t}+\theta_{j t}+\psi_{i j}+\beta E I A_{i j t}+v_{i j t}
$$

where $\eta_{i t}$ is an exporter-year fixed effect, $\theta_{j t}$ is an importer-year fixed effect, $\psi_{i j}$ is a country-pair fixed effect, and $v_{i j t}$ is an error term. Equation (1) is commonly referred to as a "fixed effects" model. However, it will be useful now to emphasize as well that this is also a "fixed parameters" model (i.e., $\beta$ is a fixed parameter). Hence, BB was a fixed effects, fixed parameter model, and that is also the case - to the best of our knowledge - for virtually all like gravity analyses. A key insight of BB was to show methodologically and empirically the importance of the country-pair fixed effect for controlling for the endogeneity of the EIA variable.

As noted earlier in the quote from Anderson and van Wincoop (2004), a limitation of equation (1) is that it imposes a common estimated average partial effect for all EIAs; EIAs and their effects on trade flows are likely to be heterogeneous. In specifications such as equation (1), this heterogeneity in EIAs' partial effects is captured in the error term, $v_{i j t}$, which is assumed to be uncorrelated with the other right-hand-side (RHS) variables.

Three issues arise when considering the potentially heterogeneous effects of EIA dummies. One issue is that a single EIA dummy cannot capture the heterogeneity among EIAs in their degrees of trade liberalization, cf., the quote in the introduction by Anderson and van Wincoop (2004). Historically, several studies have attempted to allow for (ex post) heterogeneous EIA effects by introducing instead a multitude of dummies - one for each agreement. However, this approach often leads to weak estimates. The reason is that - unless the EIA is plurilateral with numerous common memberships - there is insufficient variation in the RHS dummy variables. This was the dilemma Tinbergen (1962) faced, leading to the trivial EIA effects of the British Commonwealth and BENELUX economic union. ${ }^{8}$ Second, even within a plurilateral agreement, it is possible that the bilateral effect of a common EIA differs owing to variance in geographic, institutional, and cultural factors, ignored in in typical gravity estimates. Third, as will be discussed more later, even if individual EIA dummies' partial effect could be estimated with precision and consistency, they

\footnotetext{
${ }^{7}$ For now, we ignore zero trade flows, allowing a log-linear gravity equation. See BB and BBF for theoretical gravity-equation motivation for equation (1).

${ }^{8}$ There were only three countries in each agreement in his sample and only six " 1 's" in each of the dummy variables.
} 
remain only ex post estimates.

Among several issues addressed, BBF dealt with the first issue - avoiding weak estimates associated with a multitude of dummies - by running a specification including separate dummies for one-way PTAs (OWPTA), two-way PTAs (TWPTA), FTAs, and a dummy combining customs unions, common markets, and economic unions (CUCMECU), due to the limited number of these more integrated EIAs in their sample ending in $2005 .{ }^{9}$ Hence, BBF ran the fixed effects, fixed parameters model:

$$
\begin{array}{r}
\ln X_{i j t}=\alpha+\eta_{i t}+\theta_{j t}+\psi_{i j}+\beta_{1} O W P T A_{i j t}+\beta_{2} T W P T A_{i j t}+\beta_{3} F T A_{i j t} \\
+\beta_{4} C U C M E C U_{i j t}+v_{i j t}
\end{array}
$$

using OLS. ${ }^{10}$ Among other findings, BBF found that deeper economic integration agreements had, as expected, larger partial effects on bilateral trade flows.

A second issue is that the partial effect on trade of EIAs with a given degree of trade liberalization may be heterogeneous due to variable and/or fixed bilateral export costs. For tractability, suppose EI $A_{i j t}$ represents EIAs with a given degree of trade liberalization. Following Cameron and Trivedi (2005) (p. 774), we can consider the specification:

$$
\ln X_{i j t}=\alpha+\eta_{i t}+\theta_{j t}+\psi_{i j}+\beta_{i j} E I A_{i j t}+v_{i j t}
$$

where the partial effect of an EIA on $\ln X_{i j t}$ is allowed to be pair-specific. One way to interpret the heterogeneity in the $\beta_{i j}$ 's is to assume it is random. For instance, assume $\beta_{i j}=\beta+b_{i j}$ where $b_{i j}$ is a zero mean random variable. In this case, the expectation of $\beta_{i j}$ is:

$$
E\left(\beta_{i j} \mid \eta_{i t}, \theta_{j t}, \psi_{i j}, E I A_{i j t}\right)=\beta
$$

In section 2.2 below, we make this assumption to illustrate the enormous heterogeneity in values of $\beta_{i j}$, even after accounting for different degrees of trade liberalization. We will refer to these regressions as the "random coefficients" models.

Alternatively, suppose there exists a set of variables $Z_{i j}$ such that:

$$
E\left(\ln X_{i j t} \mid \alpha, \eta_{i t}, \theta_{j t}, \psi_{i j}, \beta_{i j}, E I A_{i j t}, Z_{i j}\right)=\alpha+\eta_{i t}+\theta_{j t}+\psi_{i j}+\beta_{i j} E I A_{i j t}
$$

\footnotetext{
${ }^{9}$ In this paper, we have extended that data set to 2011, enlarging substantially the number of EIAs with customs unions (CUs), common markets (CMs), and economic unions (ECUs), and so will treat each of those types separately.

${ }^{10}$ Ignoring zeros could potentially bias results, due to country selection; moreover, one must account for potential bias due to firm heterogeneity in aggregate data, cf., Helpman, Melitz, and Rubinstein (2008). However, BBF showed that potential bias due to country selection and firm heterogeneity was largely cross sectional in nature and could be accounted for in panel data by the pair fixed effects; see BBF and its Online Theoretical Supplement for a comprehensive discussion. Also, due to potential heteroskedasticity owing to Jensen's inequality, some studies have employed Poisson Quasi-Maximum Likelihood (PQML). Due to our specification using a very large number of fixed effects, researchers have only been able to obtain convergence under PQML for a limited time series in the panel (i.e., a short panel), cf., Bergstrand, Larch, and Yotov (2015). Consequently, due to our long panel, this limitation allows us to only use OLS. We also note that Bergstrand, Larch, and Yotov (2015) found, if anything, that OLS biased downward the EIA partial effect estimates relative to PQML estimates.
} 
Without knowing the true values of the $\beta_{i j}$, we take expectations over all variables to obtain:

$$
\begin{gathered}
E\left(\ln X_{i j t} \mid \alpha, \eta_{i t}, \theta_{j t}, \psi_{i j}, E I A_{i j t}, Z_{i j}\right)=\alpha+\eta_{i t}+\theta_{j t}+\psi_{i j} \\
+E\left(\beta_{i j} \mid \alpha, \eta_{i t}, \theta_{j t}, \psi_{i j}, E I A_{i j t}, Z_{i j}\right) E I A_{i j t}
\end{gathered}
$$

We assume that the expected effect of an EIA between $i$ and $j$, conditioning on all other variables, is given by:

$$
E\left(\beta_{i j} \mid \eta_{i t}, \theta_{j t}, \psi_{i j}, Z_{i j}\right)=\beta+b_{Z}\left(Z_{i j}-\mu_{Z}\right)
$$

where $Z_{i j}-\mu_{Z}$ denotes the de-meaned values of $Z_{i j}$. Absent knowledge of $\beta_{i j}$, following Cameron and Trivedi (2005) we should estimate instead:

$$
E\left(\ln X_{i j t} \mid \alpha, \eta_{i t}, \theta_{j t}, \psi_{i j}, E I A_{i j t}, Z_{i j}\right)=\alpha+\eta_{i t}+\theta_{j t}+\psi_{i j}+\beta E I A_{i j t}+b_{Z}\left(Z_{i j}-\mu_{Z}\right) E I A_{i j t}
$$

One of the main goals of this paper is to identify the variables in $Z_{i j}$ to determine the best linear unbiased predictors. In fact, Sections 3 and 4 below will first motivate theoretically in the context of Armington and Melitz models the roles of bilateral variable trade costs and of bilateral fixed and variable export costs, respectively, in explaining the heterogeneous $\beta_{i j}$ we find empirically in Section 6.

A third issue is that previous estimates of EIA partial effects have been ex post. As mentioned at the paper's outset, the link between estimated ex post gravity EIA partial effects and the ex ante welfare effects of a trade liberalization has been - at best - tenuous. In this paper, our identification of the geographic, institutional and cultural factors that explain heterogeneous EIA partial effects $\beta_{i j}$ can be used potentially for predicting ex ante the partial trade effect of a specific country-pair's EIA. In the spirit of the "sufficient statistics" approach in ACR, we show specifically that the ex ante change in welfare in importing country $j$ from an EIA with exporting country $i$ can be represented by the product of $\beta_{i j}$ (using estimates of $b_{Z}$ ), the share of $i$ 's exports in $j$ 's aggregate expenditures $\left(\lambda_{i j}\right)$, the CES utility parameter, and an error term capturing general equilibrium influences. Later, we will show empirically that data only on $\lambda_{i j}$ and estimates of $\beta_{i j}$ can explain between 83-94 percent of the welfare gains for an importing country of an EIA, and thus potentially can be used for ex ante welfare predictions.

However, before we proceed to exploring potential sources of $Z_{i j}$, it would be useful first just to get a sense of how large the potential heterogeneity of $\beta_{i j}$ might be - even without knowing the source (i.e., the $Z_{i j}$ ). Consequently, to illustrate how large the heterogeneity of $\beta_{i j}$ might be, we will estimate equation (3) allowing for all six different types of EIAs using the "random coefficients" approach. Estimation of equation (3) will account for the heterogeneity in different degrees of trade liberalization; however, without controlling at this stage for the $Z_{i j}-\mu_{Z}$, we anticipate bias in these preliminary (motivating) random coefficient estimation results. ${ }^{11}$

\footnotetext{
${ }^{11}$ One further consideration is noteworthy. Since gravity equations typically use binary variables to capture the policy change rather than an ad valorem variable such as $\tau_{i j t}$, the dummy variable's coefficient estimate is a combi-
} 


\subsection{Data and Results}

Nominal trade flows are from the United Nations' COMTRADE database for the years 1965, 1970, 1975, 1980, 1985, 1990, 1995, 2000, 2005 and 2010. Bilateral distances, adjacency, common language, religion similarity, common legal origin, and common colonial history (used later) are from the BACI data set. The data set for EIAs comes from Baier and Bergstrand's data set for $2014 .{ }^{12}$ There are 183 countries included in our data set. Online Appendix 1 lists the EIAs in our sample and (at its end) the countries included.

Table 1 provides a decomposition of the data set into types of agreements. Note that the vast majority of observations have no economic integration agreement and less than 6 percent of the observations have FTAs, CUs, CMs, or ECUs. In Table 1, the subtotal of 726,468 observations indicates the total number of annual positive trade flow observations for 49 years from 1962-2010 for the 33,306 country-pairs; the "missing observations" are composed largely of zeros. ${ }^{13}$ As discussed in $\mathrm{BB}$ and $\mathrm{BBF}$, we only use observations from every five years. The primary reason is that Cheng and Wall (2005) and Wooldridge (2000) both argue in favor of using data drawn from a period longer than annually. For instance, Cheng and Wall (2005) note that "Fixed-effects estimations are sometimes criticized when applied to data pooled over consecutive years on the the grounds that dependent and independent variables cannot fully adjust in a singe year's time" (p. 8; italics added). A second reason is that the number of fixed effects related to equation (3) or (4) with potentially 33,306 (directional) bilateral trade flows and 49 years, or 1,631,994 potential observations (or even 726,468 ), is only computable in STATA using "higher dimension" fixed effects; restricting the data to every five years from 1965-2010 reduces the number of fixed effects to a manageable level for estimation without such techniques. Consequently, our potential number of observations, based on positive trade flows, is 155,718 .

Table 2 presents several sets of results. Since this is the first paper to also provide separate partial effects for all six EIA categories in the Baier-Bergstrand EIA Database, before providing the results from the random coefficients specification we provide the results first for various versions of fixed effects, fixed parameters equations (1) and (2), where equation (2) is modified to include six dummy variables. Table 2 has ten columns, reporting the results of eight different specifications of equations (1) and (2). Column (1) provides the names of alternative groupings of EIAs. Column 2 provides the expected coefficient sign. The first three specifications in columns (3)-(5) are similar to equation (1), with no lags and combining different EIA types into one or two dummy variables; t-statistics are in parentheses. The fourth specification in column (6) is similar to equation (2). The last four specifications in columns (7)-(10) include additionally a five-year lag of each RHS variable.

nation of $\epsilon$ and $-\rho$, where $-\rho$ is an estimate of the effect of the EIA's formation on lowering $\tau_{i j t}$. For this study, we will use the differences in partial effects across types of EIAs to gain insight about $-\rho$. For example, the difference in BBF between a deeper EIA and a one-way PTA (e.g., Generalized System of Preferences agreement) is 0.295 $(=0.696-0.401)$. For a common $\epsilon$, this difference informs us of the relative change of $\tau$ between the two types of agreements.

${ }^{12}$ See www.nd.edu/ jbergstr. The version we use is a cleaned and extended-to-2011 version of the May 2013 data set; it is available on request.

${ }^{13}$ Recall our earlier footnote on why our results will not be subject to selection or firm-heterogeneity bias, following methodology used in BBF. 
Previous studies such as BB and BBF have shown that, due to phase-ins of agreements as well as lagged effects of EIAs on terms-of-trade, EIA dummies tend to have lagged effects on trade flows.

Specification 1 in column 3 uses a conventional grouping of EIAs: free trade agreements (FTAs, or 3), customs unions (CUs, or 4), common markets (CMs, or 5) and economic unions (ECUs, or 6). We denote this grouping EIA3-6, which reflects the inclusion of EIAs of levels 3-6. The coefficient estimate of 0.56 is very similar to the partial effect estimated in BB; it implies the typical EIA using categories 3-6 increases trade (absent any general equilibrium effects) by approximately 90 percent. This coefficient estimate of 0.56 is very similar also to the mean estimate of 0.59 in the meta analyses in both Cipollina and Salvatici (2010) and Head and Mayer (2014).

Specification 2 in column 4 adds another EIA dummy to capture the effects of preferential trade agreements (PTAs). In the Baier-Bergstrand EIA database, a 1 denotes a one-way PTA (OWPTA), including Generalized System of Preferences (GSP) agreements. A 2 denotes a two-way preferential trade agreement (TWPTA), where there are preferences extended but it is not an FTA. In Specification 2, we include EIA1-2 as well as EIA3-6; EIA1-2 denotes a one if two countries have a one-way or two-way PTA. Not surprisingly, the coefficient estimate for EIA1-2, 0.096, is considerably smaller than that for EIA3-6; there is less liberalization typically in agreements in EIA1-2.

Specification 3 in column 5 uses EIA1-6, all six levels of EIAs. Not surprisingly, the partial effect is roughly half of that for EIA3-6 in column 3 and roughly halfway between the coefficient estimates in column 4.

Specification 4 in column 6 includes six dummies, one for each of the six types of EIAs in the Baier-Bergstrand EIA data set, which now has observations through 2011. The coefficient estimates tend to reflect the increasing order of perceived trade liberalizations underlying each type of EIA. The statistically insignificant partial effect of 0.02 for one-way PTAs (EIA1) is consistent with other studies examining such agreements' trade effects. The coefficient estimate of 0.25 for two-way PTAs is statistically significant. The statistically significant FTA coefficient estimate of 0.53 accords with other studies for FTAs. The statistically significant customs union coefficient estimate of 0.84 implies that such existing agreements tend to have deeper integration than FTAs. Common markets are expected to be even more integrated than FTAs and CUs, so the statistically significant coefficient estimate of 1.12 for EIA5 (CMs) is consistent with this notion. Finally, economic unions tend to be more integrated than common markets, but are differentiated more along the lines of coordinated monetary and/or fiscal policies than deeper integration in trade. Consequently, the slightly lower coefficient estimate for ECUs of 1.032 is plausible in light of the estimate for the common market's coefficient. However, the coefficient estimates for CM and ECU are not statistically different from each other. ${ }^{14}$ Clearly, a considerable portion of the heterogeneity of partial effects of EIAs is explained by varying degrees of trade liberalization.

The specifications in columns 7-10 in Table 2 are analogous to the specifications in columns 3-6 except for including additionally a five-year lag of the EIA. We will not go through these results

\footnotetext{
${ }^{14}$ Once lagged EIA effects are included, the total EIA coefficient estimates for common markets and economic unions are nearly identical.
} 
in detail, as the outcomes conform to those in earlier studies such as BB and BBF, whereby EIAs have lagged effects on trade flows due to phasing-in of agreements and lagged terms-of-trade effects. None of the results in Table 2's specifications 7-10 are inconsistent with expectations. Note that the total EIA effect for common markets is 1.16 whereas that for economic unions is 1.17.

We now turn to the results of estimating a modification of equation (3), described in equation (6) below:

$$
\begin{array}{r}
\ln X_{i j t}=\alpha+\eta_{i t}+\theta_{j t}+\psi_{i j}+\beta_{1 i j} O W P T A_{i j t}+\beta_{2 i j} T W P T A_{i j t}+\beta_{3 i j} F T A_{i j t} \\
+\beta_{4 i j} C U_{i j t}+\beta_{5 i j} C M_{i j t}+\beta_{6 i j} E C U_{i j t}+v_{i j t}
\end{array}
$$

Because of the enormous number of heterogeneous partial effects, we cannot use traditional reporting in the form of a table. For tractability, the results are presented in graphical form. For brevity, we present the results for the four most interesting types of EIAs: FTAs, CUs, CMs, and ECUs. For each type of EIA, we ordered coefficient estimates from lowest value to highest value and constructed the kernel density plots to visualize the range of coefficient estimates. For instance, for FTAs there are approximately 2,500 coefficient estimates $\beta_{3 i j}$. For each of CUs, CMs, and ECUs, there are smaller numbers of coefficient estimates, as there are fewer numbers of such types of EIAs.

Figure 1 provides the results from the random coefficients model estimation. We note several distinguishing features of the results. The first important conclusion from these results is that there is considerable heterogeneity in the (partial) effects of EIAs on trade flows. Second, the heterogeneity in EIA effects cannot be explained solely by the depth of liberalization. FTAs have an average partial EIA effect of 0.33 , CUs have an average effect of 0.92 , CMs have an average effect of 0.91 , and ECUs have an average effect of 1.08. Note that these estimates vary from the corresponding EIAs' partial effects in Table 2. As noted in Section 2.1, this is to be expected; without the inclusion of the $Z_{i j}-\mu_{Z}$ in the regressions, the estimated partial effects in the random coefficients regressions are expected to be biased. Thus, while there is heterogeneity in the EIA effects across EIA types, there remains considerable heterogeneity across EIAs even within each type of agreement. As shown below in Sections 3 and 4, the standard quantitative trade models that dominate the theoretical international trade literature of determinants of bilateral trade - in such papers as Baier and Bergstrand (2001), Eaton and Kortum (2002), Anderson and van Wincoop (2003), and Chaney (2008) - do not predict heterogeneous partial effects; the partial trade-cost elasticity is a parameter. Consequently, these preliminary empirical results call first for extending the theoretical foundations for the gravity equation to determine factors that might explain such heterogeneous partial EIA effects (independent of and complementary to issues raised in Melitz and Redding (2015)). 


\section{A Simple Armington Trade Model with Only Variable Trade Costs}

"Duty is not assessed on CIF charges. Customs and Border Protection (CBP) value is determined based on the "Price Paid" or "Payable" for the goods, which is usually on the bill of sale or invoice and bill of lading as the Freight On Board (FOB) price." (U.S. Customs and Border Protection web site, 2015)

One of the persuasive aspects of ACR was first demonstrating their main results in the simplest possible framework: an Armington trade model. The purpose of this section is to illustrate similarly in a simple Armington trade model how the elasticity of bilateral trade between a country-pair with respect to ad valorem tariffs - the trade-cost elasticity $(1-\sigma$, in the Armington model $)$ - can be sensitive to the amount of distance between the country-pair.

First, in a seminal article using the Armington model, Anderson and van Wincoop (2003) show that the three assumptions of (i) an $N$-country endowment economy where each country produces a differentiated good, (ii) consumers have identical constant-elasticity-of-substitution (CES) preferences, and (iii) market-clearing yield a gravity equation:

$$
X_{i j}=\frac{Y_{i} Y_{j}}{Y_{W}} \frac{\tau_{i j}^{1-\sigma}}{\Pi_{i}^{1-\sigma} P_{j}^{1-\sigma}}, \quad \text { where } \quad \Pi_{i}^{1-\sigma}=\sum_{j=1}^{N} \frac{Y_{j}}{Y_{W}} \frac{\tau_{i j}^{1-\sigma}}{P_{j}^{1-\sigma}}, \quad P_{j}^{1-\sigma}=\sum_{i=1}^{N} \frac{Y_{i}}{Y_{W}} \frac{\tau_{i j}^{1-\sigma}}{\Pi_{i}^{1-\sigma}},
$$

where $X_{i j}$ is the nominal trade flow from country $i$ to country $j, Y_{i}\left(Y_{j}\right)$ is the nominal GDP in $i$ $(j), Y_{W}$ is world GDP, $\tau_{i j}$ is ad valorem gross trade costs (including tariffs and transportation costs) on goods exported from $i$ to $j\left(\tau_{i j}>1\right), \sigma$ is the elasticity of substitution in consumption, and:

$$
P_{j}=\left[\sum_{i=1}^{N}\left(p_{i} \tau_{i j}\right)^{1-\sigma}\right]^{1 /(1-\sigma)}
$$

where $p_{i}$ is exporter $i$ 's Freight-On-Board $(F O B)$ price of its differentiated product.

Second, following Hummels and Skiba (2004), we assume the price of a good produced in country $i$ facing importer $j, p_{i j}$, depends on the exporter's $F O B$ price, $p_{i}$, and a two-part trade cost that includes both an ad valorem gross tariff rate, $t_{i j}>1$, and per unit shipping costs, freight $t_{i j}$ :

$$
p_{i j}=p_{i} t_{i j}+\text { freight }_{i j}
$$

Note that, consistent with the quote above, tariff duties are applied to the $F O B$ price. Equation (9) can be rewritten as:

$$
p_{i j}=p_{i} \tau_{i j}=p_{i}\left(t_{i j}+f_{i j}\right)
$$

where $f_{i j}>0$ is the ad valorem-equivalent of freight charges $\left(f_{i j}=f r e i g h t_{i j} / p_{i}\right)$. See Hummels and Skiba (2004) for empirical support for this specification. Substituting equation (10) into equations 
(7) and (8) yields:

$$
X_{i j}=\frac{Y_{i} Y_{j}}{Y_{W}} \frac{\left(t_{i j}+f_{i j}\right)^{1-\sigma}}{\Pi_{i}^{1-\sigma} P_{j}^{1-\sigma}}
$$

which is analogous to equation (18) in Anderson and van Wincoop (2004, p. 715), ignoring for brevity the $z$ terms in their paper (which are not important here).

Third, taking the logarithm of equation (11) and differentiating $\ln X_{i j}$ with respect to $\ln t_{i j}$ yields the trade-cost elasticity for the bilateral tariff rate:

$$
d \ln X_{i j} / d \ln t_{i j}=\frac{1}{\left(f_{i j} / t_{i j}\right)+1}(1-\sigma)
$$

Consequently, in light of the additive relationship between $f_{i j}$ and $t_{i j}$ in equations (10) and (11), the trade-cost elasticity for tariff rates is no longer exogenous, as in all the so-called "quantitative trade models" noted earlier; it is sensitive to $f_{i j}$. Moreover, as well established in Hummels and Skiba (2004) and Hummels (2007), ad valorem bilateral freight costs $f_{i j}$ are highly positively correlated with bilateral distances. Hence, (in absolute terms) the elasticity of bilateral imports with respect to ad valorem tariff rates is a negative function of bilateral distance. Since EIAs reduce tariff rates, this suggests the hypothesis that the elasticity of (the intensive margin of) trade flows with respect to $E I A_{i j}$ may be negatively related to bilateral distance (and perhaps other bilateral trade impediments).

\section{A Melitz-Type Model with Variable and Fixed Export Costs and Endogenous Network Effects}

The previous simple Armington trade model establishes that the elasticity of trade with respect to EIAs may be heterogeneous (and endogenous) - depending upon bilateral distance and possibly other bilateral trade impediments. However, the simple Armington model allows only for variable trade costs and changes in trade on the intensive margin. In this section, we provide a more general model that also includes policy and non-policy fixed export costs, firm heterogeneity, and endogenous network effects. We show how the elasticity of the extensive margin of trade with respect to tariff rates may also be sensitive to variable and fixed export costs. Moreover, we show that the elasticity of the extensive margin of trade with respect to policy-oriented fixed export costs may be sensitive to various economic factors.

\subsection{The Theoretical Model}

Our theoretical model picks up where Krautheim (2012) left off in two novel features. First, we account explicitly for exogenous fixed export costs independent of and in addition to network spillovers. Second, we distinguish between exogenous policy-oriented and non-policy-oriented fixed export costs. 
The main contribution of Krautheim (2012) was to develop a "baseline" Melitz-type model where export fixed costs are endogenous and a function of the (endogenous) number of exporters from country $i$ to country $j$ in the representative industry (his sections 1-3). As Krautheim noted, the "great advantage" of his (baseline) model was to obtain a closed-form solution. In his final section 4 , he notes, "It is quite likely, however, that in reality some fixed costs are entirely (or at least mainly) independent of the number of exporters" (p. 33; italics added) and these independent and exogenous fixed costs may influence the elasticity of export fixed costs with respect to the number of exporters. However, he does not provide a closed-form general equilibrium model of these influences in his paper; this is the purpose of this section (and Online Appendix 2). Moreover, he concludes his last substantive section of the paper suggesting "future empirical work" should investigate the variability of trade-cost elasticities to changes in these exogenous (spillover-insensitive) fixed export cost determinants. Such empirical work is another potential contribution of our paper.

Our theoretical model solves for the closed-form solutions and structural gravity equation of this Melitz-type model allowing for exogenous policy and non-policy fixed export costs (linearly) independent of the endogenous (network-spillover-based) fixed export costs. ${ }^{15}$ We assume a world economy with $N$ countries and let $L_{j}$ denote the (internationally immobile) population and labor force in country $j$. We assume a single aggregate industry with heterogeneous firms each producing differentiated products under increasing returns to scale.

Consumers (workers) are identical and have the utility function:

$$
U=\left(\int_{\omega \in \Omega} q(\omega)^{\frac{\sigma-1}{\sigma}} d \omega\right)^{\frac{\sigma}{\sigma-1}}
$$

where $q(\omega)$ denotes the quantity consumed of product $\omega$ from the set of varieties $\Omega$ available and $\sigma$ is the elasticity of substitution in consumption across varieties $(\sigma>1)$. Consumers maximize utility subject to a standard income constraint yielding a demand function in country $j$ for variety $\omega$ imported from country $i$ :

$$
q_{i j}(\omega)=\left(\frac{p_{i j}(\omega)}{P_{j}}\right)^{-\sigma}\left(\frac{w_{j} L_{j}}{P_{j}}\right)
$$

where $P_{j}=\left[\int_{\omega \in \Omega} p(\omega)^{1-\sigma} d \omega\right]^{\frac{1}{1-\sigma}}, w_{j}$ is the wage rate in country $j$, and hence $w_{j} L_{j}$ is aggregate income in country $j$.

Firms in country $i$ are assumed to have heterogeneous productivities. Potential entrants face a fixed entry cost, $F_{i}^{E}$. In order to sell in a foreign market $j$, a firm has to pay an additional fixed export cost, $F_{i j}^{X}{ }^{16}$ We assume furthermore that fixed export costs $F_{i j}^{X}$ can be decomposed linearly into fixed costs associated with - what we term - "natural" (or non-policy) impediments into markets (such as costs associated with geographic distance or cultural differences), $F_{i j}^{X N}$, and

\footnotetext{
${ }^{15}$ Online Appendix 2 provides a non-trivial extension of Krautheim's baseline model to include additively separable exogenous and endogenous export fixed costs, and provides closed form solutions to a general equilibrium model with labor-market clearing and free entry and exit of firms. Moreover, at the end of this appendix, we demonstrate formally the mathematical difficulty of combining our trade-cost function in Section 3 with the Melitz model in Section 4 into one tractable model.

${ }^{16}$ Krautheim (2012) uses instead $C_{i j}$ to denote these fixed costs.
} 
fixed export costs associated with the destination market's trade "policy" impediments (such as regulatory costs associated with institutional differences), $F_{i j}^{X} P$. We assume that the costs for a firm $(c)$ with productivity $\varphi$ in country $i$ to sell $q_{i j}$ units of output in country $j$ facing (gross) $a d$ valorem iceberg variable trade costs $\tau_{i j}$ (hence, assuming $\tau_{i j} \geq 1$ ) is given by:

$$
c\left(q_{i j}\right)=\frac{w_{i} q_{i j} \tau_{i j}}{\varphi}+w_{j}\left(F_{i j}^{X N}+F_{i j}^{X P}\right)
$$

Facing demand curve equation (14), the price charged in $j$ by a firm in $i$ is given by:

$$
p_{i j}(\varphi)=\frac{w_{i} \tau_{i j}}{\rho \varphi}
$$

where $\rho=(\sigma-1) / \sigma$.

Up to now, our economy is characterized by a standard Melitz model, except for distinguishing two types of export fixed costs (policy and non-policy). Following Krautheim (2012), we introduce network effects into the "natural" fixed export costs $\left(F_{i j}^{X N}\right)$. Distinct from the baseline model in Krautheim (2012), we assume that natural fixed export costs are determined by an exogenous component $\left(A_{i j}^{X N}\right)$ and an endogenous component reflecting network effects $\left(n_{i j}^{-\eta}\right)$. We note now that we will demonstrate that the presence of exogenous fixed export component $A_{i j}^{X N}$ can influence the effect of an EIA with or without network spillovers; moreover, network spillovers can influence the effect of an EIA on trade without exogenous fixed export costs. As in Krautheim (2012) we assume that the fixed costs of selling a product from $i$ to $j$ are inversely related to the number of firms in $i$ selling in $j, n_{i j}$, which itself is endogenous to the model. Fixed costs are assumed to be:

$$
w_{j}\left(F_{i j}^{X N}+F_{i j}^{X P}\right)=w_{j}\left[A_{i j}^{X N}+n_{i j}^{-\eta}+F_{i j}^{X P}\right]
$$

where $\eta$ is the elasticity of fixed costs with respect to the number of firms in $i$ exporting to $j$ (as in Krautheim (2012)). ${ }^{17}$

In this setting, the profits of firm $\varphi$ in $i$ to export to $j\left(\pi_{i j}\right)$ are:

$$
\pi_{i j}(\varphi)=\operatorname{Max}\left[0,\left(\frac{w_{i} \tau_{i j}}{\rho \varphi P_{j}}\right)^{1-\sigma} \frac{w_{j} L_{j}}{\sigma}-w_{j}\left[A_{i j}^{X N}+n_{i j}^{-\eta}+F_{i j}^{X P}\right]\right]
$$

Firms in $i$ will choose to export as long as profits are positive. The marginal exporter from $i$ to $j$, where profits approach zero, defines the "cutoff" productivity $\left(\varphi_{i j}^{*}\right)$ :

$$
\left(\frac{w_{i} \tau_{i j}}{\rho P_{j}}\right)^{1-\sigma} \frac{w_{j} L_{j}}{\sigma}\left(\varphi_{i j}^{*}\right)^{\sigma-1}=w_{j}\left[A_{i j}^{X N}+n_{i j}^{-\eta}+F_{i j}^{X P}\right]
$$

\footnotetext{
${ }^{17}$ See Krautheim (2012) on the economic rationale for $n_{i j}^{-\eta}$ to capture network spillovers. We discuss later how the exogenous component determining natural fixed export costs, $A_{i j}^{X N}$, is likely influenced by (observable) geographic and cultural factors such as bilateral distance and the presence or absence of common land borders, official languages, and predominant religions. By contrast, the level of policy-oriented fixed export costs, $F_{i j}^{X P}$, is likely influenced by (observable) institutional similarities such as common legal origins and colonial histories. See our Section 5 later.
} 
In Krautheim (2012), without the additive exogenous fixed costs $A_{i j}^{X N}+F_{i j}^{X P}$, one can easily solve for the cutoff productivity $\varphi_{i j}^{*}$. However, the presence of the additive factor $A_{i j}^{X N}+F_{i j}^{X P}$ makes the determination here of $\varphi_{i j}^{*}$ more complex. The closed-form solutions are provided in Online Appendix 2.

\subsection{Structural Gravity}

We can provide a structural gravity representation of aggregate trade flows. The aggregate bilateral trade flow from country $i$ to country $j$ is:

$$
X_{i j}=n_{i j} \int_{\varphi_{i j}^{*}}^{\infty}\left(\frac{w_{i} \tau_{i j}}{\rho P_{j}}\right)^{1-\sigma} \frac{w_{j} L_{j}}{\sigma} \sigma \gamma \varphi^{-(\gamma-\sigma+1)}\left(\varphi_{i j}^{*}\right)^{\gamma} d \varphi
$$

Online Appendix 2 shows that, through appropriate substitutions, we can solve for a simple structural gravity equation in the form:

$$
X_{i j}=\left(\frac{\left(\varphi_{i j}^{*} / \bar{\varphi}\right)^{-\gamma} F_{i j}^{X}}{\Omega_{i} \Lambda_{j}}\right)\left(w_{i} L_{i}\right)\left(w_{j} L_{j}\right)
$$

where

$$
\Omega_{i}=\sum_{j} w_{j}\left(\frac{\varphi_{i j}^{*}}{\bar{\varphi}}\right)^{-\gamma} F_{i j}^{X}\left(\frac{\sigma \gamma}{\gamma-\sigma+1}\right)=\sum_{j} \frac{w_{j} L_{j}}{\Lambda_{j}} F_{i j}^{X}\left(\frac{\varphi_{i j}^{*}}{\bar{\varphi}}\right)^{-\gamma}
$$

and

$$
\Lambda_{j}=\sum_{i} N_{i} F_{i j}^{X}\left(\frac{\varphi_{i j}^{*}}{\bar{\varphi}}\right)^{-\gamma}=\sum_{i} \frac{w_{i} L_{i}}{\Omega_{i}} F_{i j}^{X}\left(\frac{\varphi_{i j}^{*}}{\bar{\varphi}}\right)^{-\gamma}
$$

which is analogous to the structural gravity model in Anderson and van Wincoop (2003), or equation (7) above. Interestingly, bilateral variable trade cost $\tau_{i j}$ is not explicit in equation (21); it is subsumed in $\varphi_{i j}^{*} / \bar{\varphi}$, as will become apparent shortly. However, comparative statics in the next section will help motivate standard gravity covariates for the estimable version of equation (21).

\subsection{Comparative Statics}

We find several additional theoretical insights beyond Krautheim (2012) by using the additive version of exogenous and endogenous fixed export costs, as well as distinguishing exogenous natural fixed export costs $\left(A_{i j}^{X N}\right)$ from exogenous policy-oriented fixed export costs $\left(F_{i j}^{X P}\right)$. As in that study, we assume an untruncated Pareto distribution for productivities, with the measure of productivity heterogeneity given by $\gamma$ and let $\bar{\varphi}$ be the lower bound of the support of the Pareto productivity distribution. As we know from Melitz and Redding (2015), a truncated Pareto distribution is sufficient in this type of model to generate endogenous trade-cost elasticities. By assuming an untruncated Pareto distribution, our endogenous trade-cost elasticities in this model surface from novel channels (not present in HMR, Krautheim (2012), or Melitz and Redding (2015)); however, our channels complement those in Melitz and Redding (2015).

For tractability, we organize the eight comparative statics in this section into two sets. Each set 
is composed for four comparative statics. Comparative statics (1a)-(1d) are related to an exogenous change in ad valorem bilateral variable exports $\operatorname{costs}\left(d \ln \tau_{i j}\right)$. Comparative statics $(2 \mathrm{a})-(2 \mathrm{~d})$ are related to an exogenous change in policy-oriented bilateral export fixed costs $\left(d \ln F_{i j}^{X P}\right)$.

\subsubsection{Comparative Static 1a}

First, we find that the effect of changes in variable trade costs $\left(\tau_{i j}\right)$ on the export cutoff productivity is no longer parametric but is related to the importance of exogenous export fixed costs in total export fixed costs:

$$
d \ln \varphi_{i j}^{*}=\frac{1}{1-\frac{\gamma}{\sigma-1} \eta s_{i j}} d \ln \tau_{i j}
$$

where

$$
s_{i j}=\frac{\delta_{i}^{-\eta}\left(\varphi_{i j}^{*} / \bar{\varphi}\right)^{\gamma \eta}}{\left(A_{i j}^{X N}+F_{i j}^{X P}\right)+\delta_{i}^{-\eta}\left(\varphi_{i j}^{*} / \bar{\varphi}\right)^{\gamma \eta}}=\frac{n_{i j}^{-\eta}}{\left(A_{i j}^{X N}+F_{i j}^{X P}\right)+n_{i j}^{-\eta}}=\frac{1}{1+\frac{A_{i j}^{X N}+F_{i j}^{X P}}{n_{i j}^{-\eta}}}
$$

and

$$
\delta_{i}=\frac{\sigma-1}{\gamma \sigma F_{i}^{E}} L_{i}
$$

Note that $s_{i j}$ and exogeneous export fixed costs $\left(A_{i j}^{X N}+F_{i j}^{X P}\right)$ are inversely related; $s_{i j}$ is defined as the share of endogenous export fixed costs in total export fixed costs. In the case of Krautheim (2012) without the additive export fixed costs (when $A_{i j}^{X N}+F_{i j}^{X P}=0$ ), equation (22)'s coefficient on $d \ln \tau_{i j}$ simplifies to $1 /\left[1-\frac{\gamma}{\sigma-1} \eta\right]$, which is exogenous. Note that a variable trade-cost $\left(\tau_{i j}\right)$ decline directly lowers the export cutoff productivity $\left(\varphi_{i j}^{*}\right)$ but also indirectly lowers $\varphi_{i j}^{*}$ by increasing the number of exporting firms $\left(n_{i j}\right)$, consequently expanding the network effect and further lowering this cutoff productivity. Note also that the presence of the additive exogenous fixed export costs $\left(A_{i j}^{X N}+F_{i j}^{X P}\right)$ better ensures the positive relationship between $\tau_{i j}$ and $\varphi_{i j}^{*}$ by scaling down the value of $\frac{\gamma \eta}{\sigma-1}$, imposing lower restrictions on the value of $\eta$. We show in Online Appendix 2 that the stability condition for the determination of the export cutoff productivity is $\frac{\gamma}{\sigma-1} \eta s_{i j}<1 .{ }^{18}$ Hence, if there is a stable cutoff productivity, the effect of $d \ln \tau_{i j}$ on $d \ln \varphi_{i j}^{*}$ is positive. Finally, as shown in Online Appendix 2, the number of exporting firms from $i$ to $j$ is a function of the export cutoff productivity:

$$
n_{i j}=\frac{\sigma-1}{\gamma \sigma F_{i}^{E}} L_{i}\left(\varphi_{i j}^{*} / \bar{\varphi}\right)^{-\gamma}=\delta_{i}\left(\varphi_{i j}^{*} / \bar{\varphi}\right)^{-\gamma}
$$

\subsubsection{Comparative Static $1 b$}

The next result from our model has important implications for estimation of gravity equations of trade flows. Gravity equations are typically specified in multiplicative form in levels of variables or linearly in the logs of variables. Historically, coefficient estimates have been assumed to be "parameters," cf., equation (1) above. Even in Krautheim (2012), the trade effect of a one percent

\footnotetext{
${ }^{18}$ Krautheim (2012), where $s_{i j}$ is assumed to be unity, assumes analogously $\frac{\gamma}{\sigma-1} \eta<1$. This assumption insures that the fixed costs decline sufficiently slowly in the number of exporters to insure interior solutions.
} 
decline in $\tau_{i j}$ is parametric. Using our theoretical model, we can show that the elasticity of bilateral trade (on the extensive margin) to a one percent change in ad valorem trade costs $\left(\tau_{i j}\right)$ is sensitive to the relative importance of exogenous fixed export costs in total fixed export costs (inverse of $s_{i j}$ ):

$$
d \ln X_{i j}=-\gamma\left(\frac{1-\eta s_{i j}}{1-\frac{\gamma}{\sigma-1} \eta s_{i j}}\right) d \ln \tau_{i j}
$$

because:

$$
d \ln X_{i j}=-\gamma\left(1-\eta s_{j}\right) d \ln \varphi_{i j}^{*}
$$

as shown in Online Appendix 2. Note that $d \ln X_{i j} / d \ln \tau_{i j}$ is no longer parametric. Moreover, with some algebra, we can show:

$$
d \ln X_{i j}=\left[-(\sigma-1)-\left(\frac{\gamma-(\sigma-1)}{1-\frac{\gamma}{\sigma-1} \eta s_{i j}}\right)\right] d \ln \tau_{i j}
$$

With $s_{i j}$ inversely related to exogenous export fixed costs $A_{i j}^{X N}+F_{i j}^{X P}$, a fall in exogenous fixed export costs - keeping relative natural and policy exogenous fixed export costs constant - will raise $s_{i j}$, lower the denominator of the second RHS term in brackets, raising the effect of the tariff decline on the aggregate trade flow change. (Recall that the stability condition for the export productivity cutoff requires $\frac{\gamma}{\sigma-1} \eta s_{i j}<1$.) $)^{19}$

\subsubsection{Comparative Statics 1c and 1d}

Two more comparative statics are readily obtained. We can decompose the log change in the trade flow into the log changes in the intensive margin $(I M)$ and extensive margin $(E M)$. This is apparent in equation (28). We show in Online Appendix 2 that the intensive margin effect is:

$$
d \ln I M_{i j}=-(\sigma-1) d \ln \tau_{i j}
$$

and the extensive margin effect is:

$$
d \ln E M_{i j}=-\left(\frac{\gamma-(\sigma-1)}{1-\frac{\gamma}{\sigma-1} \eta s_{i j}}\right) d \ln \tau_{i j}
$$

It is important to note that the intensive margin elasticity here for $d \ln \tau_{i j}$ is parametric, as in a standard Melitz model, cf., Chaney (2008). However, introducing the considerations from the Armington model in Section 3 into the Melitz model here is not a trivial extension. We discuss this at the end of Online Appendix 2 and demonstrate the conditions necessary to solve such a model. This is why we present both the Armington and Melitz models separately.

The next four comparative statics, (2a)-(2d), are related to the analogous effects on the cutoff productivity, trade flow, intensive margin, and extensive margin of an exogenous change in policy-

\footnotetext{
${ }^{19}$ Note in equation (28) that if $s_{i j}=1$ (no exogenous export fixed costs), the comparative static simplifies to that in Krautheim (2012). Furthermore, if $\eta=0$, it simplifies to that in a Melitz model, $-\gamma$, as in Chaney (2008).
} 
oriented bilateral fixed export $\operatorname{costs}\left(F_{i j}^{X P}\right)$.

\subsubsection{Comparative Static 2a}

We can solve explicitly for the effect of changes in exogenous policy-based fixed export $\operatorname{costs}\left(F_{i j}^{X P}\right)$ that may arise from an EIA on the export cutoff productivity:

$$
d \ln \varphi_{i j}^{*}=\frac{F_{i j}^{X P} /\left(A_{i j}^{X N}+F_{i j}^{X P}+n_{i j}^{-\eta}\right)}{(\sigma-1)\left(1-\frac{\gamma}{\sigma-1} \eta s_{i j}\right)} d \ln F_{i j}^{X P}
$$

If the stability condition is met, then the relationship between $d \ln F_{i j}^{X P}$ and $d \ln \varphi_{i j}^{*}$ is positive.

However, the numerator suggests that the effect of $d \ln F_{i j}^{X P}$ on $d \ln \varphi_{i j}^{*}$ is diminished the lower is the existing level of exogenous policy-oriented fixed export costs relative to exogenous natural fixed export costs. This is important for understanding the effects of existing institutions on the impact of an EIA. For instance, if a pair of countries has a common legal origin, then the level of $F_{i j}^{X P}$ is lower. Consequently, the impact of a one percent fall in $F_{i j}^{X P}$ from an EIA on lowering the cutoff productivity is diminished. This will feed into the subsequent comparative statics.

\subsubsection{Comparative Static $2 b$}

As shown in Online Appendix 2, the comparative static effect of a one percent decline in policy fixed export costs on the trade flow is::

$$
d \ln X_{i j}=-\left(\frac{\frac{\gamma}{\sigma-1}-1}{1-\frac{\gamma}{\sigma-1} \eta s_{i j}}\right)\left(\frac{F_{i j}^{X P}}{A_{i j}^{X N}+F_{i j}^{X P}+n_{i j}^{-\eta}}\right) d \ln F_{i j}^{X P}
$$

This result is novel for several reasons. First, Krautheim (2012) did not solve for any comparative statics for exogenous policy (or non-policy) fixed export cost changes because he did not have closedform solutions for such a model. Second, this paper is the first to show the impact on trade of a one percent change in exogenous policy fixed export costs in the presence of policy and non-policy export fixed costs and network effects. Given the stability condition for the export productivity cutoff is met, a fall in exogenous policy fixed export costs - potentially due to an EIA - has a positive impact on bilateral trade. Third, in the case as in Chaney (2008), if network effects were absent $(\eta=0)$ and there was only one type of exogenous fixed export costs, such as $F_{i j}^{X P}$ (hence, $\left.A_{i j}^{X N}=0\right)$, then equation (32) reduces to:

$$
d \ln X_{i j}=-\left(\frac{\gamma}{\sigma-1}-1\right) d \ln F_{i j}^{X P}
$$

exactly as in Chaney (2008). 


\subsubsection{Comparative Statics $2 c$ and $2 d$}

Two more comparative statics are readily obtained. We can decompose the log change in the trade flow into the log changes in the intensive margin $(I M)$ and extensive margin $(E M)$. We show in Online Appendix 2 that the intensive margin effect is:

$$
d \ln I M_{i j} / d \ln F_{i j}^{X P}=0
$$

and the extensive margin effect is:

$$
d \ln E M_{i j}=-\left(\frac{\frac{\gamma}{\sigma-1}-1}{1-\frac{\gamma}{\sigma-1} \eta s_{i j}}\right)\left(\frac{F_{i j}^{X P}}{A_{i j}^{X N}+F_{i j}^{X P}+n_{i j}^{-\eta}}\right) d \ln F_{i j}^{X P}
$$

We now note two important considerations that will be useful shortly as we examine empirical relationships between trade flow and extensive margin elasticities due to differences in country-pairs' levels of cultural (non-policy) variables or institutional (policy) variables. First, equations (32) and (35) imply that the lower is the initial level of exogenous non-policy fixed export $\operatorname{costs}\left(A_{i j}^{X N}\right)$, the higher (in absolute terms) will be the impact of a one percent change in $F_{i j}^{X P}$ on the extensive margin and on the trade flow. For example, the impact of an EIA on the extensive margin and trade flow will likely be higher if the two countries have a common predominant religion or common official language (which likely lower $A_{i j}^{X N}$ ). The reason is that a lower value of $A_{i j}^{X N}$ raises both $s_{i j}$ and $F_{i j}^{X P} /\left(A_{i j}^{X N}+F_{i j}^{X P}+n_{i j}^{-\eta}\right)$, which increase the extensive margin response to a one percent change in $F_{i j}^{X P}$. Moreover, an EIA causes a fall in tariffs $\left(d \ln \tau_{i j}\right)$, which also raises $\ln E M_{i j}$, as shown in equation (30).

Second, equations (32) and (35) suggest that the lower is the initial level of exogenous policy fixed export costs $\left(F_{i j}^{X P}\right)$, the extensive margin impact of $d \ln F_{i j}^{X P}$ might be higher or lower. A lower level of $F_{i j}^{X P}$ will raise $s_{i j}$, tending to raise the impact of $d \ln F_{i j}^{X P}$ on the extensive margin. However, a lower $F_{i j}^{X P}$ will lower $F_{i j}^{X P} /\left(A_{i j}^{X N}+F_{i j}^{X P}+n_{i j}^{-\eta}\right)$, tending to lower (in absolute terms) the impact of a one percent change in $F_{i j}^{X P}$ on the extensive margin and consequently on the trade flow. However, as shown in Online Appendix 2, the latter effect dominates as long as we assume, as in Krautheim (2012), that $\frac{\gamma \eta}{\sigma-1}<1$; this assumption was made in Krautheim (2012) to insure that fixed costs decline sufficiently slowly in $n_{i j}$ to insure interior solutions. Despite this result, the impact of an EIA on the responses of the extensive margin and trade flow will still be ambiguous if, say, the two countries have a common legal origin or common colonial history - which likely lower the level of $F_{i j}^{X P}$ - because an EIA also lowers $\ln \tau_{i j}$; as shown in equation (30), this extensive margin elasticity is positively related to the level of $s_{i j}$ and negatively related to the level of $F_{i j}^{X P}$.

Finally, even if network externalities did not exist, declines in fixed export costs associated with EIAs $\left(d \ln F_{i j}^{X P}\right)$ could lead to heterogeneous EIA effects. We show in Online Appendix 2 that when $\eta=0$ :

$$
d \ln E M_{i j}=-\left(\frac{\gamma}{\sigma-1}-1\right)\left(\frac{F_{i j}^{X P}}{F_{i j}^{X P}+A_{i j}^{X N}}\right) d \ln F_{i j}^{X P}
$$


implying the elasticity of $E M_{i j}$ with respect to $F_{i j}^{X P}$ is sensitive to the relative levels of $A_{i j}^{X N}$ and $F_{i j}^{X P}$. Moreover, with $\eta=0$, a lower level of $F_{i j}^{X P}$ will unambiguously cause the extensive margin elasticity to a one percent change in $F_{i j}^{X P}$ to decline. Thus, the endogenous trade-cost elasticities in this paper surface with or without network externalities and with an untruncated Pareto productivity distribution. In the next section, we turn to HMR to suggest a set of geographic, institutional, and cultural variables to measure variable non-policy trade costs, exogenous non-policy fixed export costs, and exogenous policy fixed export costs.

\section{From Theory to Empirics: Hypothesized Observable Determi- nants of Heterogeneous EIA Effects}

So what observable factors might influence the unobservable exogenous variable non-policy export costs $\left(f_{i j}\right)$, exogenous non-policy fixed export costs $\left(A_{i j}^{X N}\right)$, and exogenous policy fixed export costs $\left(F_{i j}^{X P}\right)$ discussed in the previous two sections? Beginning with Tinbergen (1962), the empirical gravity equation literature provides 50 years of econometric examination of observable bilateral variables that likely affect trade flows via bilateral trade costs. Typical variables that have surfaced over decades are bilateral distance, measures of religious similarities, and dummy variables for common land border, primary language, legal origin and colonial history, cf., Head and Mayer (2014). Up until 2000, this literature has interpreted the channel of influence of these variables on trade flows as the intensive margin. However, two pertinent issues suggest that some or all of these six - what we will term - "standard gravity covariates" might influence fixed export costs. First, the trade literature since 2000 has called considerable attention to the theoretical importance of fixed export costs for explaining zeros in trade. Second, HMR, Egger, Larch, Staub, and Winkelmann (2011) (or ELSW), and Baldwin and Harrigan (2011) (or BH) have shown empirically that some of these six variables actually explain the extensive, as well as intensive, margin of trade. However, they also reveal that there are quantitative as well as qualitative differences in the impacts of these variables on the two margins of trade. For instance, bilateral distance negatively influences both the probability and volume of trade in all three studies. However, contiguity of nations (i.e., sharing a common land border) influences positively the intensive margin, but negatively the extensive margin, in HMR and ELSW (contiguity was omitted in BH). Hence, we look to observable standard gravity covariates to explain empirically bilateral variability of $f_{i j}, A_{i j}^{X N}$, and $F_{i j}^{X P}$, key factors in explaining heterogenous EIA effects in the context of our Armington and Melitz models.

In this section, we offer six hypotheses about how these six observable factors may influence unobservable non-policy variable export costs, non-policy fixed export costs, and policy fixed export costs, and consequently the elasticity of bilateral trade, the intensive margin, and the extensive margin to an EIA. Unfortunately, the world is not so generous as to provide formal linkages from these three unobservables to each of these six observables. However, HMR provides excellent guidance. Appendix 1 in HMR discusses how they used the CIA's World Factbook to construct a number of observable variables which they classified as geographic (bilateral distances and a dummy for common international land border), cultural (religious similarities and a dummy for common official 
language), and institutional (dummies for common legal origin and common colonial history). In the context of our three unobservable variables from the models, we consider geographic variables distance and common land border dummy as proxies for non-policy variable export costs $f_{i j}$. In this context, we consider cultural variables common language dummies and religious similarities, and geographic distance and dummy for international land border, as proxies for non-policy fixed export $\operatorname{costs} A_{i j}^{X N}$. In this context, we consider institutional variables common legal origin and common colonial history dummies as proxies for policy fixed export costs $F_{i j}^{X P}$.

While it is plausible to interpret geographic and cultural variables as related to "natural" (or non-policy) trade costs and institutional variables as related to "policy-oriented" trade costs, we also receive guidance from the results of these three previous empirical studies for such interpretations. First, bilateral distance likely affects both variable and fixed non-policy export costs positively. HMR and ELSW found economically and statistically significant negative effects of distance on the probability of positive exports from $i$ to $j$ and on their level. ${ }^{20}$ Regarding the intensive margin, our equation (13) from the Armington model suggests that the elasticity of the intensive margin of trade to the decline in tariff rates from an EIA may be sensitive to $f_{i j}$. Hummels and Skiba (2004) and Hummels (2007) provide evidence that $f_{i j}$ and bilateral distance are strongly positively related, likely due to transportation costs; consequently, we expect the EIA elasticity of the intensive margin to be negatively correlated with bilateral distance. Our Melitz model suggests that the tariff-rate elasticity of the extensive margin is likely also to be negatively related to distance. Bilateral distance has also been shown to be positively related to information costs, which could raise $A_{i j}^{X N}$. Equations (24) and (29) suggest that a rise in $A_{i j}^{X N}$ (as a result of greater distance) might decrease $s_{i j}$, which tends to decrease the (absolute) tariff-rate elasticity of the extensive margin. Furthermore, a rise in $A_{i j}^{X N}$ (as a result of greater distance) will tend to lower $s_{i j}$ and $F_{i j}^{X P} /\left(A_{i j}^{X N}+F_{i j}^{X P}+n_{i j}^{-\eta}\right)$ and consequently lower the extensive margin response to a fall in $\ln F_{i j}^{X P}$ from an EIA, given equation (36).

Second, one of the most common findings in the large early literature using gravity equations is that - other things constant - adjacency of two countries increased their trade. However, most of those studies ignored zeros in international trade. HMR and ELSW both found that - while adjacency increases the level of trade conditioned on positive trade - adjacency of two countries decreases the probability of positive exports; these results were statistically significant. Physical adjacency of two countries should tend to lower natural variable export costs, $f_{i j}$; consequently, we expect a positive coefficient sign for a common land border through the intensive margin channel in the Armington model. However, the negative common land border coefficient for the probability of exporting, found in HMR and ELSW, was a mystery. HMR interpreted the negative effect of a common land border dummy on the probability of trade as adjacent countries have typically had more military border conflicts; it is the case that measures of cumulative duration of wars between countries negatively influence trade. However, we offer an alternative explanation for this negative impact using our Melitz model. The well-known McCallum (1995) "border puzzle"

\footnotetext{
${ }^{20} \mathrm{BH}$ also found a negative effect on the extensive margin. A fourth study, Bernard, Redding and Schott (2011), also found negative relationships between bilateral distance and the intensive and extensive margins of firms and products.
} 
showed that an international border between U.S. states and Canadian provinces diminished trade, controlling for distance. It is possible that the dummy variable capturing a common land border is reflecting this "international border" effect. If so, adjacency between two countries - capturing the international border effect - could raise natural export fixed costs and diminish the probability of trade. Consequently, we expect that sharing a common land border should increase $A_{i j}^{X N}$, decrease $s_{i j}$, and decrease the impact of an EIA between $i$ and $j$ on their extensive margin via equations (29) and (31). Moreover, equations (33) and (36) support this conclusion; an increase $A_{i j}^{X N}$ also lowers $F_{i j}^{X P} /\left(A_{i j}^{X N}+F_{i j}^{X P}+n_{i j}^{-\eta}\right)$ and consequently lowers the extensive margin response to a fall in $\ln F_{i j}^{X P}$ from an EIA.

Third, HMR and ELSW found that one of the cultural factors that had the largest positive (and statistically significant) impact on the probability of positive exports from $i$ to $j$ was having a common language. Intuitively, sharing a common language should reduce the fixed costs of establishing a trade relationship. Historically in gravity equations (ignoring zeros), common language has been an economically and statistically significant positive contributor to explaining trade flow levels as well. Interestingly, HMR and ELSW found that - with their preferred two-stage estimation - language had a statistically significant positive effect on the probability of trade, but economically and statistically weaker effects on the level of trade (conditioned on positive trade), cf., HMR, Table II and ELSW Tables 2 and 3. Like HMR and ELSW, BH found a positive impact of language on the probability of trade. We expect that sharing a common language should reduce exogenous natural fixed export costs $A_{i j}^{X N}$, increase $s_{i j}$ and $F_{i j}^{X P} /\left(A_{i j}^{X N}+F_{i j}^{X P}+n_{i j}^{-\eta}\right)$, and increase the impact of an EIA between $i$ and $j$ on the extensive margin via equations (30) and (35); however, we expect no effect of common language on the impact of an EIA on the intensive margin.

Fourth, several earlier gravity equation analyses of trade flows (ignoring zeros) included measures of religious similarity and generally found positive effects on bilateral trade. One of the intriguing results of HMR was the finding - using two-stage estimation - that religious similarity had an economically and statistically significant effect on the probability of positive exports from $i$ to $j$, but no statistically significant effect on the level of exports from $i$ to $j$ (conditioned on positive trade), cf., HMR, Table II. HMR consequently relied on religious similarity as their exclusion variable for their second-stage regression. Like sharing a common language, religious similarity creates a trust that lowers exogenous natural fixed export costs $A_{i j}^{X N}$. We expect that religious similarity should reduce $A_{i j}^{X N}$, increase $s_{i j}$ and $F_{i j}^{X P} /\left(A_{i j}^{X N}+F_{i j}^{X P}+n_{i j}^{-\eta}\right)$, and increase the impact of an EIA between $i$ and $j$ on the extensive margin via equations (30) and (35); we expect no effect of religious similarity on the impact of an EIA on the intensive margin. ${ }^{21}$

Fifth, another common finding in the large earlier literature using gravity equations (but ignoring zeros) is that two countries with a common legal origin tend to trade more. In HMR's two-stage estimation, while common legal origin retained its economically and statistically significant positive effect on the intensive margin, its effect on the country extensive margin was much smaller quantitatively. ELSW and BH omitted a common legal origins dummy. Yet, one of the main purposes of an

\footnotetext{
${ }^{21}$ Note also for the previous two variables that the lower level of $A_{i j}^{X N}$, by lowering $s_{i j}$, also raises the extensive margin impact of an EIA's $d \ln \tau_{i j}$.
} 
EIA is to harmonize legal issues. However, if two countries have a common legal origin, their level of $F_{i j}^{X P}$ is lower, ceteris paribus. As discussed in the previous section, a lower level of $F_{i j}^{X P}$ will lower (the absolute value of) the extensive margin elasticity of a one percent fall in $F_{i j}^{X P}$. However, this negative effect on the extensive margin elasticity could be offset by the $d \ln \tau_{i j}$ effect of an EIA. Due to equation (30), the extensive margin elasticity increases (in absolute value) with a lower initial level of $F_{i j}^{X P}$. We cannot sign this interaction effect's coefficient unambiguously.

Sixth, similar to legal origins, if two countries have a common colonial history, their level of $F_{i j}^{X P}$ is lower, ceteris paribus. A lower initial level of $F_{i j}^{X P}$ will lower the extensive margin response to a fall in $\ln F_{i j}^{X P}$ in our model as a result of an EIA. However, an EIA causes a fall in $\ln \tau_{i j}$; this extensive margin elasticity increases with a lower initial level of $F_{i j}^{X} P$. The net effect is ambiguous, as for common legal origins.

Hence, we use six standard gravity covariates to explain the heterogeneity in EIAs effects on members' trade flows beyond what can be explained by the depth of the EIAs' various liberalizations. Table 3 summarizes succinctly the expected effects of each of the variables on enhancing or reducing the trade, intensive margin, and extensive margin impacts of an EIA as just described. In principle, we could account for many other economic, political, legal, and cultural differences for explaining the effectiveness of an EIA on two members' trade; our goal here is to provide an initial empirical investigation of standard gravity covariates based upon our theoretical framework. Moreover, we will find later that these relationships potentially provide guidance for ex ante analysis of the effects of EIAs on economic welfare.

\section{Econometric Specification and Empirical Results}

The first section of this part presents the main econometric specification. The second section presents the main empirical results. The third, fourth, and fifth sections present robustness analyses. Data sources were presented earlier.

\subsection{Main Econometric Specification}

Following our discussion in Section 2.1 earlier, the main specification introduces interaction terms motivated by our theoretical models. Our theory suggests that the effect of an EIA on bilateral trade is non-linear in factors influencing variable and fixed bilateral export costs. All interaction terms enter as de-meaned values. Consequently, following equation (5) in Section 2.1, our main specification is:

$$
\begin{aligned}
\ln X_{i j t} & =\alpha+\eta_{i t}+\theta_{j t}+\psi_{i j}+\beta_{0} E I A_{i j t}+\beta_{1}\left(E I A_{i j t} * \ln D I S T_{i j}\right) \\
& +\beta_{2}\left(E I A_{i j t} * A D J_{i j}\right)+\beta_{3}\left(E I A_{i j t} * L A N G_{i j}\right)+\beta_{4}\left(E I A_{i j t} * R E L I G_{i j}\right) \\
& +\beta_{5}\left(E I A_{i j t} * L E G A L_{i j}\right)+\beta_{6}\left(E I A_{i j t} * C O L O N Y_{i j}\right)+\zeta_{i j t}
\end{aligned}
$$

where $\ln D I S T_{i j}$ is the (de-meaned) natural logarithm of bilateral distance between $i$ and $j, A D J_{i j}$ is a dummy assuming the value 1 if $i$ and $j$ share a common international land border (are adjacent) 
and 0 otherwise, $L A N G_{i j}$ is a dummy assuming the value 1 if $i$ and $j$ share a common official language and 0 otherwise, $R E L I G_{i j}$ is a measure of religious similarity between countries $i$ and $j$, $L E G A L_{i j}$ is a dummy assuming the value 1 if $i$ and $j$ share common legal origins and 0 otherwise, and $C O L O N Y_{i j}$ is a dummy assuming the value 1 if $i$ and $j$ share a common colonial history and 0 otherwise.

\subsection{Main Empirical Results with EIA Interactions}

Table 4 provides the results of estimating equation (37) using OLS and panel data for every five years from 1965-2010. ${ }^{22}$ Column (2) of Table 4 provides also the expected coefficient signs based upon Section 5's hypotheses, summarized in Table 3. Column (3) provides the coefficient estimates for equation (37); t-statistics are reported in parentheses. Our EIA variable is our benchmark categorization, EIA3-6, described earlier. ${ }^{23}$

Columns 2 and 3 in Table 4 reveal that the coefficient estimates all have the expected qualitative effects (when designated), based upon the hypotheses noted above and discussion there. First, note the fall in the partial effect independent of the other variables (the first line of coefficient estimates in column 3) compared to results in Table 2. This reflects the partial effect of an EIA if the country-pair was at the mean of all these bilateral variables. However, for example, most EIAs are "regional" in nature - hence among close countries - and share common cultural characteristics (such as primary languages and religions). So the EIA's effect with interactions must be evaluated for its particular pair's characteristics. Second, note that all six interaction effects are statistically significant. Third, as noted, the interaction terms' coefficient signs are as expected (when designated). Countries that are closer have larger EIA (partial) effects; this is consistent with our hypotheses regarding the intensive and extensive margin effects. However, countries that are adjacent have a lower EIA effect. This is consistent with adjacency having a positive effect on the intensive margin of trade, but simultaneously having a negative effect on the extensive margin of trade due to higher export fixed costs associated with an international "border effect." Language has a positive effect on the EIA's impact; this is consistent with our hypothesis that a common language lowers exogenous natural fixed export costs. We find that religious similarity increases an EIA's impact on trade, likely by reducing also exogenous natural fixed export costs. As discussed in Section 5, having common legal origins or common colonial histories could increase or decrease the extensive margin and aggregate trade elasticities, depending upon the relative changes in $d \ln \tau_{i j}$ and $d \ln F_{i j}^{X P}$. Negative coefficient estimate signs for the common legal origins and common colonial history interaction terms are quite plausible given our discussion in section 5 .

In the next three sections, we pursue sensitivity analyses. Our robustness analyses address three issues for which the results may be sensitive. First, Table 2 introduced lagged effects of EIAs on

\footnotetext{
${ }^{22}$ See BBF (including their Online Appendix) on rationales for using OLS and rationalization of the benefits of five-year intervals. Potential biases due to issues of selection into exporting and firm heterogeneity are accounted for. The issue of potential heteroskedasticity bias is not accounted for using estimators such as Poisson Quasi-Maximum Likelihood (PQML) or Gamma; see footnote 10 earlier.

${ }^{23} \mathrm{It}$ is important to recall that - in the presence of the country-pair $(i j)$ fixed effects - the (separate) level effects of $\ln D I S T_{i j}$ and the other time-invariant bilateral (dummy) variables on $X_{i j t}$ are subsumed in the country-pair fixed effects.
} 
trade flows. We investigate whether our interaction results are sensitive to lagged effects. Second, BBF introduced a decomposition between the intensive and extensive product margins using the decomposition technique in Hummels and Klenow (2005). We investigate whether the results for aggregate trade, the intensive margin and the extensive margin are consistent with our hypotheses. Third, Table 2 introduced six categories of types of EIAs. We investigate whether the results hold up for each type of EIA (and hence different degrees of liberalizations, i.e., different levels of reductions

in $\tau_{i j}$ and $F_{i j}^{X P}$ ). For the first two robustness analyses, our EIA categorization is EIA3-6, as used before.

\subsection{Lagged Effects}

In Table 2, we found that EIAs have lagged effects on trade flows. Allowing for lags, in many cases the complete effects of EIAs were augmented. In this section, we augment the model in equation (37) to include five-year lags of the RHS variables. Column 4 in Table 4 includes additional lagged values of each of the RHS variables. Importantly, the addition of one five-year lag reduces the size of the sample, so coefficients are not directly comparable.

We note several results. First, the effect of an EIA at the means of all the other RHS variables for the current period falls only slightly from 0.25 to 0.24 , but remains statistically significant. The lagged effect of 0.07 is statistically insignificant. The addition of a lag increases the total (absolute) effect of distance on the partial effect from -0.25 to -0.30 and the lagged effect is statistically significant. The addition of a lag increased the total negative effect of adjacency on the effect of an EIA. The addition of a lag had no material effect on the partial effect of common language on EIA's effect; the coefficient estimate fell from 0.32 to 0.30 and remained significant. For religion, the effect in the current period is diminished, but still statistically significant; the lagged effect is economically and statistically insignificant. The effect of common legal origins on the partial EIA effect was marginally significant in column (3); its effect becomes statistically insignificant in column (4). Finally, the effect of common colonial ties on the partial effect of EIA3-6 remains virtually unaltered from introducing a lag and the coefficient estimate on the current level remains statistically significant. Since the results are quite similar with and without lags, for the remainder of the analysis we will ignore lags; this will preserve the larger number of observations and also facilitate computation later when we separate EIA effects by the six types of agreement.

\subsection{Intensive and Extensive Margins}

Our theoretical framework suggests that the partial effects of EIAs on trade flows are potentially influenced at both the intensive and extensive margins. In this section, we extend the methodology employed in BBF to determine these relative influences on intensive and extensive margins. BBF combined the approach in BB with the Hummels and Klenow (2005) margin-decomposition methodology to determine the impact of EIAs on aggregate trade, the intensive margin, and the extensive margin. However, in this paper, we estimate heterogeneous EIA partial effects. 
Hummels and Klenow (2005), or HK, was the first paper to highlight a tractable method for decomposing transparently the extensive and intensive goods margins of trade for a large set of countries' bilateral trade flows using publicly available disaggregate trade data. ${ }^{24}$ Let $X_{i j t}$ denote the value of country $i$ 's exports to country $j$ in year $t$. Following HK, the extensive margin of goods exported from $i$ to $j$ in any year $t$ is defined as:

$$
E M_{i j t}=\frac{\sum_{m \in M_{i j t}} X_{W j t}^{m}}{\sum_{m \in M_{W j t}} X_{W j t}^{m}}
$$

where $X_{W j t}^{m}$ is the value of country $j$ 's imports from the world in product $m$ in year $t, M_{W j t}$ is the set of all products exported by the world to $j$ in year $t$, and $M_{i j t}$ is the subset of all products exported from $i$ to $j$ in year $t$. Hence, $E M_{i j t}$ is a measure of the fraction of all products that are exported from $i$ to $j$ in year $t$, where each product is weighted by the importance of that product in world exports to $j$ in year $t .^{25}$

HK define the intensive margin of goods exported from $i$ to $j$ as:

$$
I M_{i j t}=\frac{\sum_{m \in M_{i j t}} X_{i j t}^{m}}{\sum_{m \in M_{i j t}} X_{W j t}^{m}}
$$

where $X_{i j t}^{m}$ is the value of exports from $i$ to $j$ in product $m$ in year $t$. Thus, $I M_{i j t}$ represents the market share of country $i$ in country $j$ 's imports from the world within the set of products that $i$ exports to $j$ in year $t$.

One of the notable properties of the HK decomposition methodology is that the product of the two margins equals the ratio of exports from $i$ to $j$ relative to country $j$ total imports:

$$
E M_{i j t} I M_{i j t}=\frac{\sum_{m \in M_{i j t}} X_{i j m t}}{\sum_{m \in M_{W j t}} X_{W j m t}}=X_{i j t} / X_{j t}
$$

where $X_{j t}$ denotes $j$ 's imports from the world. Taking the natural logs of equation (32) and some algebra yields:

$$
\ln X_{i j t}=\ln E M_{i j t}+\ln I M_{i j t}+\ln X_{j t}
$$

Consequently, the HK decomposition methodology yields that the log of the value of the trade flow from $i$ to $j$ in any year $t$ can be decomposed linearly into (logs of) an extensive margin, an

\footnotetext{
${ }^{24}$ Studies have also used country-specific data on individual plants (or firms) to study the extensive and intensive firm margins of trade liberalization, but such studies have necessarily been confined to particular countries because such data is widely known to be much more costly to access and such data sets have not been concorded for international comparisons, as noted in HMR. See Eaton, Kortum, and Kramarz (2011) for a study of French firms, Trefler (2004) for a study of Canada and the United States, and Pavcnik (2002) for a study of Chilean firms. Another relevant theoretical and empirical piece with similar overtones is Arkolakis, Demidova, Klenow, and Rodriguez-Clare (2008).

${ }^{25}$ Alternatively, one could use an unweighted average, which would then be simply the fraction of all products exported from $i$ to $j$. However, HK - as well as researchers since then - use the weighted average. A weighted average seems more appropriate since cars and pencils do not have the same values in trade. Also, since we will use a time series of cross sections, we will consider later two alternative methods for fixing the trade-share weights over time.
} 
intensive margin, and the value of $j$ 's imports from the world. We note three issues regarding the HK methodology. First, the term $\ln X_{j t}$ will be subsumed in the importer-time fixed effect. Second, HK applied their methodology to only a cross section. By contrast, we are applying it to a time series of cross sections. Consequently, the trade weights used in constructing $E X_{i j t}$ and $I M_{i j t}$ will likely vary from year to year. To address this, BBF also considered in a sensitivity analysis a chain-weighting technique. However, their results were robust to this alternative weighting procedure. Third, there are numerous zeros in the variables and the results may be biased by ignoring the existence of firm heterogeneity. However, as discussed in BBF and their Online Appendix, our panel approach largely alleviates sample-selection bias and firm-heterogeneity bias as raised in HMR. ${ }^{26}$

Table 5 provides the results using EIA3-6 as our EIA dummy variable. Table 5 has seven columns with column (1) providing the variable names. Columns (2), (4) and (6) provide the expected coefficient signs for the interaction terms for aggregate trade, the intensive margin, and the extensive margin, respectively, guided by our hypotheses in Section 5 and summarized in Table 3. Several results are worth noting. First, the coefficient estimates for the interaction terms in the aggregate trade regression column (3) not only conform to expectations, but also are (with the exception of Adjacency) qualitatively identical to and quantitatively similar to those in Table 4 column (3), despite a large loss in number of observations due to the zeros issue (associated with imposing a "cutoff" in the data for traded vs. nontraded goods). Second, note that for the intensive margin results in column (5) the only two variables that have significant effects on the EIA (partial) effect are bilateral distance and the adjacency dummy. Interestingly, our theoretical model in section 3 motivated heterogeneous intensive margin EIA trade effects via the sensitivity of the tariff-rate elasticity to levels of freight costs, $f_{i j}$. The two variables of the six in Table 5 that are likely most related to freight costs are bilateral distance and adjacency. Third, note the importance of all six interaction terms for influencing the partial EIA effect on the extensive margin of trade. All six coefficient estimates for the extensive margin conform to expectations based on our Melitz model. Fourth, note the qualitatively different effects of the adjacency interaction term on the intensive margin's EIA effect versus the extensive margin's EIA effect. Adjacency has a significant positive effect on the EIA intensive margin partial effect, consistent with the influence of $f_{i j}$ on the EIA's effect. By contrast, adjacency has a significant negative effect on the EIA extensive margin partial effect. This is consistent with HMR which found that adjacency has a negative effect on the probability of trade, or the extensive country margin. Our result here for adjacency is consistent with our hypothesis that an "international border" may be an impediment to the extensive margin of trade.

Figure 2 provides a density plot illustrating the heterogeneous EIA (partial) effects for total trade (solid line), the intensive margin (dashed line), and the extensive margin (dotted line). Several points are worth noting. First, the dashed line shows the enormous dispersion of EIA total trade effects from -0.1 to 1.5, attributable to different geographic, cultural, and institutional characteristics

\footnotetext{
${ }^{26}$ See BBF and their Online Appendix. Besedes and Prusa (2011) emphasize that extensive margin (intensive margin) effects may be overstated (understated) in examining effects of liberalizations using panel data, due to "survival" issues. Addressing this issue is beyond the scope of this particular paper. However, our results may not be biased excessively by this issue since we find material intensive margin effects from EIAs.
} 
shared by country-pairs likely associated with bilateral variable and fixed export costs. The mean effect is slightly greater than 0.5 , consistent with earlier findings. Second, the other two lines indicate that the average intensive margin effect is less than the average extensive margin effect. Third, there is more dispersion in the extensive margin effects relative to the intensive margin effects. This is likely attributable to more of the cultural and institutional factors having significant influence on the extensive margin effects relative to the intensive margin effects, cf., Table 5.

Finally, as raised in Kehoe and Ruhl (2013), the effects of EIAs on the extensive and intensive margins are sensitive to the choice of "cutoff" values determining traded from nontraded goods. As noted there, to characterize an extensive margin, one needs a definition of a nontraded good. Kehoe and Ruhl (2013) show for many trade liberalizations that - using even an absolute cutoff of 50,000 US dollars - there was no extensive margin impacts of EIAs. Using their "relative cutoff" approach, some country pairs' cutoffs for nontraded goods are several millions of US dollars, cf., Table 7 in Kehoe and Ruhl (2013). We have also estimated the results discussed above using cutoffs of 25,000, $50,000,100,000,250,000$, and 500,000 US dollars, in addition to the 1 million US dollar cutoff used for Table 5. Table 6, for instance, provides the results using the 100,000 US dollar cutoff. With regard to the statistically significant coefficient estimates, the results between the two tables are fundamentally the same, with the exception of the religion interaction term. In Table 5 , religion has a significant impact on EIA's extensive margin effect; by contrast, in Table 6 religion has instead a significant impact on EIA's intensive margin effect.

\subsection{Interactions by Type of EIA}

We showed in Table 2 that our approach could be applied using each of the six EIA types in the sample. We found that EIA partial effects were smaller for types of agreements with less trade liberalization, as expected. In this section, we investigate whether the interaction terms have the expected effects by EIA type. Thus, we determine here empirically whether there are heterogeneous impacts of EIAs at each level of degree of trade liberalization.

Because of the very large number of coefficient estimates and t-statistics - 126 - the complete set of results by each EIA type including the interaction terms is presented in Online Appendix 3, Table 1. For brevity we present here two representative sets of results in Tables 7 and 8 . Table 7 provides the results for FTAs extracted from Online Appendix 3, Table 1, using the USD 1 million cutoff; there are 21 coefficient estimates (and t-statistics). Consistent with Table 5 , all the interaction terms have coefficient estimate signs consistent with expectations (when designated). Greater distance diminishes both the intensive and extensive margin elasticities as in Table 5. Adjacency increases the intensive margin elasticity and decreases the extensive margin elasticity as before. Common language and religious similarity have no material effect on the intensive margin elasticities and have significant positive effects on the extensive margin elasticities, as expected. Common legal origins and common colonial history have no measurable effects on the intensive margin elasticities and have significant negative effects on the extensive margin elasticities, as before.

Table 8 provides the results for customs unions extracted from Online Appendix 3, Table 1; again, there are 21 coefficient estimates. Consistent with Tables 5 and 7 , all the interaction terms 
have coefficient signs consistent with expectations (when designated). The only notable difference is that the coefficient estimates for the $C U * L E G A L$ for aggregate trade and the extensive margin are positive, but they are statistically insignificant. A more detailed review of Online Appendix 3, Table 1 shows that the results are largely the same for all six EIA types.

We also estimated the specifications above using the alternative cutoff of USD 100,000. The results, analogous to those in Online Appendix 3, Table 1, are presented in Online Appendix 3, Table 2. For brevity, we will not provide a detailed discussion of these results as they are quite similar to those using the USD 1 million cutoff. Regarding Online Appendix 3, Table 2, there are few changes relative to the Online Appendix 3, Table 1 results that cannot be explained by the fact that - with a lower nontraded good cutoff - there are larger impacts of the interaction variables on intensive margin EIA effects relative to extensive margin EIA effects.

Finally, as we did earlier for EIA3-6, we present density plots of the trade, intensive margin, and extensive margin heterogeneous partial effects for FTAs, customs unions, common markets, and economic unions, in Figures 3-6, respectively. As before, we use the USD 1 million nontraded good cutoff. The distinguishing feature of comparing the results is that the average extensive margin effects are larger than the average intensive margin effects for lower levels of trade liberalization, FTAs and customs unions. For common markets and economic unions, the average intensive margin effects are larger than the average extensive margin effects. The economic explanation for this result is intuitive. Deeper levels of economic integration, such as common markets and economic unions, have already likely overcome export fixed costs in earlier stages of integration. Consequently, it is the less liberalized EIAs - such as FTAs and customs unions - where the benefits of having common cultural and institutional factors influence to a larger extent the effect of an FTA or CU by reducing export fixed costs.

\section{$7 \quad$ EIAs and Welfare}

This section has three parts. First, we review the relationship between aggregate bilateral trade flows, partial EIA effects, general equilibrium EIA effects, and economic welfare in a wide class of quantitative trade models and provide some novel empirical evidence to show that trade diversion effects for the typical bilateral trade flow are very small relative to trade creation effects, suggesting that the bilateral trade-creation (average treatment) effects are likely highly correlated with economic welfare effects of EIA liberalizations. This sets the stage for showing that three readily obtainable statistics - the bilateral trade flow share $\left(\lambda_{i j}\right)$, the CES utility elasticity, and the het-

erogeneous EIA partial effect $\left(\widehat{\beta_{i j}}\right)$ - can largely explain (net general equilibrium) welfare effects of EIAs. Second, for robustness we establish the relationship between the probability of a pair of countries forming an EIA and the EIA partial effects. Third, we show that average treatment effects of EIAs on the treated (ATTs) have systematically declined over the past half century, consistent with the notion that the earliest EIAs in the post-World War II period were likely the most welfare improving. 


\subsection{Explaining Welfare Changes with Partial Equilibrium Effects}

\subsubsection{Theory}

As emphasized in ACR, welfare changes from trade liberalizations in a country $j$ depend on termsof-trade changes. However, terms-of-trade changes can be inferred from changes in the relative demand for goods from different countries. With preferences that can be represented with a CES utility function, welfare of a representative agent in country $j\left(W_{j}\right)$ can be expressed as

$$
W_{j}=\frac{w_{j}}{P_{j}}
$$

where $w_{j}$ is $j$ 's wage rate and $P_{j}$ is the CES price index, as defined in the paper. For a large class of international trade models, such as the one in Section 3, welfare can be determined from the following conditions:

$$
\begin{gathered}
P_{j}=\left[\sum_{k=1}^{N}\left(\frac{\tau_{k j}}{\Pi_{k}}\right)^{\epsilon} w_{k} L_{k}\right]^{\frac{1}{\epsilon}} j=1, . ., . N \\
\Pi_{i}=\left[\sum_{k=1}^{N}\left(\frac{\tau_{i k}}{P_{k}}\right)^{\epsilon} w_{k} L_{k}\right]^{\frac{1}{\epsilon}} i=1, . ., . N \\
w_{i}=\phi_{i} \Pi_{i}^{\frac{-\epsilon}{(\epsilon-1)}} i=1, . . . N
\end{gathered}
$$

Equation (42) is the inward multilateral resistance term, equation (43) is the outward multilateral resistance term, equation (44) is obtained from the goods market-clearing conditions, $\phi_{i}$ is a function of the parameters of the model that are related to tastes and technology but unrelated to trade, and $\epsilon<0$. As described in HMR (their Appendix II), this system can be generalized to incorporate selection into exporting and firm heterogeneity; for tractability and brevity, we omit these considerations here and leave these for future research.

The partial equilibrium impact of a change in bilateral trade costs between $i$ and $j$ on $j$ 's welfare $\left(d \ln W_{i j}^{P E}\right)$ can be obtained by differentiating the above system of equations holding wages and prices constant. This implies that the partial equilibrium effect is given by:

$$
d \ln W_{i j}^{P E}=-\left[\left(\frac{\tau_{i j}}{\Pi_{i} P_{j}}\right)^{\epsilon} w_{k} L_{k}\right] \frac{d \tau_{i j}}{\tau_{i j}}=-\lambda_{i j} \frac{d \tau_{i j}}{\tau_{i j}}
$$

where $\lambda_{i j}$ is the share of country $j^{\prime} s$ expenditures on goods produced in country $i$. With the trade cost function given by $\tau_{i j}^{\epsilon}=\psi_{i j} \exp \left[\beta_{i j} E I A_{i j}\right]$, then formation of $E I A_{i j}$ implies:

$$
\frac{d \tau_{i j}}{\tau_{i j}}=\frac{\beta_{i j}}{\epsilon}
$$

which implies:

$$
d \ln W_{i j}^{P E}=-\lambda_{i j}\left(\frac{\beta_{i j}}{\epsilon}\right)
$$


where, from section $2, \beta_{i j}=\beta+b_{Z}\left(Z_{i j}-\mu_{z}\right){ }^{27}$

We now compare these partial equilibrium welfare effects to the general equilibrium welfare effects that can be obtained from the above system of equations. Substituting the wage equation into the inward and outward multilateral resistance terms and differentiating yields:

$$
\begin{gathered}
\hat{P}_{j}=\lambda_{i j}\left(\frac{\beta_{i j}}{\epsilon}\right)-\left(\frac{\epsilon}{\epsilon-1}\right)\left[\sum_{k=1}^{N} \lambda_{k j} \hat{\Pi}_{k}\right] \\
\left.\hat{\Pi}_{i}=\delta_{i j}\left(\frac{\beta_{i j}}{\epsilon}\right)-\sum_{k=1}^{N} \delta_{i k} \hat{P}_{k}+\frac{1}{(\epsilon-1)}\right) \sum_{k=1}^{N} \delta_{i k} \hat{\Pi}_{k}
\end{gathered}
$$

where $\delta_{i j}$ is the fraction of output produced in $i$ that is shipped to $j$ and a variable with a small hat denotes a percentage change in the underlying variable. The general equilibrium welfare effect $\left(d \ln W_{i j}^{G E}\right)$ for country $j$ from a reciprocal trade agreement agreement with country $i$ is given by:

$$
d \ln W_{i j}^{G E}=\underbrace{-\lambda_{i j}\left(\frac{\beta_{i j}}{\epsilon}\right)}_{\text {direct effect (same as partial equilbirum effect) }}-\underbrace{\delta_{j i}\left(\frac{\beta_{j i}}{\epsilon-1}\right)}_{\text {indirect wage effect from EIA }}-
$$

$$
\underbrace{\frac{\epsilon}{\epsilon-1}\left[\sum_{k=1}^{N}\left(\frac{\delta_{j k}}{\epsilon-1}+\lambda_{k j}\right) \hat{\Pi}_{k}+\sum_{k=1}^{N} \delta_{j k} \hat{P}_{k}\right]}_{\text {Indirect effects through MR terms }}
$$

The first term on the RHS is the partial effect and the second and third terms are the general equilibrium effects. In the spirit of ACR, our goal here is to use a "sufficient statistics approach" to make welfare predictions without having to solve "for all endogenous variables in the model." As ACR note, "In a field such as international trade where general equilibrium effects are numerous, this represents a significant benefit" (p. 96). Our first RHS term is composed of three sufficient and readily observable - statistics.

While considerable advances have been made econometically using gravity equations for providing precise and consistent estimates of trade creation - that is, EI $A_{i j t}$ on $X_{i j t}$ - advances in estimation using gravity equations of the trade diversion effects has made little progress. A few studies have incorporated dummy variables to try to estimate trade-diversion effects. Beginning with Frankel (1997), some researchers have included a dummy variable if either the exporter $i$ has an EIA with any country other than importer $j\left(E I A_{i t}\right)$ and a dummy variable if importer $j$ has an EIA with any country other than exporter $i\left(E I A_{j t}\right)$. Typically researchers have found - if anything - a negative effect of these dummies on $X_{i j t}$. Ghosh and Yamarik (2004), Eicher, Henn, and Papageorgiou (2012), and Dai, Yotov, and Zylkin (2014) all included dummies of this type. However, to date the empirical findings largely indicate minimal trade diversion effects.

\footnotetext{
${ }^{27}$ For instance, in section 3 we assumed $\tau_{i j}^{\epsilon}=\left(f_{i j}+t_{i j}\right)^{\epsilon}$. In this case, the partial welfare effect is $\left(-\lambda_{i j} / \epsilon\right)\left(1 /\left(f_{i j} / t_{i j}+1\right)\right) d \ln t_{i j}^{\epsilon}$.
} 
Consequently, our goal in the next section is to determine if the relationship in the equation above can be approximated by:

$$
d \ln W_{i j}^{G E}=(-1 / \epsilon) \lambda_{i j} \widehat{\beta_{i j}}+\phi_{i j}
$$

where $\widehat{\beta_{i j}}$ denotes an estimate of $\beta_{i j}$ and $\phi_{i j}$ is treated as a random error.

\subsubsection{Econometric Issues and Empirical Results}

In this section, we estimate equation (45) using the welfare changes for importing country $j$ from an EIA of $i$ and $j$ on the LHS and estimates of $\lambda_{i j}$ and of $\widehat{\beta_{i j}}$ on the RHS, where we treat $\phi_{i j}$ as an error term. In a robustness analysis, we will try to account explicitly for variation in $\phi_{i j}$ using importer fixed effects. Moreover, we will also later introduce exporter and importer fixed effects as another robustness analysis. To anticipate the results, we will show that at least 83 percent of the variation in $d \ln W_{i j}^{G E}$ is explained by variation in $\lambda_{i j}$ and $\widehat{\beta_{i j}}$. Hence, it is reasonable to treat $\phi_{i j}$ as an error term.

We now discuss the construction of all three variables. First, as mentioned, our empirical analysis earlier used interaction terms in a panel gravity equation to estimate 2,313 heterogeneous EIA partial effects, $\widehat{\beta_{i j}}$. Second, $d \ln W_{i j}^{G E}$ are generated from the following exercise. Using the Anderson and van Wincoop (2003) structural gravity model (cf., Head and Mayer (2014)), we calculate the level of welfare for the importing country $j$ for all 2,313 observations for which we have EIAs; as standard, welfare is defined as the importer's nominal wage rate divided by the importer's CES price index. Given the actual trade flows and the model's structure, we can calculate each country's endogenous wage rate level, $w_{j}$, national income $\left(Y_{j}\right)$, and importer CES price index $\left(P_{j}\right)$. For each of the 2,313 observations, we remove an EIA, say, $E I A_{i j}$; we then calculate the new bilateral trade flows, wage rates, national incomes, and importer CES price indexes under each of the 2,313 new equilibria. This generates the data on $d \ln W_{i j}^{G E}$. Third, we combine the actual trade flows $X_{i j}$ with the initially computed values of $Y_{j}$ to calculate the $\lambda_{i j}$.

Specifically, we use an iterative method to solve for the multilateral resistance indices, allow wages and prices to change in a manner consistent with a change in the multilateral resistance terms, and recompute the multilateral resistance indices and prices until wages and prices converge. We set world production to a constant value as the numeraire; that is $\sum_{i=1}^{N} w_{i} L_{i}=\sum_{i=1}^{N} \phi_{i} \Pi_{i}^{\frac{-\epsilon}{(\epsilon-1)}} L_{i}=Y$. For each pair $i j$, we change $E I A_{i j}$ :

1. Holding the wage rate constant, we solve for the values of the multilateral resistance indices in equations (42) and (43) given the change in trade costs between $i$ and $j$.

2. Given the new values for the multilateral resistance indices, we recompute the wage rate for each country as given in equation (44).

3. Given the new wages and the change in trade costs, we recalculate the multilateral resistance indices in equations (42) and (43). 
4. Given the new values for the multilateral resistance indices, we recompute the wage rate for each country as given in equation (44).

5. Repeat steps 3 and 4 and until the change in the wage rate is sufficiently small.

To calibrate the model, we used per capita GDP as a measure of the wage rate. For the vector of standard gravity bilateral trade-cost proxies, numbers in parentheses following each variable were used in the simulation exercise: In DIST (-1.03), ADJ (1.15), LANG (0.60), RELIG (0.25), LEGAL (0.41), and COLONY $(0.25)$. The $\widehat{\beta_{i j}}$ are determined by the interactions of the EIA dummy with the other measures of trade costs $\left(Z_{i j}\right)$ and these are taken from Table 4 , column 3.

Since our empirical work cannot identify uniquely the trade cost elasticity $(\epsilon)$, we also needed to choose a value for this parameter. For the trade cost elasticity, we use a value of $\epsilon=-5$. We used the normalization on world income to identify the underlying "productivities" that are consistent with the initial wage rates and the initial outward multilateral resistance indices as specified in equation (44). ${ }^{28}$

We estimate equation (45) using ordinary least squares (OLS). However, as in the gravity equation literature, the relationship between the variables of interest is multiplicative. For OLS, we follow the traditional gravity equation literature - prior to Santos Silva and Tenreyro (2006) where we assume the error term, $\Phi_{i j}$, is multiplicative and rewrite equation (45) as:

$$
d \ln W_{i j}^{G E}=(-1 / \epsilon) \lambda_{i j} \widehat{\beta_{i j}} \Phi_{i j}
$$

Taking the logarithm of equation (46) yields a log-linear equation suitable for OLS:

$$
\ln \left(d \ln W_{i j}^{G E}\right)=\delta_{0}+\delta_{1} \ln \left(\lambda_{i j}\right)+\delta_{2} \ln \left(\widehat{\beta_{i j}}\right)+\ln \Phi_{i j}
$$

Our theory suggests the hypothesis that $\delta_{1}=\delta_{2}=1$.

Table 9 reports the results of estimating equation (47) under four alternative specifications. Specification (1) is equation (47), but constraining the coefficients $\delta_{1}$ and $\delta_{2}$ to be equal. Column (3) shows that the coefficient estimate for $\ln \left(\lambda_{i j} \widehat{\beta_{i j}}\right)$ is positive and statistically significant. Moreover, the coefficient estimate of 0.92 is very close to the expected estimate of 1 . Variation in $\ln \left(\lambda_{i j} \widehat{\beta_{i j}}\right)$ explains 83 percent of the variation in $\ln \left(d \ln W_{j}^{i}\right)$.

In specification (2) in column (4), we allow the coefficient estimates for $\ln \lambda_{i j}$ and $\ln \widehat{\beta_{i j}}$ to be unconstrained. Column (4) shows that $\ln \lambda_{i j}$ and $\ln \widehat{\beta_{i j}}$ have positive and statistically significant effects on $\ln \left(d \ln W_{i j}^{G E}\right)$. Both variables explain 85 percent of the variation in $d \ln W_{i j}^{G E}$. This suggests that the correlation between the welfare effect and the direct partial effect is extremely strong. Naturally, we would expect a correlation because the welfare effect is a function of the partial effect; for an excellent discussion and quantitative analysis of the relationship of the partial effect

\footnotetext{
${ }^{28}$ We do not address explicitly the new "margin" of trade in welfare calculations and issues in Melitz and Redding (2015) regarding welfare calculations in cases where the productivity distribution is not untruncated Pareto. However, as addressed in Melitz and Redding (2015), computations of welfare changes from reductions of $\tau$ that are small (0.25) and when $\tau$ is not far from unity (1.5) are similar whether using the approach in Melitz and Redding (2015) or that in ACR. The values of $\gamma(=4)$ and $d \ln \tau(=0.25)$ in Melitz and Redding (2015) imply changes in trade-cost values similar to ours.
} 
to the welfare effect, see section 4.3 in Head and Mayer (2014). Nevertheless, our result suggests that trade diversion plays a limited role empirically relative to trade creation in influencing welfare. Finally, the coefficient estimate on $\ln \lambda_{i j}$ is economically very close to unity, as suggested by theory, though it is statistically different from unity (at the 1 percent significance level).

Specification (3) in column (5) adds an importer fixed effect to account for general equilibrium effects. The $R^{2}$ value rises from 0.85 to 0.91 with the inclusion of the importer fixed effect. Moreover, there is no material change in the estimated coefficients relative to specification (2). For completeness, specification (4) in column (6) includes an importer fixed effect and an exporter fixed effect. As for specification (3), the $R^{2}$ value rises from 0.91 to 0.94 with the inclusion of the importer and exporter fixed effects. Once again, there is no material change in the estimated coefficients relative to specification (2).

Figure 7 illustrates the relationship between the (log) general equilibrium welfare effect and the (log) partial equilibrium effect, $\ln \lambda_{i j} \widehat{\beta_{i j}}$, based upon the results from specification (1) in column (3). ${ }^{29}$ On net, the results suggest that welfare changes for importer $j$ from an EIA with exporter $i$ are well-approximated by partial effect estimates $\ln \lambda_{i j} \widehat{\beta_{i j}}$. However, since the "data" used for the LHS variable in the regressions just reported $\left(d \ln W_{i j}^{G E}\right)$ are generated from a general equilibrium model that incorporates the partial effect estimate, we evaluate next the robustness of these results. We do this by examining the roles of $\ln \widehat{\beta_{i j}}$ and $\ln \lambda_{i j}$ for explaining an empirically generated measure of the potential welfare gain from an EIA between $i$ and $j$, suggested by the methodology in Baier and Bergstrand (2004): probit estimates of the likelihood of an EIA.

\subsection{Probability of an EIA and the EIA Partial Effect}

As just noted, one of the constraints of the previous regressions is that the welfare changes are functions of the partial effects by construction. The purpose of the preceding analysis was to show that general equilibrium effects played little role. However, there is another way to show that $\ln \widehat{\beta_{i j}}$ and $\ln \lambda_{i j}$ are useful and readily available variables for predicting welfare changes from an EIA. Baier and Bergstrand (2004) provided a framework for predicting the probability that a pair of countries would have an EIA. Based upon a general equilibrium model, the authors showed that the welfare of two countries' representative consumers would be enhanced by an EIA the closer they were to each other, the more remote they were from the rest-of-the-world $(R O W)$, the larger and more similar their economic sizes, and the larger their differences in relative factor endowments. Following the qualitative choice model of McFadden (1975) and McFadden (1976), they showed that these economic factors would also be related to the probability of having an EIA. Their results indicated that the country-pairs that tended to have EIAs tended to have the economic characteristics consistent with such EIAs being welfare improving. Moreover, the econometric model predicted correctly 85 percent of the 286 EIAs in 1996 among the 1,431 country-pairs and predicted correctly 97 percent of the remaining 1,145 pairs with no EIA.

The econometric framework we employ is the qualitative choice model of McFadden $(1975,1976)$.

\footnotetext{
${ }^{29}$ We show the results for this specification so that later, in our ex ante analysis of the proposed Trans-Atlantic Trade and Investment Partnership EIA, we can avoid importer and exporter fixed effects.
} 
A qualitative choice model can be derived from an underlying latent variable model. For instance, let $y *$ denote an unobserved (or latent) variable, where for simplicity we ignore the observation subscript. As in Wooldridge (2000), let $y *$ represent the difference in utility levels from an action (the formation of an FTA), where:

$$
y *=\varsigma_{0}+x \varsigma+\epsilon
$$

where $x$ is a vector of explanatory variables (i.e., common economic characteristics), $\varsigma$ is a vector of parameters, and error term $\epsilon$ is assumed to be independent of $x$ and to have a standard normal distribution. In the context of this model, $y *=\min \left(\Delta U_{i}, \Delta U_{j}\right)$. Hence, both countries' consumers need to benefit from an EIA for their governments to form one. Since $y *$ is unobservable, we define an indicator variable, EIA which takes the value 1 if two countries have an EIA (indicating $y *>0$ ), and 0 otherwise (indicating $y * \leq 0$ ). The response probability, $P$, for EIA is:

$$
P(E I A=1)=P(y *>0)=G\left(\varsigma_{0}+x \varsigma\right)
$$

where $\mathrm{G}(\cdot)$ is the standard normal cumulative distribution function, which ensures that $P(E I A=1)$ lies between 0 and 1 .

In this context, we predicted the probabilities of country-pairs having EIAs for the nine years 1970, 1975, ..., 2010 using similar economic characteristics; the probit results are provided in Online Appendix 4. The relationships between the economic characteristics with the probabilities are qualitatively very similar across the nine years and are consistent with findings in Baier and Bergstrand (2004). As expected based upon the theoretical framework in Baier and Bergstrand (2004), the likelihood of an EIA is negatively related to distance, positively related to economic size (joint GDP), and negatively related to GDP dissimilarity. We also find that that the probability of an EIA is positively related to having a common primary language and religious similarity. In the context of the Baier-Bergstrand model, the country-pairs that tend to have EIAs tend to have the economic characteristics consistent with such EIAs being welfare improving.

Our goal in this section is to determine whether $\ln \widehat{\beta_{i j}}$ and $\ln \lambda_{i j}$ can also explain the variation in the probabilities of EIAs, which serve as proxies for the welfare gains of a country-pair from an EIA. Table 10 presents the results of five alternative specifications. The number of observations is limited to 2,360, as these are the number of estimates of $\ln \widehat{\beta_{i j}}$ from our earlier results. The first specification, shown in column (3), regresses $\ln P\left(E I A_{i j t}\right)$ on $\ln \lambda_{i j}, \ln \widehat{\beta_{i j}}$, and a constant. Two results are worth noting. First, both variables have the expected qualitative relationship with $\ln P\left(E I A_{i j t}\right)$; as $\ln P\left(E I A_{i j t}\right)$ serves as a proxy for $d \ln W_{i j}^{G E}$, we cannot assign a specific expected quantitative value for the coefficients. Second, we note that the pseudo $R^{2}$ value is 53 percent.

One possible concern, however, is that the $\ln \widehat{\beta_{i j}}$ work well to explain the probability of an EIA because the $\ln \widehat{\beta_{i j}}$ themselves will tend to be higher when variable and fixed export costs are low, as our theory suggested. Consequently, $\ln \widehat{\beta_{i j}}$ may have an economically and statistically significant effect simply because $\ln \widehat{\beta_{i j}}$ and $\ln P\left(E I A_{i j t}\right)$ are influenced by common variables, such as bilateral distance, adjacency, etc. To address the robustness of our results, we considered several other specifications. Column (4) adds the $\log$ of bilateral distance to the regression. Column (4) 
shows that - while $\ln D I S T_{i j}$ helps to explain $\ln P\left(E I A_{i j t}\right)-\ln \lambda_{i j}$ and $\ln \widehat{\beta_{i j}}$ still have significant explanatory power. Moreover, adding only distance increases the explanatory power from 53 percent to 85 percent. In the next sensitivity analysis, we included bilateral distance as well as all the other variables used earlier to explain variable and fixed export costs (and which are determinants of the predicted probabilities, as shown in Online Appendix 4). Column (5) shows that - although all these observables are statistically significant in explaining $\ln P\left(E I A_{i j t}\right)-\ln \lambda_{i j}$ and $\ln \widehat{\beta_{i j}}$ still retain significant explanatory power. Moreover, the coefficient estimates for $\ln \lambda_{i j}$ and $\ln \widehat{\beta_{i j}}$ hardly change at all. The specification in column (6) adds an importer fixed effect. As shown in column (6), this has no material effect on the explanatory power of $\ln \lambda_{i j}$ and $\ln \widehat{\beta_{i j}}$. Finally, for completeness, the specification in column (7) adds both an importer and exporter fixed effect. Although the coefficient estimate for $\ln \lambda_{i j}$ becomes negative and marginally significant, the coefficient estimate for $\ln \widehat{\beta_{i j}}$ has no material change.

\subsection{Timing of Average Treatment Effects on the Treated}

We consider one other approach to show that the partial effects of EIAs are consistent with welfare improvement from EIAs. As discussed in $\mathrm{BB}$ and BBF, one of the benefits of using panel data to estimate partial effects is that it can account for the endogeneity of EIAs. However, one of the drawbacks of estimating partial effects using panel data is that the treatment effect is assumed to be constant across all years; in our analysis, that is 1965-2010. As now apparent, a main thrust of our paper has been to show that partial effects vary by country-pair; however, we have not allowed any variation in treatment effects over time. In this section, we examine in particular the average treatment effects on treated pairs (ATTs) across nine periods.

We now provide motivation for estimating the ATT for each of nine periods. Following the logic of Baier and Bergstrand (2004), if country-pairs' governments are maximizing welfare of their consumers, then the EIAs that are formed will likely have economic characteristics consistent with welfare maximization. For instance, Baier and Bergstrand (2004) showed theoretically that if country-pairs are physically close and have large and similar GDPs, they will benefit more from an EIA. Baier and Bergstrand (2009) showed for nine cross-sections 5-years apart (1960-2000) that countries that are close and have large and similar GDPs tend to have EIAs. Moreover, Bergstrand, Egger, and Larch (2015) show that the countries that are closer and have larger and more similar GDPs have higher probabilities of forming EIAs sooner. If indeed country-pairs' governments are maximizing their consumers' welfare, then not only is the probability higher that they will form an EIA earlier but - in the context of our paper - the ATTs of the EIAs should be larger in earlier years than later years.

In this section, we examine the ATTs from our panel data estimates. That is, using the methodology described earlier, we have estimates $\beta_{i j}$ for every country-pair that was treated. We then group the partial effects by nine periods in which these EIAs formed: 1965-1970, 1965-1975, 1965$1980, \ldots, 1965-2010$. We then take the average of the partial effects for each of these nine periods. These are - what we term here - the ATTs for each period. ${ }^{30}$ These are reported in Table 11.

\footnotetext{
${ }^{30}$ Note that the approach here uses a parametric approach to derive ATTs. This differs from the nonparametric
} 
Table 11 has six columns. The first column provides the period in which all EIAs were formed in that period. ${ }^{31}$ The second column provides the (cumulative) number of EIAs formed. The third column provides the ATTs for EIAs formed during that period. The fourth column provides the standard deviation of the ATTs during that period. The fifth column provides the percentage of the EIA number of estimated partial effects that were positive during that period. Finally, column (6) reports estimates of the average treatment effect on the untreated, and we will explain shortly the insight from calculating those.

There are several important findings. First, column (3) shows that the ATTs in the earlier years are the highest. The ATT by period falls (though not strictly monotonically) over time indicating that the EIAs that formed first had the highest ATTs, implying - given our discussion above and Figure 7 - the highest welfare gains. This result is consistent with Bergstrand, Egger, and Larch (2015).

Second, column (5) indicates that the number of negative partial effects is very low. For the period 1965-1995, 99 percent of the ATTs were positive. This result is consistent with the findings shown in Figures 2-6 earlier.

Third, we also report in column (6) a measure called the average treatment effect on the untreated (ATU). The ATU is not as prevalent in econometric reporting as the ATT; the ATT makes intuitive sense because typically one is interested in measuring the effect of a treatment on those actually treated. However, for our purposes the ATU is informative for two reasons. One, the ATU in any given period should be smaller than the ATT. That the ATT in a period exceeds the ATU suggests - again recalling the earlier discussion and Figure 7 - that the welfare gains were highest for the countries that formed EIAs in the designated period. Two, just as the ATTs decline over time, the ATUs decline over time as well. This suggests that over time as some country-pairs without EIAs form ones, the remaining country-pairs have less to gain in trade and welfare; this should be the case.

\section{Ex Ante Predictions for the Proposed Transatlantic Trade and Investment Partnership}

Our analysis in this paper suggests three readily observable statistics to "approximate" general equilibrium welfare gains of EIAs and - in particular - highlights the benefits of using dummy variables and treatment effects to help quantify the trade and welfare effects of EIAs. Where might such methodologies be warranted?

In April 2007, one of the first in-depth discussions of a potential Transatlantic Trade and Investment Partnership (TTIP) agreement took place at a European Union-United States (EU-US)

approach used in Baier and Bergstrand (2009). In that paper, the authors used nonparametric (matching) techniques to estimate ATTs. Such techniques were useful to identify in a time-series of cross-sections the average treatment effects on treated pairs over time also, accounting (in cross-sections) for the endogeneity of EIAs using treated and control groups. See that paper for such an alternative technique, beyond the scope of this already lengthy paper.

${ }^{31}$ The Baier-Bergstrand data set is a comprehensive data set of EIA formations from 1950 to 2010 for 195 countries in the world. 
summit. This summit inspired the European Commission to award a consortium of economic consulting firms to study quantitatively the potential impacts on trade, investment, and welfare of reductions in non-tariff measures (NTMs) on trade and investment; NTMs remain the main policy barriers to trade and investment between two of the largest economic regions in the world. Furthermore, the study authorized the quantitative analysis of reductions in the remaining tariffs on goods and services, which most observers know are quite low already. A major contribution of this analysis, reported in Berden, Francois, Tamminen, Thelle, and Wymenga (2010), was developing a methodology to estimate ad valorem equivalents of the non-tariff barriers to international trade and investment, which was no small task. ${ }^{32}$ A subsequent study, Francois, Manchin, Norberg, Pindyuk, and Tornberger (2013), extended the analysis in Berden et al. (2010) to provide trade and welfare effect estimates of the proposed TTIP.

In this section, we use the methodology of this paper to conduct an ex ante analysis of the TTIP, and then compare the results to those in Francois et al. (2013). Because of the substantive length of this paper already, we constrain our analysis here to aggregate (final goods) trade effects and welfare gains only; we leave analysis of foreign direct investment and sectoral decomposition for others. Basically, we calculated $\widehat{\beta_{i j}}$ for the US (both as importer and exporter) with 26 members of the $\mathrm{EU}$ (for which data was readily available) using our regression coefficient estimates from earlier in the paper. We combined these with estimates of $\lambda_{i j}$, the shares of $i$ 's goods in $j$ 's domestic expenditures (expressed in percentages).

Table 12 provides the values of the $\widehat{\beta_{i j}}$ and $\lambda_{i j}$ for all of the 52 country-pairs; their products are in column (5). Several results are worth noting. First, virtually all of the $\widehat{\beta_{i j}}$ are positive. Excluding the two negative $\widehat{\beta_{i j}}$ estimates, the heterogeneous partial trade effects range from 0.0572 (about 5.9 percent) to 0.3838 (about 46.8 percent). The typical effect is about 23 percent, with heterogeneity very similar to that shown earlier.

Second, column (4) reports the values of $\lambda_{i j}$, expressed in percentages. Note that these values are small, since exports and imports are only 15 percent of US expenditures and no single EU exporter dominates exports to the US. We do not report yet the welfare effect; the reason is that the welfare effect is sensitive to the CES utility parameter, labeled here $\epsilon(\epsilon<0) .{ }^{33}$ We will provide shortly ex ante welfare effect predictions using representative values of $-\epsilon{ }^{34}$

It is useful to ask: Are these estimates plausible? Naturally, it would be beneficial to have some other estimates with which to compare. There is only a small number of analyses of TTIP, summarized in a European Parliament study by Bendini and Micco (2014). However, according to Bendini and Micco (2014), "The principal study cited by the European Commission to support the initiation of TTIP talks" is Francois et al. (2013), mentioned above. Francois et al. (2013) considered fundamentally two alternative approaches in their analysis. The first was a set of "Lim-

\footnotetext{
${ }^{32}$ The Academic Advisory Team for this study's methodology was James Anderson, Jeffrey Bergstrand, Peter Egger and Joseph Francois. The published study is Berden et al. (2010). The economic methodology is in Anderson, Bergstrand, Egger, and Francois (2008) and summarized in Berden et al. (2010). See also http://ntm.ecorys.com .

${ }^{33}$ As discussed in ACR, $\epsilon$ can have alternative interpretations depending on the underlying model.

${ }^{34}$ Although the welfare gains for the US are simply the sum of the bilateral welfare gains with each EU exporter, the welfare gains of the EU as importer need to account for the relative importance of each country in the EU. We used population shares to weight the relative importance of each bilateral welfare gain.
} 
ited Scenarios"; these addressed partial agreements that focused on tariff reductions only, services liberalization only, or procurement liberalization only. The second was a set of "Full-fledged Free Trade Agreements." Within this set, they considered two alternative scenarios. One was a "Less Ambitious" TTIP that included full (actually, 98 percent) tariff removals and a 10 percent reduction in (ad valorem estimates of) trade costs from nontariff barriers (NTBs). The other was a "More Ambitious" TTIP that included full tariff removals and a 25 percent reduction in trade costs from NTBs. ${ }^{35}$

However, at least one serious issue facing any comparison of welfare effects across studies is the assumption on values of $-\epsilon$. Unfortunately, Francois et al. (2013) does not report such values, which will differ by sector in their work due to disaggregation. However, much of Francois et al. (2013) is based upon estimates in Berden et al. (2010), for which estimated values of $-\epsilon$ ranged from 0.8 to 14.5. Consequently, comparison of welfare effects is difficult.

Because of this issue, it will be useful first to compare predicted trade impacts. Our model's predicted trade impacts are provided in column (3) of Table 12; these are heterogeneous across partners. For the US as importer, for example, the (exponentiated) trade impacts range from -14 percent to 46 percent; only 2 of the 26 estimates are negative. The median estimate is 23 percent $(=\exp (0.2037))$. In Francois et al. (2013), the Less Ambitious TTIP scenario predicts a 16 percent increase in US imports from the EU and the More Ambitious TTIP scenario predicts a 29 percent increase in US imports from the EU. Thus, our estimates accord with those in Francois et al. (2013). For the EU as importer, our (exponentiated) trade impacts are similar to the estimates for the US as importer due to the symmetry in factors explaining the heterogeneous partial impacts. In Francois et al. (2013), the Less Ambitious TTIP scenario predicts a 22 percent increase in EU imports from the US and the More Ambitious TTIP scenario predicts a 35 percent increase in EU imports from the US. Francois et al. (2013) estimates are higher primarily due to higher initial EU tariffs in their model. In general, our partial trade impacts are similar to those in Francois et al. (2013), even though that study does not report the bilateral partial trade impacts.

Finally, based upon our framework we can provide ex ante TTIP welfare impacts for both the US and for the EU, which depend upon our choice of $\epsilon$. A typical value of $-\epsilon$ is 3 . In the context of the Armington model, this corresponds with an elasticity of substitution of 4; in the Chaney (2008) model, this corresponds with a productivity heterogeneity parameter of 4 . Using our approach, the TTIP ex ante welfare effect for the US as importer is 0.09 percent; given the strong symmetry in our approach, the welfare effect for the EU is also 0.09 percent. ${ }^{36}$

Table 13 presents the welfare gains (in percent, national income) from Francois et al. (2013). While not directly comparable to our estimates, they shed some light on the matter. First, EU welfare gains are larger than US welfare gains; as Francois et al. (2013) note, they use higher initial EU tariffs, based upon results from Berden et al. (2010). Second, the welfare gains increase for each region as the degree of trade liberalization increases from a reduction in tariffs only all the way to the More Ambitious TTIP scenario.

\footnotetext{
${ }^{35}$ Other issues were addressed also, but are not relevant for our comparison here to our results.

${ }^{36}$ For $\epsilon=-7$, the welfare effect is 0.04 percent for both countries; for $\epsilon=-1$, the welfare effect for the US is 0.26 percent and for the EU is 0.27 percent.
} 
While a direct comparison of welfare effects between our study and Francois et al. (2013) has limitations, our results are suggestive. The results show that our approach provides some credible ex ante estimates of the welfare gains from the TTIP. For a value of $-\epsilon=3$, our approach suggests welfare gains from TTIP of about 0.09 percent for each of the US and the EU. Such gains are in line with estimates based upon Francois et al. (2013), lying between the tariff only and less ambitious liberalization scenarios. Future studies using more precise estimates of ad valorem changes in tariffs and non-tariff barriers from TTIP - beyond our limited and preliminary exercise here - potentially could provide even stronger support for the usefulness of our approach.

\section{Conclusion}

The following summarizes the contributions of this paper. Using a random coefficients gravity equation, we demonstrated extensive heterogeneity in EIAs' partial effects on trade flows beyond differences in degrees of trade liberalization, controlling for endogeneity using the panel techniques of BB and BBF. Using an Armington theoretical trade model, we demonstrated why the heterogeneity in partial effects of EIAs in gravity equations may be related to factors associated with variable trade costs such as freight charges, influencing the intensive product margin of trade. Using a Melitztype theoretical model, we demonstrated why the heterogeneity in partial effects of EIAs may be related to factors associated with variable and fixed export costs, influencing the extensive product margin of trade. Extending BBF, we demonstrated that six standard covariates explaining trade flows (also used in HMR) have economically and statistically significant impacts on the quantitative partial effects of EIAs on trade flows. Distance and adjacency explain the heterogeneous EIA effects on the intensive margins of trade. Distance, adjacency, language, religion, legal origins, and colonial history explain the heterogeneous EIA effects on extensive margins of trade. Moreover, the qualitatively different impacts of institutional variables versus cultural variables on the extensive margin effect is consistent with the novel aspect of our Melitz model distinguishing policy from non-policy exogenous export fixed costs. We showed that 83 percent or more of the variation in welfare effects for importers from EIAs could be explained by two "readily observable" statistics: the share of the trade flow from $i$ to $j$ relative to importer $j$ 's expenditures $\left(\lambda_{i j}\right)$ and the heterogeneous partial effect $\left(\widehat{\beta_{i j}}\right)$. Moreover, in the spirit of Baier and Bergstrand (2004), we showed that 85 percent or more of the variation in the probability of an EIA between $i$ and $j$ could be explained by the above two factors, along with bilateral distance. We showed that the average treatment effects on the treated pairs were highest for the EIAs that formed the earliest, and then declined nearly monotonically; this is consistent with Bergstrand, Egger, and Larch (2015) and the notion that the earliest EIAs were formed by country-pairs with likely the most to gain in welfare from their EIAs. In a comparison of our model's ex ante welfare gains predictions for the US and EU associated with the proposed TTIP relative to those from the principal study cited by the European Parliament, our ex ante welfare predictions lie between those suggested by Francois et al. (2013) for a Tariff Only and a Less Ambitious TTIP, providing support for the relevance of our approach.

Nevertheless, our approach in this paper could be enhanced in future work along at least two 
dimensions. Theoretically, we have provided two models - an Armington model and a Melitz model - to introduce heterogeneous EIA effects for intensive and extensive margins, respectively. Merging the two models is not a trivial exercise mathematically due to the complexity of the model. And although we provide guidance in Online Appendix 2 toward solving such a model, future work may try to build such a model explicitly. Empirically, we have relied upon dummy variables and average treatment effect estimates to capture the impacts on trade of tariff rates and non-tariff measures from EIA formations, partly due to the paucity of good data on trade policies and partly due to the benefits of using a "treatment effects" approach. Continued advances in developing more credible measures of tariff and especially nontariff barriers to capture ad valorem trade costs - beyond the techniques advanced in Anderson et al. (2008) and Berden et al. (2010) - are needed, and such refined continuous measures should be considered when estimating heterogenous effects of EIAs on trade flows.

\section{References}

Anderson, J., J. Bergstrand, P. Egger, and J. Francois (2008): "Non-Tariff Barrier Study Methodology," http://ntm.ecorys.com.

Anderson, J., And E. Van Wincoop (2003): "Gravity with Gravitas: A Solution to the Border Puzzle," American Economic Review, 93(1), 170-192.

Anderson, J., And E. VAn Wincoop (2004): "Trade Costs," Journal of Economic Literature, $42(3), 691-751$.

Anderson, J., and Y. Yotov (2011): "Terms of Trade and Global Efficiency Effects of Free Trade Agreements," NBER Working Paper No. 17003.

Arkolakis, C., A. Costinot, and A. Rodriguez-Clare (2012): "New Trade Models, Same Old Gains?," American Economic Review, 102(1), 94-130.

Arkolakis, C., S. Demidova, P. Klenow, and A. Rodriguez-Clare (2008): "Endogenous Variety and the Gains from Trade," American Economic Review, 98(2), 444-450.

Baier, S., and J. Bergstrand (2001): "The Growth of World Trade: Tariffs, Transport Costs, and Income Similarity," Journal of International Economics, 53(1), 1-27.

(2004): "The Economic Determinants of Free Trade Agreements," Journal of International Economics, 64(1), 29-63.

(2007): "Do Free Trade Agreements Actually
Journal of International Economics, 71(1), 72-95.

(2009): "Estimating the Effects of Free Trade Agreements on International Trade Flows using Matching Econometrics," Journal of International Economics, 77(1), 63-76. 
Baier, S., J. Bergstrand, and M. Clance (2015): "Preliminary Examination of Heterogeneous Effects on International Trade of Economic Integration Agreements," in Trade Cooperation, ed. by A. Dur, and M. Elsig, pp. 355-373. Cambridge University Press, Cambridge, UK.

Baier, S., J. Bergstrand, and M. Feng (2014): "Economic Integration Agreements and the Margins of International Trade," Journal of International Economics, 93(2), 339-350.

Baldwin, R., And J. HARRigan (2011): "Zeros, Quality, and Space: Trade Theory and Trade Evidence," American Economic Journal: Micoreconomics, 3(2), 60-88.

Bendini, R., And P. D. Micco (2014): "The Expected Impact of the TTIP on EU Member States and Selected Third Countries," Directorate-General for External Policies, European Parliament.

Berden, K., J. Francois, S. Tamminen, M. Thelle, and P. Wymenga (2010): Non-Tariff Measures in EU-US Trade and Investment. ECORYS, The Netherlands.

Bergstrand, J., P. Egger, and M. Larch (2015): "Economic Determinants of the Timing of Preferential Trade Agreement Formations and Enlargements," Economic Inquiry, forthcoming.

Bergstrand, J., M. Larch, and Y. Yotov (2015): "Economic Integration Agreements, Border Effects, and Distance Elasticities in the Gravity Equation," European Economic Review, forthcoming.

Besedes, T., and T. Prusa (2011): "The Role of Extensive and Intensive Margins and Export Growth," Journal of Development Economics, 96(2), 371-379.

Cameron, A., and P. Trivedi (2005): Microeconometrics - Methods and Applications. Cambridge University Press, Cambridge, United Kingdom.

Chaney, T. (2008): "Distorted Gravity: The Intensive and Extensive Margins of International Trade," American Economic Review, 98(4), 1707-1721.

Cheng, I., and H. Wall (2005): "Controlling for Heterogeneity in Gravity Models of Trade and Integration," Federal Reserve Bank of St. Louis Review, 87(1), 49-63.

Cheong, J., D. Kwak, and K. Tang (2015): "Heterogeneous Effects of Preferential Trade Agreements," World Development, 66, 222-236.

Cipollina, M., and L. Salvatici (2010): "Reciprocal Trade Agreements in Gravity Models: A Meta-Analysis," Review of Economic Literature, 18(1), 63-80.

Dai, M., Y. Yotov, and T. Zylkin (2014): "On the Trade-Diversion Effects of Free Trade Agreements," Economics Letters, 122(2), 321-325.

Eaton, J., And S. Kortum (2002): "Technology, Geography and Trade," Econometrica, 70(5), $1741-1779$. 
Eaton, J., S. Kortum, and F. Kramarz (2011): "An Anatomy of International Trade: Evidence from French Firms," Econometrica, 79(5), 1453-1498.

Egger, P., M. Larch, K. Staub, and R. Winkelmann (2011): "The Trade Effects of Endogenous Preferential Trade Agreements," American Economic Journal: Economic Policy, 3(3), 113-143.

Eicher, T., C. Henn, and C. Papageorgiou (2012): "Trade Creation and Diversion Revisited: Accounting for Model Uncertainty and Natural Trading Partner Effects," Journal of Applied Econometrics, 27(2), 296-321.

Francois, J., M. Manchin, H. Norberg, O. Pindyuk, and P. Tornberger (2013): "Reducing Transatlantic Barriers to Trade and Investment," CEPR.

Frankel, J. (1997): Regional Trading Blocs. Institute for International Economics, Washington, DC.

Ghosh, S., And S. Yamarik (2004): "Are Regional Trade Agreements Trade Creating?," Journal of International Economics, 63(2), 369-395.

Head, K., and T. Mayer (2014): "Gravity Equations: Workhorse, Toolkit, and Cookbook," in Handbook of Interantional Economics, Volume 4, ed. by G. Gopinath, E. Helpman, and K. Rogoff. Elsevier, Amsterdam.

Helpman, E., M. Melitz, and Y. Rubinstein (2008): "Trading Partners and Trading Volumes," Quarterly Journal of Economics, 123(2), 441-487.

Horn, H., P. Mavroidis, and A. SAPIR (2010): "Beyond the WTO? An Anatomy of EU and US Preferential Trade Agreements," The World Economy, 33(11), 1565-1588.

Hummels, D. (2007): "transportation Costs and International Trade in teh Second Era of Globalization," Journal of Economic Perspectives, 21(3), 131-154.

Hummels, D., And P. Klenow (2005): "The Variety and Quality of a Nation's Exports," American Economic Review, 95(3), 704-723.

Hummels, D., And A. Skiba (2004): "A Virtuous Circle? Regional Tariff Liberalization and Scale Economies in Transport," in: Estevadeordal, A., D. Rodrik, A. Taylor, and A. Velasco (eds.): Integrating the Americas: FTAA and Beyond. Harvard University Press, Cambridge, Massachusetts.

Kehoe, T., and K. Ruhl (2013): "How Important is the New Goods Margin in International Trade?," Journal of Political Economy, 121(2), 358-392.

Kohl, T., S. Brakman, and H. Garretsen (2014): "Do Trade Agreements Stimulate International Trade Differently?," working paper. 
Krautheim, S. (2012): "Heterogeneous Firms, Exporter Networks and the Effect of Distance on International Trade," Journal of International Economics, forthcoming.

McCallum, J. (1995): "National Borders Matter," American Economic Review, 85(3), 615-623.

McFadden, D. (1975): "The Revealed Preferences of a Government Bureaucracy: Theory," Bell Journal of Economics, 6, 401-416. (1976): "Quantal Choice Analysis: A Survey," Annals of Economic and Social Measurement, $5,363-390$.

Melitz, M., And S. Redding (2015): "New Trade Models, New Welfare Implications," American Economic Review, 105(3), 1105-1146.

Novy, D. (2013): "International Trade without CES: Estimating Translog Gravity," Journal of International Economics, 89(2), 271-282.

PAVCNIK, N. (2002): "Trade Liberalization, Exit, and Productivity Improvements: Evidence from Chilean Plants," Review of Economic Studies, 69, 245-276.

Santos Silva, J., and S. Tenreyro (2006): "The Log of Gravity," Review of Economics and Statistics, 88(4), 641-658.

Tinbergen, J. (1962): Shaping the World Economy: Suggestions for an International Economic Policy. The Twentieth Century Fund, New York.

Trefler, D. (2004): "The Long and Short of the Canada-U.S. Free Trade Agreement," American Economic Review, 94(4), 870-895.

VicARD, V. (2011): "Determinants of Successful Regional Trade Agreements," Economics Letters, $111,188-190$.

Wooldridge, J. (2000): Introductory Econometrics. South-Western, Chicago. 
Table 1: Data Description ${ }^{1}$

\begin{tabular}{lccc}
\hline Integration Index & Count & Percent of Total & Percent of subtotal \\
\hline 0 (None) & 567,531 & 34.8 & 78.1 \\
1 (1-way PTA) & 94,789 & 5.8 & 13.0 \\
2 (2-way PTA) & 23,184 & 1.4 & 3.2 \\
3 (FTA) & 25,570 & 1.6 & 3.5 \\
4 (Customs Union) & 7,259 & 0.4 & 1.0 \\
5 (Common Market) & 5,516 & 0.3 & 0.8 \\
6 (Economic Union) & 2,619 & 0.2 & 0.4 \\
Subtotal & 726,468 & - & 100.0 \\
Missing observations & 905,526 & 55.5 & \\
Total & $1,631,994$ & 100.0 & \\
\hline \hline
\end{tabular}

1 Total observations are based upon 183 countries $(183 \times 182=33,306)$ for 49 years (1962-2010). Missing observations include country pairs with zero trade value and/or one country (or both) of a bilateral pair did not officially exist. See data source at www.nd.edu/ jbergstr. 
Table 2: EIA Coefficient Estimates

\begin{tabular}{|c|c|c|c|c|c|c|c|c|c|}
\hline $\begin{array}{c}(1) \\
\text { Variables }\end{array}$ & $\begin{array}{c}(2) \\
\text { Expected Sign }\end{array}$ & (3) & (4) & (5) & (6) & (7) & (8) & (9) & (10) \\
\hline$E I A 3-6_{t}$ & + & $\begin{array}{c}0.56 * * * \\
(16.85)\end{array}$ & $\begin{array}{c}0.60 * * * \\
(16.91)\end{array}$ & & & $\begin{array}{c}0.33 * * * \\
(7.82)\end{array}$ & $\begin{array}{c}0.34 * * * \\
(7.46)\end{array}$ & & \\
\hline$E I A 3-6_{t-5}$ & + & & & & & $\begin{array}{c}0.28 * * * \\
(6.03)\end{array}$ & $\begin{array}{c}0.31 * * * \\
(6.23)\end{array}$ & & \\
\hline$E I A 1-2_{t}$ & + & & $\begin{array}{c}0.10 * * * \\
(3.19)\end{array}$ & & & & $\begin{array}{c}0.02 \\
(0.56)\end{array}$ & & \\
\hline$E I A 1-2_{t-5}$ & + & & & & & & $\begin{array}{c}0.06 \\
(1.42)\end{array}$ & & \\
\hline$E I A 1-6_{t}$ & + & & & $\begin{array}{c}0.29 * * * \\
(10.74)\end{array}$ & & & & $\begin{array}{c}0.13 * * * \\
(3.99)\end{array}$ & \\
\hline$E I A 1-6 t-5$ & + & & & & & & & $\begin{array}{c}0.18 * * * \\
(5.25)\end{array}$ & \\
\hline$O W P T A_{t}$ & + & & & & $\begin{array}{c}0.02 \\
(0.62)\end{array}$ & & & & $\begin{array}{c}0.01 \\
(0.12)\end{array}$ \\
\hline$O W P T A_{t-5}$ & + & & & & & & & & $\begin{array}{c}-0.03 \\
(-0.61)\end{array}$ \\
\hline$T W P T A_{t}$ & + & & & & $\begin{array}{c}0.25 * * * \\
(6.53)\end{array}$ & & & & $\begin{array}{c}0.10 * * \\
(2.28)\end{array}$ \\
\hline$T W P T A_{t-5}$ & + & & & & & & & & $\begin{array}{c}0.21 * * * \\
(3.82)\end{array}$ \\
\hline$F T A_{t}$ & + & & & & $\begin{array}{c}0.53 * * * \\
(14.22)\end{array}$ & & & & $\begin{array}{c}0.32 * * * \\
(6.96)\end{array}$ \\
\hline$F T A_{t-5}$ & + & & & & & & & & $\begin{array}{c}0.21 * * * \\
(4.07)\end{array}$ \\
\hline$C U_{t}$ & + & & & & $\begin{array}{c}0.84 * * * \\
(8.55)\end{array}$ & & & & $\begin{array}{c}0.57 * * * \\
(4.81)\end{array}$ \\
\hline$C U_{t-5}$ & + & & & & & & & & $\begin{array}{c}0.36 * * * \\
(3.01)\end{array}$ \\
\hline$C M_{t}$ & + & & & & $\begin{array}{c}1.12 * * * \\
(15.39)\end{array}$ & & & & $\begin{array}{c}0.82 * * * \\
(8.79)\end{array}$ \\
\hline$C M_{t-5}$ & + & & & & & & & & $\begin{array}{c}0.34 * * * \\
(3.08)\end{array}$ \\
\hline$E C U_{t}$ & & & & & $\begin{array}{c}1.03 * * * \\
(10.27)\end{array}$ & & & & $\begin{array}{c}0.59 * * * \\
(3.77)\end{array}$ \\
\hline$E C U_{t-5}$ & & & & & & & & & $\begin{array}{c}0.58 * * * \\
(3.25)\end{array}$ \\
\hline$\overline{R^{2}}$ & & 0.846 & 0.846 & 0.846 & 0.846 & 0.864 & 0.864 & 0.864 & 0.864 \\
\hline$N$ & & 155,718 & 155,718 & 155,718 & 155,718 & 117,132 & 117,132 & 117,132 & 117,132 \\
\hline
\end{tabular}

Notes: ${ }^{*},{ }^{* *}$, and ${ }^{* * *}$ denote $p<0.10, p<0.05$, and $p<0.01$, respectively. 
Table 3

\begin{tabular}{lccc}
\hline \hline \multicolumn{1}{c}{$(1)$} & $(2)$ & $(3)$ & $(4)$ \\
Variables & $\begin{array}{c}\text { Expected Sign } \\
\text { Trade }\end{array}$ & $\begin{array}{c}\text { Expected Sign } \\
\text { Intensive }\end{array}$ & $\begin{array}{c}\text { Expected Sign } \\
\text { Extensive }\end{array}$ \\
\hline$E I A_{t}$ & + & + & + \\
$E I A_{t} * \ln$ DIST & - & - & - \\
$E I A_{t} *$ ADJ & $?$ & + & - \\
$E I A_{t} *$ LANG & + & 0 & + \\
$E I A_{t} *$ RELIG & + & 0 & + \\
$E I A_{t} *$ LEGAL & $?$ & 0 & $?$ \\
$E I A_{t} *$ COLONY & $?$ & 0 & $?$ \\
\hline \hline
\end{tabular}

Notes: See Section 5 for hypotheses for expected signs. 
Table 4

\begin{tabular}{|c|c|c|c|}
\hline (1) & (2) & (3) & (4) \\
\hline Variables & Expected Sign & Without Lags & With Lags \\
\hline$E I A_{t}$ & + & $\begin{array}{c}0.25 * * * \\
(4.53)\end{array}$ & $\begin{array}{c}0.24 * * * \\
(3.52)\end{array}$ \\
\hline$E I A_{t-5}$ & + & & $\begin{array}{c}0.07 \\
(0.80)\end{array}$ \\
\hline$E I A_{t} * \ln \mathrm{DIST}$ & - & $\begin{array}{c}-0.25 * * * \\
(-5.92)\end{array}$ & $\begin{array}{c}-0.11 * * \\
(-2.11)\end{array}$ \\
\hline$E I A_{t-5} * \ln \mathrm{DIST}$ & - & & $\begin{array}{c}-0.19 * * * \\
(0.70)\end{array}$ \\
\hline$E I A_{t} * \mathrm{ADJ}$ & $?$ & $\begin{array}{c}-0.36 * * * \\
(-3.42)\end{array}$ & $\begin{array}{l}-0.24 * \\
(-1.65)\end{array}$ \\
\hline$E I A_{t-5} * \mathrm{ADJ}$ & $?$ & & $\begin{array}{c}-0.19 * * * \\
(-3.13)\end{array}$ \\
\hline$E I A_{t} * \mathrm{LANG}$ & + & $\begin{array}{c}0.32 * * * \\
(3.68)\end{array}$ & $\begin{array}{c}0.30 * * * \\
(2.71)\end{array}$ \\
\hline$E I A_{t-5} * \mathrm{LANG}$ & + & & $\begin{array}{c}-0.08 \\
(-0.66)\end{array}$ \\
\hline$E I A_{t} *$ RELIG & + & $\begin{array}{c}0.31 * * * \\
(3.47)\end{array}$ & $\begin{array}{c}0.23 * * \\
(1.97)\end{array}$ \\
\hline$E I A_{t-5} *$ RELIG & + & & $\begin{array}{c}0.09 \\
(1.23)\end{array}$ \\
\hline$E I A_{t} * \mathrm{LEGAL}$ & $?$ & $\begin{array}{c}-0.14 * \\
(-1.91)\end{array}$ & $\begin{array}{l}-0.09 \\
(-0.91)\end{array}$ \\
\hline$E I A_{t-5} *$ LEGAL & $?$ & & $\begin{array}{c}-0.03 \\
(-0.30)\end{array}$ \\
\hline$E I A_{t} * \mathrm{COLONY}$ & $?$ & $\begin{array}{c}-0.56 * * * \\
(-2.86)\end{array}$ & $\begin{array}{c}-0.57 * * \\
(-2.07)\end{array}$ \\
\hline$E I A_{t-5} * \mathrm{COLONY}$ & $?$ & & $\begin{array}{c}-0.02 \\
(-0.07)\end{array}$ \\
\hline \multicolumn{4}{|l|}{ Fixed Effects: } \\
\hline Exporter-Year & & Yes & Yes \\
\hline Importer-Year & & Yes & Yes \\
\hline Country-Pair & & Yes & Yes \\
\hline$R^{2}$ & & 0.847 & 0.851 \\
\hline$N$ & & 155,779 & 147,713 \\
\hline
\end{tabular}

Notes: ${ }^{*}, * *$, and ${ }^{* * *}$ denote $p<0.10, p<0.05$, and $p<0.01$, respectively. 
Table 5

\begin{tabular}{|c|c|c|c|c|c|c|}
\hline (1) & $\begin{array}{c}(2) \\
\text { Expected Sign }\end{array}$ & (3) & $\begin{array}{c}(4) \\
\text { Expected Sign }\end{array}$ & $(5)$ & $\begin{array}{c}(6) \\
\text { Expected Sign }\end{array}$ & (7) \\
\hline Variables & Trade & Trade & Intensive & Intensive & Extensive & Extensive \\
\hline$E I A_{t}$ & + & $\begin{array}{c}0.23 * * * \\
(6.94)\end{array}$ & + & $\begin{array}{c}0.07^{* *} \\
(2.31)\end{array}$ & + & $\begin{array}{c}0.16^{* * *} \\
(4.08)\end{array}$ \\
\hline$E I A_{t} * \ln \mathrm{DIST}$ & - & $\begin{array}{c}-0.24 * * * \\
(-9.88)\end{array}$ & - & $\begin{array}{c}-0.09 * * * \\
(-3.83)\end{array}$ & - & $\begin{array}{c}-0.15 * * * \\
(-5.18)\end{array}$ \\
\hline$E I A_{t} * \mathrm{ADJ}$ & $?$ & $\begin{array}{c}0.03 \\
(0.58)\end{array}$ & + & $\begin{array}{c}0.24 * * * \\
(4.23)\end{array}$ & - & $\begin{array}{c}-0.21 * * * \\
(-3.00)\end{array}$ \\
\hline$E I A_{t} * \mathrm{LANG}$ & + & $\begin{array}{c}0.20^{* * *} \\
(3.82)\end{array}$ & 0 & $\begin{array}{c}0.02 \\
(0.47)\end{array}$ & + & $\begin{array}{c}0.17 * * * \\
(2.92)\end{array}$ \\
\hline$E I A_{t} *$ RELIG & + & $\begin{array}{c}0.23 * * * \\
(4.51)\end{array}$ & 0 & $\begin{array}{c}0.07 \\
(1.39)\end{array}$ & + & $\begin{array}{c}0.16 * * * \\
(2.75)\end{array}$ \\
\hline$E I A_{t} *$ LEGAL & $?$ & $\begin{array}{c}-0.12 * * * \\
(-2.80)\end{array}$ & 0 & $\begin{array}{c}0.02 \\
(0.60)\end{array}$ & $?$ & $\begin{array}{c}-0.14 * * * \\
(-2.92)\end{array}$ \\
\hline$E I A_{t} * \mathrm{COLONY}$ & ? & $\begin{array}{c}-0.25 * * \\
(-2.52)\end{array}$ & 0 & $\begin{array}{c}0.10 \\
(1.02)\end{array}$ & $?$ & $\begin{array}{c}-0.35 * * * \\
(-3.04)\end{array}$ \\
\hline \multicolumn{7}{|l|}{ Fixed Effects: } \\
\hline Exporter-Year & & Yes & & Yes & & Yes \\
\hline Importer-Year & & Yes & & Yes & & Yes \\
\hline Country-Pair & & Yes & & Yes & & Yes \\
\hline$R^{2}$ & & 0.912 & & 0.821 & & 0.824 \\
\hline $\mathrm{N}$ & & 70,173 & & 70,173 & & 70,173 \\
\hline
\end{tabular}

Notes: ${ }^{*},{ }^{* *}$, and ${ }^{* * *}$ denote $p<0.10, p<0.05$, and $p<0.01$, respectively. Cutoff for nontraded goods is $\$ 1,000,000$; this affects the sample size. 
Table 6

\begin{tabular}{|c|c|c|c|c|c|c|}
\hline $\begin{array}{c}(1) \\
\text { Variables }\end{array}$ & $\begin{array}{c}(2) \\
\text { Expected Sign } \\
\text { Trade }\end{array}$ & Trade & $\begin{array}{c}(4) \\
\text { Expected Sign } \\
\text { Intensive }\end{array}$ & Intensive & $\begin{array}{c}(6) \\
\text { Expected Sign } \\
\text { Extensive }\end{array}$ & $\begin{array}{c}(7) \\
\text { Extensive }\end{array}$ \\
\hline$E I A_{t}$ & + & $\begin{array}{c}0.21 * * * \\
(6.03)\end{array}$ & + & $\begin{array}{c}0.20 * * * \\
(6.03)\end{array}$ & + & $\begin{array}{c}0.01 \\
(0.20)\end{array}$ \\
\hline$E I A_{t} * \ln$ DIST & - & $\begin{array}{c}-0.20 * * * \\
(-7.69)\end{array}$ & - & $\begin{array}{c}-0.14 * * * \\
(-5.44)\end{array}$ & - & $\begin{array}{c}-0.06 * * \\
(-2.46)\end{array}$ \\
\hline$E I A_{t} * \mathrm{ADJ}$ & $?$ & $\begin{array}{l}-0.07 \\
(-1.14)\end{array}$ & + & $\begin{array}{c}0.21 * * * \\
(3.40)\end{array}$ & - & $\begin{array}{c}-0.28 * * * \\
(-4.30)\end{array}$ \\
\hline$E I A_{t} * \mathrm{LANG}$ & + & $\begin{array}{c}0.21 * * * \\
(3.81)\end{array}$ & 0 & $\begin{array}{c}0.05 \\
(1.04)\end{array}$ & + & $\begin{array}{c}0.15 * * * \\
(2.76)\end{array}$ \\
\hline$E I A_{t} *$ RELIG & + & $\begin{array}{c}0.29 * * * \\
(5.55)\end{array}$ & 0 & $\begin{array}{c}0.21 * * * \\
(4.08)\end{array}$ & + & $\begin{array}{c}0.09 \\
(1.56)\end{array}$ \\
\hline$E I A_{t} *$ LEGAL & $?$ & $\begin{array}{c}-0.13 * * * \\
(-3.02)\end{array}$ & 0 & $\begin{array}{l}-0.05 \\
(-1.14)\end{array}$ & $?$ & $\begin{array}{l}-0.09 * \\
(-1.88)\end{array}$ \\
\hline$E I A_{t} * \mathrm{COLONY}$ & $?$ & $\begin{array}{c}-0.37 * * * \\
(-3.19) \\
\end{array}$ & 0 & $\begin{array}{c}0.16 \\
(1.49) \\
\end{array}$ & $?$ & $\begin{array}{c}-0.53 * * * \\
(-4.54) \\
\end{array}$ \\
\hline \multicolumn{7}{|l|}{ Fixed Effects: } \\
\hline Exporter-Year & & Yes & & Yes & & Yes \\
\hline Importer-Year & & Yes & & Yes & & Yes \\
\hline Country-Pair & & Yes & & Yes & & Yes \\
\hline$\overline{R^{2}}$ & & 0.896 & & 0.799 & & 0.821 \\
\hline $\mathrm{N}$ & & 103,147 & & 103,147 & & 103,147 \\
\hline
\end{tabular}

Notes: ${ }^{*},{ }^{* *}$, and ${ }^{* * *}$ denote $p<0.10, p<0.05$, and $p<0.01$, respectively. Cutoff for nontraded goods is $\$ 100,000$; this affects the sample size. 
Table 7

\begin{tabular}{|c|c|c|c|c|c|c|}
\hline $\begin{array}{c}\text { (1) } \\
\text { Variables }\end{array}$ & $\begin{array}{c}(2) \\
\text { Expected Sign } \\
\text { Trade }\end{array}$ & Trade & $\begin{array}{c}(4) \\
\text { Expected Sign } \\
\text { Intensive }\end{array}$ & Intensive & $\begin{array}{c}(6) \\
\text { Expected Sign } \\
\text { Extensive }\end{array}$ & Extensive \\
\hline$F T A_{t}$ & + & $\begin{array}{c}0.20 * * * \\
(5.94)\end{array}$ & + & $\begin{array}{c}0.11^{* * *} \\
(3.30)\end{array}$ & + & $\begin{array}{c}0.09^{* *} \\
(2.33)\end{array}$ \\
\hline$F T A_{t} * \ln$ DIST & - & $\begin{array}{c}-0.21 * * * \\
(-8.12)\end{array}$ & - & $\begin{array}{l}-0.04^{*} \\
(-1.76)\end{array}$ & - & $\begin{array}{c}-0.17 * * * \\
(-5.57)\end{array}$ \\
\hline$F T A_{t} * \mathrm{ADJ}$ & $?$ & $\begin{array}{c}0.12 * * * \\
(16.76)\end{array}$ & + & $\begin{array}{c}0.30 * * * \\
(14.46)\end{array}$ & - & $\begin{array}{c}-0.19 * * \\
(-2.24)\end{array}$ \\
\hline$F T A_{t} * \mathrm{LANG}$ & + & $\begin{array}{c}0.19 * * * \\
(3.31)\end{array}$ & 0 & $\begin{array}{c}0.04 \\
(0.79)\end{array}$ & + & $\begin{array}{c}0.15^{* *} \\
(2.21)\end{array}$ \\
\hline$F T A_{t} *$ RELIG & + & $\begin{array}{c}0.20 * * * \\
(3.45)\end{array}$ & 0 & $\begin{array}{l}-0.06 \\
(-1.07)\end{array}$ & + & $\begin{array}{c}0.26 * * * \\
(3.88)\end{array}$ \\
\hline$F T A_{t} * \mathrm{LEGAL}$ & $?$ & $\begin{array}{c}-0.10 * * \\
(-2.13)\end{array}$ & 0 & $\begin{array}{c}0.07 \\
(1.55)\end{array}$ & $?$ & $\begin{array}{c}-0.17 * * * \\
(-3.13)\end{array}$ \\
\hline$F T A_{t} * \mathrm{COLONY}$ & $?$ & $\begin{array}{c}-0.21 * \\
(-1.89) \\
\end{array}$ & 0 & $\begin{array}{c}0.10 \\
(0.94)\end{array}$ & $?$ & $\begin{array}{c}-0.31 * * \\
(-2.41)\end{array}$ \\
\hline \multicolumn{7}{|l|}{ Fixed Effects: } \\
\hline Exporter-Year & & Yes & & Yes & & Yes \\
\hline Importer-Year & & Yes & & Yes & & Yes \\
\hline Country-Pair & & Yes & & Yes & & Yes \\
\hline$\overline{\overline{R^{2}}}$ & & 0.912 & & 0.822 & & 0.824 \\
\hline$N$ & & 70,173 & & 70,173 & & 70,173 \\
\hline
\end{tabular}

Notes: ${ }^{*},{ }^{* *}$, and ${ }^{* * *}$ denote $p<0.10, p<0.05$, and $p<0.01$, respectively. Cutoff for nontraded goods is $\$ 1,000,000$; this affects the sample size. 
Table 8

\begin{tabular}{|c|c|c|c|c|c|c|}
\hline (1) & $(2)$ & (3) & $(4)$ & $(5)$ & $(6)$ & (7) \\
\hline Variables & $\begin{array}{c}\text { Expected Sign } \\
\text { Trade }\end{array}$ & Trade & $\begin{array}{l}\text { Expected Sign } \\
\text { Intensive }\end{array}$ & Intensive & $\begin{array}{l}\text { Expected Sign } \\
\text { Extensive }\end{array}$ & Extensive \\
\hline$C U_{t}$ & + & $\begin{array}{c}0.61^{* * *} \\
(3.46)\end{array}$ & + & $\begin{array}{c}0.51^{* * *} \\
(2.99)\end{array}$ & + & $\begin{array}{c}0.10 \\
(0.49)\end{array}$ \\
\hline$C U_{t} * \ln \mathrm{DIST}$ & - & $\begin{array}{c}-0.13 \\
(-1.36)\end{array}$ & - & $\begin{array}{c}0.10 \\
(1.03)\end{array}$ & - & $\begin{array}{c}-0.23 * * \\
(-2.04)\end{array}$ \\
\hline$C U_{t} * \mathrm{ADJ}$ & $?$ & $\begin{array}{c}0.08 \\
(0.57)\end{array}$ & + & $\begin{array}{c}0.28 * * \\
(2.11)\end{array}$ & - & $\begin{array}{c}-0.20 \\
(-1.27)\end{array}$ \\
\hline$C U_{t} * \mathrm{LANG}$ & + & $\begin{array}{c}0.64 * * * \\
(4.62)\end{array}$ & 0 & $\begin{array}{c}0.06 \\
(0.45)\end{array}$ & + & $\begin{array}{c}0.58 * * * \\
(3.61)\end{array}$ \\
\hline$C U_{t} *$ RELIG & + & $\begin{array}{l}0.27^{*} \\
(1.72)\end{array}$ & 0 & $\begin{array}{c}0.03 \\
(0.18)\end{array}$ & + & $\begin{array}{c}0.25 \\
(1.34)\end{array}$ \\
\hline$C U_{t} *$ LEGAL & $?$ & $\begin{array}{c}0.09 \\
(0.69)\end{array}$ & 0 & $\begin{array}{c}0.04 \\
(0.32)\end{array}$ & $?$ & $\begin{array}{c}0.05 \\
(0.32)\end{array}$ \\
\hline$C U_{t} * \mathrm{COLONY}$ & $?$ & $\begin{array}{c}-1.17 * * * \\
(-3.31)\end{array}$ & 0 & $\begin{array}{l}-0.14 \\
(-0.41)\end{array}$ & $?$ & $\begin{array}{c}-1.03 * * \\
(-2.51)\end{array}$ \\
\hline \multicolumn{7}{|l|}{ Fixed Effects: } \\
\hline Exporter-Year & & Yes & & Yes & & Yes \\
\hline Importer-Year & & Yes & & Yes & & Yes \\
\hline Country-Pair & & Yes & & Yes & & Yes \\
\hline$R^{2}$ & & 0.912 & & 0.822 & & 0.824 \\
\hline$N$ & & 70,173 & & 70,173 & & 70,173 \\
\hline
\end{tabular}

Table 9: Determinants of (Logs of) Welfare Changes

\begin{tabular}{|c|c|c|c|c|c|}
\hline $\begin{array}{c}\text { (1) } \\
\text { Variables }\end{array}$ & $\begin{array}{c}(2) \\
\text { Expected Coefficient } \\
\text { Value }\end{array}$ & (3) & (4) & $(5)$ & (6) \\
\hline $\ln \lambda_{i j} \widehat{\beta_{i j}}$ & 1 & $\begin{array}{l}0.92 \text { *** } \\
(105.02)\end{array}$ & & & \\
\hline $\ln \lambda_{i j}$ & 1 & & $\begin{array}{c}0.99 * * * \\
(104.49)\end{array}$ & $\begin{array}{l}1.00 * * * \\
(119.66)\end{array}$ & $\begin{array}{c}0.93 * * * \\
(68.47)\end{array}$ \\
\hline $\ln \widehat{\beta_{i j}}$ & 1 & & $\begin{array}{c}0.51 * * * \\
(18.62)\end{array}$ & $\begin{array}{c}0.58 \text { *** } \\
(22.41)\end{array}$ & $\begin{array}{c}0.58 * * * \\
(21.22)\end{array}$ \\
\hline Constant & $?$ & $\begin{array}{c}3.10 * * * \\
(48.99) \\
\end{array}$ & $\begin{array}{c}3.28 * * * \\
(53.69) \\
\end{array}$ & $\begin{array}{c}3.63 * * * \\
(5.68) \\
\end{array}$ & $\begin{array}{c}0.45 \\
(0.49)\end{array}$ \\
\hline \multicolumn{6}{|c|}{ Fixed Effects: } \\
\hline Importer & & No & No & Yes & Yes \\
\hline Exporter & & No & No & No & Yes \\
\hline $\bar{R}^{2}$ & & 0.830 & 0.847 & 0.908 & 0.939 \\
\hline $\mathrm{N}$ & & 2,266 & 2,266 & 2,266 & 2,266 \\
\hline
\end{tabular}

Notes: ${ }^{*},{ }^{* *}$, and ${ }^{* * *}$ denote $p<0.10, p<0.05$, and $p<0.01$, respectively. 
Table 10: Determinants of (Logs of) Probabilities of EIAs

\begin{tabular}{|c|c|c|c|c|c|c|}
\hline $\begin{array}{c}(1) \\
\text { Variables }\end{array}$ & $\begin{array}{c}\text { (2) } \\
\text { Expected Coefficient } \\
\text { Sign }\end{array}$ & (3) & (4) & (5) & (6) & (7) \\
\hline $\ln \lambda_{i j}$ & + & $\begin{array}{c}0.24 * * * \\
(19.76)\end{array}$ & $\begin{array}{c}0.04 * * * \\
(4.63)\end{array}$ & $\begin{array}{c}0.12 * * * \\
15.91\end{array}$ & $\begin{array}{c}0.14 * * * \\
22.27\end{array}$ & $\begin{array}{c}-0.12 * * \\
-1.97\end{array}$ \\
\hline $\ln \widehat{\beta_{i j}}$ & + & $\begin{array}{c}1.55 * * * \\
(43.77)\end{array}$ & $\begin{array}{c}0.52 * * * \\
(20.52)\end{array}$ & $\begin{array}{c}0.65 * * * \\
(16.66)\end{array}$ & $\begin{array}{c}0.62 * * * \\
(19.57)\end{array}$ & $\begin{array}{c}0.52 * * * \\
(16.65)\end{array}$ \\
\hline $\ln \mathrm{DIST}_{\mathrm{ij}}$ & - & & $\begin{array}{c}-1.44 * * * \\
(-69.52)\end{array}$ & $\begin{array}{c}-1.44 * * * \\
(-54.01)\end{array}$ & $\begin{array}{c}-1.48 * * * \\
(-65.03)\end{array}$ & $\begin{array}{c}-1.68 * * * \\
(-24.14)\end{array}$ \\
\hline $\mathrm{ADJ}_{\mathrm{ij}}$ & $?$ & & & $\begin{array}{c}-0.66 * * * \\
(-12.92)\end{array}$ & $\begin{array}{c}-0.92 \\
(-21.54)\end{array}$ & $\begin{array}{c}-0.64 * * * \\
(-7.83)\end{array}$ \\
\hline $\mathrm{LANG}_{\mathrm{ij}}$ & $?$ & & & $\begin{array}{c}-0.17 * * * \\
(-4.60)\end{array}$ & $\begin{array}{c}0.13 * * * \\
(3.48)\end{array}$ & $\begin{array}{c}0.37 * * * \\
(7.90)\end{array}$ \\
\hline RELIG $_{i j}$ & $?$ & & & $\begin{array}{c}-0.20 * * * \\
(-5.30)\end{array}$ & $\begin{array}{c}-0.28 * * * \\
(-8.32)\end{array}$ & $\begin{array}{c}-0.13 * * * \\
(-3.36)\end{array}$ \\
\hline $\mathrm{LEGAL}_{\mathrm{ij}}$ & $?$ & & & $\begin{array}{c}-0.26 * * * \\
(-9.22)\end{array}$ & $\begin{array}{c}-0.16 * * * \\
(-6.50)\end{array}$ & $\begin{array}{c}-0.04 * * * \\
(-1.21)\end{array}$ \\
\hline $\mathrm{COLONY}_{\mathrm{ij}}$ & $?$ & & & $\begin{array}{c}0.96 * * * \\
(8.53)\end{array}$ & $\begin{array}{c}0.66 * * * \\
(7.41)\end{array}$ & $\begin{array}{c}0.48 * * * \\
(5.54)\end{array}$ \\
\hline Constant & & $\begin{array}{c}0.29 * * * \\
(3.62)\end{array}$ & $\begin{array}{c}9.03 * * * \\
(67.57) \\
\end{array}$ & $\begin{array}{c}9.96 * * * \\
(56.85)\end{array}$ & $\begin{array}{c}11.26 * * * \\
(26.62) \\
\end{array}$ & $\begin{array}{c}8.97 \\
(18.80) \\
\end{array}$ \\
\hline \multicolumn{7}{|c|}{ Fixed Effects: } \\
\hline Importer & & No & No & No & Yes & Yes \\
\hline Exporter & & No & No & No & No & Yes \\
\hline Pseudo $R^{2}$ & & 0.533 & 0.847 & 0.884 & 0.938 & 0.951 \\
\hline $\mathrm{N}$ & & 2,360 & 2,360 & 2,360 & 2,360 & 2,360 \\
\hline
\end{tabular}

Table 11: Average Treatment Effect on the Treated

\begin{tabular}{cccccc}
\hline \hline$(1)$ & $\begin{array}{c}(2) \\
\text { Cumulative \# } \\
\text { of EIAs }\end{array}$ & $\begin{array}{c}(3) \\
\text { ATT } \\
\text { Estimate }\end{array}$ & $\begin{array}{c}\text { Standard } \\
\text { Deviation }\end{array}$ & $\begin{array}{c}(5) \\
\text { \% of EIAs } \\
\text { Positive Effects }\end{array}$ & $\begin{array}{c}\text { ATU } \\
\text { Estimate }\end{array}$ \\
\hline $1965-1970$ & 104 & 0.750 & 0.263 & 100.0 & 0.245 \\
$1965-1975$ & 260 & 0.729 & 0.269 & 99.2 & 0.239 \\
$1965-1980$ & 262 & 0.738 & 0.289 & 99.2 & 0.239 \\
$1965-1985$ & 330 & 0.740 & 0.294 & 99.4 & 0.234 \\
$1965-1990$ & 392 & 0.688 & 0.312 & 99.0 & 0.235 \\
$1965-1995$ & 818 & 0.667 & 0.276 & 99.0 & 0.229 \\
$1965-2000$ & 1554 & 0.639 & 0.305 & 97.8 & 0.220 \\
$1965-2005$ & 2420 & 0.592 & 0.307 & 97.5 & 0.210 \\
$1965-2010$ & 2801 & 0.557 & 0.312 & 96.4 & 0.207 \\
\hline \hline
\end{tabular}

Notes: ATT (ATU) denotes average treatment effect on the treated (untreated). 
Table 12: Ex Ante Bilateral Welfare Predictions for TTIP Members

\begin{tabular}{|c|c|c|c|c|}
\hline (1) & (2) & (3) & (4) & $(5)$ \\
\hline Exporter & Importer & $\widehat{\beta}_{i j}$ & $\lambda_{i j}$ & Product \\
\hline Austria & United States & 0.2105 & 0.0343 & 0.0072 \\
\hline Belgium & United States & 0.2544 & 0.0278 & 0.0071 \\
\hline Bulgaria & United States & 0.0572 & 0.0079 & 0.0005 \\
\hline Croatia & United States & 0.1908 & 0.0092 & 0.0018 \\
\hline Cyprus & United States & -0.1013 & 0.0065 & -0.0007 \\
\hline Czech Republic & United States & 0.1349 & 0.0199 & 0.0027 \\
\hline Estonia & United States & 0.1370 & 0.0047 & 0.0006 \\
\hline Finland & United States & 0.3391 & 0.0513 & 0.0174 \\
\hline France & United States & -0.1434 & 0.2545 & -0.0365 \\
\hline Germany & United States & 0.3206 & 0.3013 & 0.0966 \\
\hline Greece & United States & 0.0487 & 0.0390 & 0.0019 \\
\hline Hungary & United States & 0.2478 & 0.0201 & 0.0050 \\
\hline Ireland & United States & 0.3429 & 0.0663 & 0.0227 \\
\hline Italy & United States & 0.1987 & 0.2372 & 0.0471 \\
\hline Latvia & United States & 0.1583 & 0.0049 & 0.0008 \\
\hline Lithuania & United States & 0.2037 & 0.0066 & 0.0013 \\
\hline Luxembourg & United States & 0.2246 & 0.0030 & 0.0007 \\
\hline Malta & United States & 0.3838 & 0.0013 & 0.0005 \\
\hline Netherlands & United States & 0.2589 & 0.0565 & 0.0146 \\
\hline Poland & United States & 0.1997 & 0.0523 & 0.0104 \\
\hline Portugal & United States & 0.2416 & 0.0475 & 0.0115 \\
\hline Romania & United States & 0.0884 & 0.0267 & 0.0024 \\
\hline Slovak Republic & United States & 0.2253 & 0.0116 & 0.0026 \\
\hline Spain & United States & -0.1491 & 0.2147 & -0.0320 \\
\hline Sweden & United States & 0.3536 & 0.0893 & 0.0316 \\
\hline United Kingdom & United States & 0.0834 & 0.5607 & 0.0468 \\
\hline United States & Austria & 0.2105 & 1.4839 & 0.3124 \\
\hline United States & Belgium & 0.2544 & 0.9674 & 0.2461 \\
\hline United States & Bulgaria & 0.0572 & 3.5877 & 0.2053 \\
\hline United States & Croatia & 0.1908 & 2.6957 & 0.5142 \\
\hline United States & Cyprus & -0.1013 & 5.0248 & -0.5092 \\
\hline United States & Czech Republic & 0.1349 & 2.0930 & 0.2823 \\
\hline United States & Estonia & 0.1370 & 4.4695 & 0.6122 \\
\hline United States & Finland & 0.3391 & 3.3849 & 1.1479 \\
\hline United States & France & -0.1434 & 1.5619 & -0.2240 \\
\hline United States & Germany & 0.3206 & 1.4337 & 0.4596 \\
\hline United States & Greece & 0.0487 & 2.1087 & 0.1027 \\
\hline United States & Hungary & 0.2478 & 2.3828 & 0.5905 \\
\hline United States & Ireland & 0.3429 & 4.2999 & 1.4742 \\
\hline United States & Italy & 0.1987 & 1.7424 & 0.3463 \\
\hline
\end{tabular}

(Continued) 
Table 12: Ex Ante Bilateral Welfare Predictions for TTIP Members

\begin{tabular}{llccc}
\hline \hline \multicolumn{1}{c}{$(1)$} & \multicolumn{1}{c}{$(2)$} & $(3)$ & $(4)$ & $(5)$ \\
Exporter & Importer & $\widehat{\beta}_{i j}$ & $\lambda_{i j}$ & Product \\
\hline United States & Latvia & 0.1583 & 4.0242 & 0.6371 \\
United States & Lithuania & 0.2037 & 3.3237 & 0.6771 \\
United States & Luxembourg & 0.2246 & 1.0534 & 0.2366 \\
United States & Malta & 0.3838 & 2.9101 & 1.1170 \\
United States & Netherlands & 0.2589 & 1.1593 & 0.3002 \\
United States & Poland & 0.1997 & 2.2552 & 0.4503 \\
United States & Portugal & 0.2416 & 3.2423 & 0.7833 \\
United States & Romania & 0.0884 & 3.5272 & 0.3119 \\
United States & Slovak Republic & 0.2253 & 2.2554 & 0.5081 \\
United States & Spain & -0.1491 & 2.4891 & -0.3711 \\
United States & Sweden & 0.3536 & 3.1561 & 1.1160 \\
United States & United Kingdom & 0.0834 & 3.2201 & 0.2687 \\
\hline \hline
\end{tabular}

Notes: See text for details. Numbers in columns (4) and (5) are in percentages. Numbers in column (5) are the product of numbers in columns (3) and (4).

Table 13: Ex Ante TTIP Welfare Gains from Francois et al. (2013)

\begin{tabular}{cccc}
\hline \hline $\begin{array}{c}(1) \\
\text { Region }\end{array}$ & $\begin{array}{c}(2) \\
\text { Tariffs Only }\end{array}$ & $\begin{array}{c}(3) \\
\text { Tariffs and NTMs } \\
\text { Less Ambitious }\end{array}$ & $\begin{array}{c}(4) \\
\text { Tariffs and NTMs } \\
\text { More Ambitious }\end{array}$ \\
\hline US & 0.03 & 0.12 & 0.22 \\
EU & 0.09 & 0.20 & 0.36 \\
\hline \hline
\end{tabular}

Notes: Numbers are in percentages. Estimates are from Francois et al. (2013). 


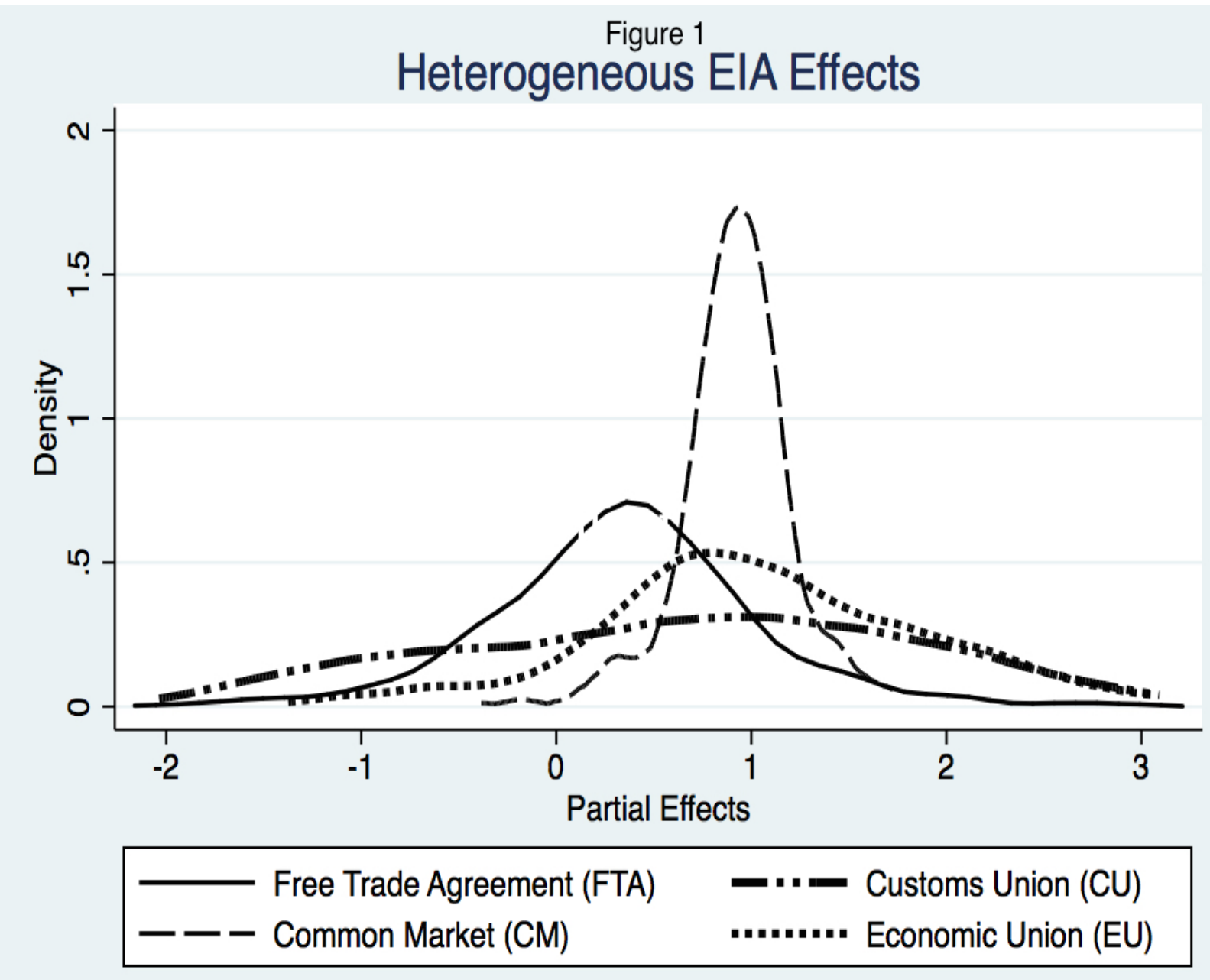

kernel $=$ epanechnikov, bandwidth $=0.1160$ 
Heterogenigure 2 EIA Effects
Fis EIA Els

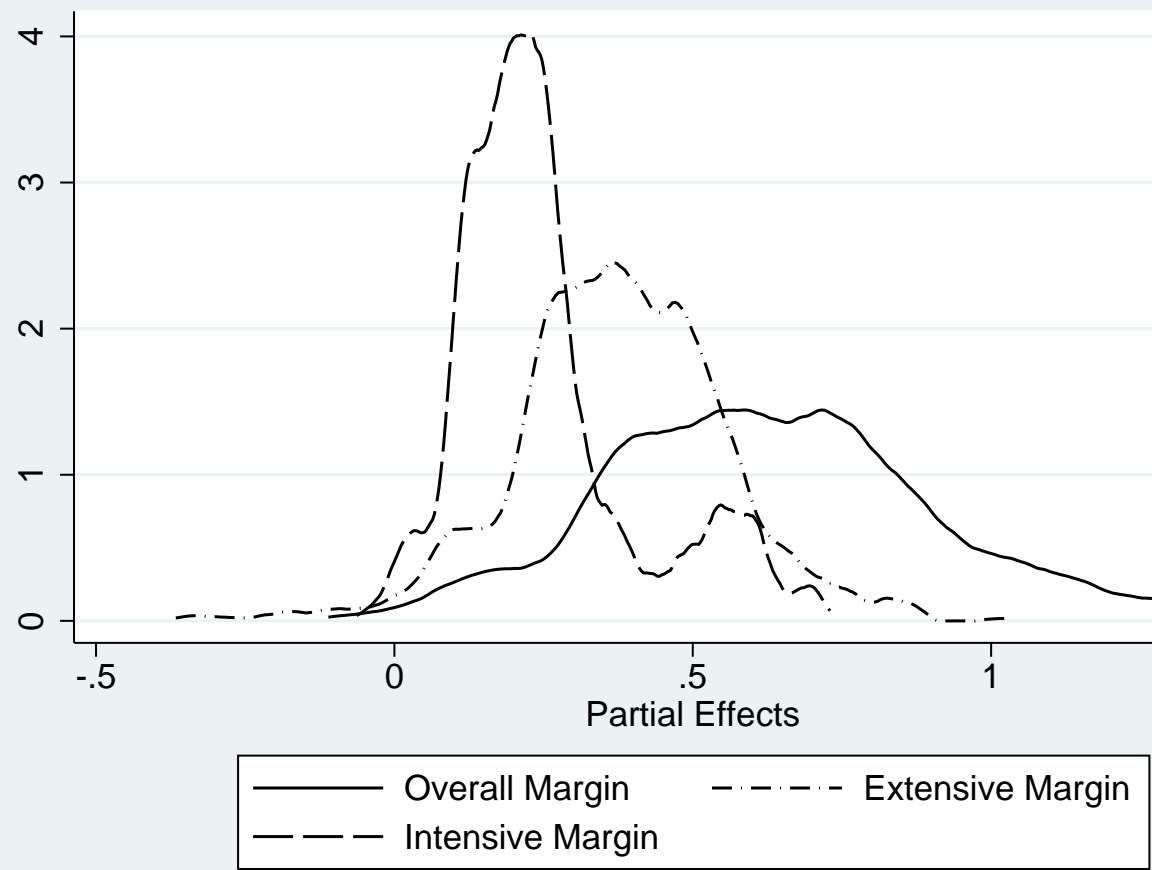




\section{Figure 3
Heterogeneous FTA Effects}

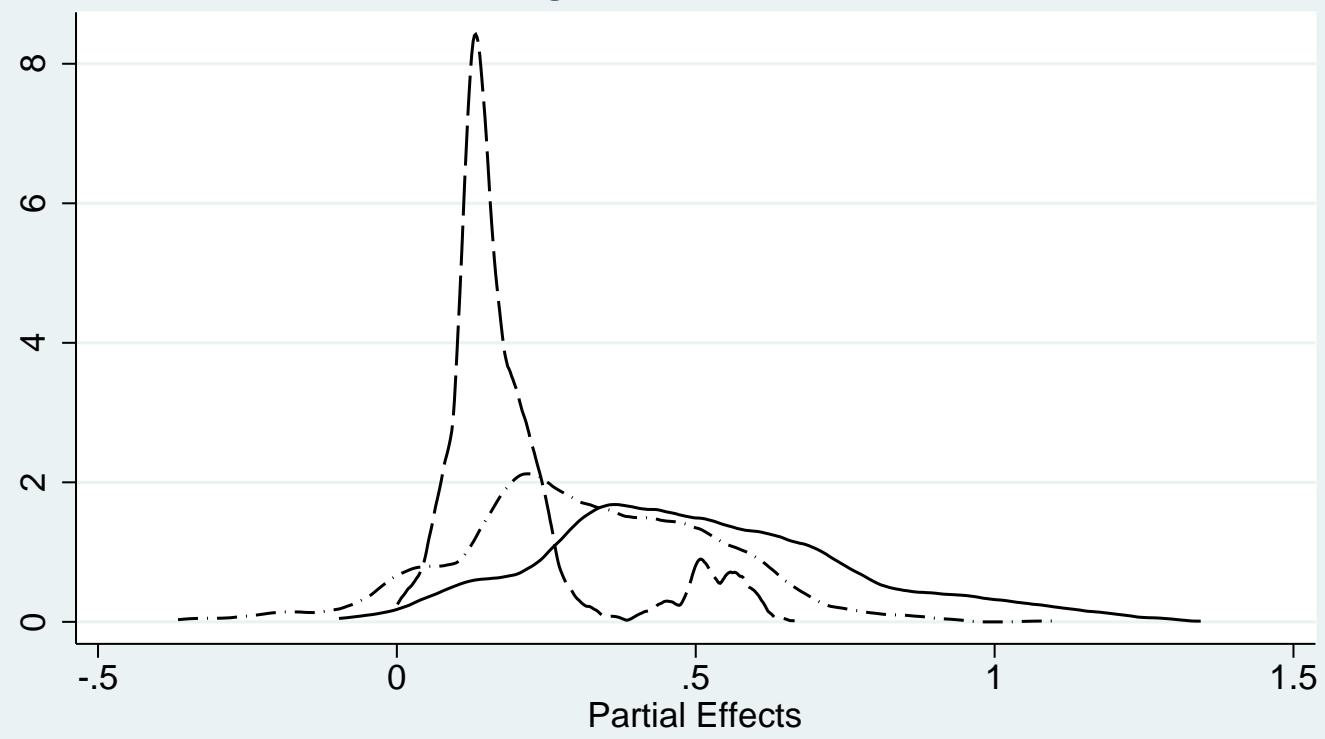

Overall Margin _ _- - Extensive Margin

- - - Intensive Margin 


\section{Heterngonoure 4}

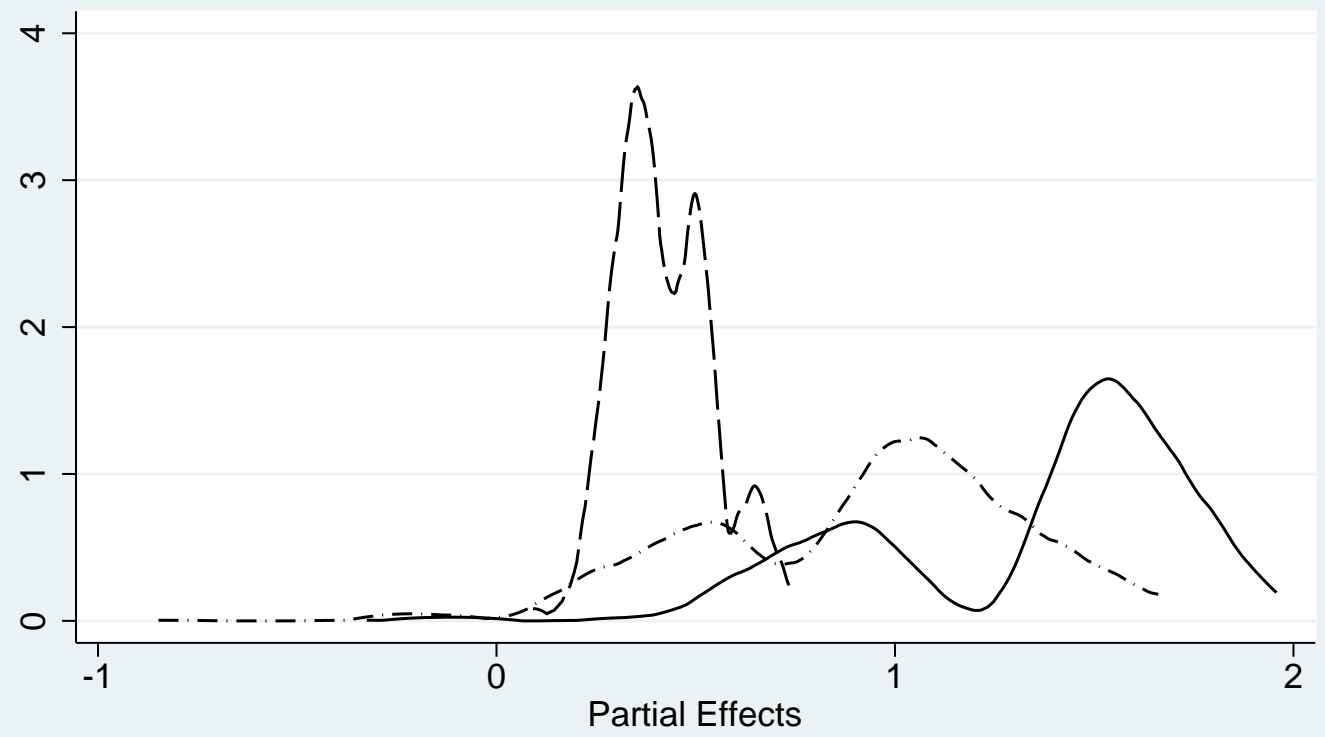




\section{Heterogeneous Corgure 5 mon Market Effects}

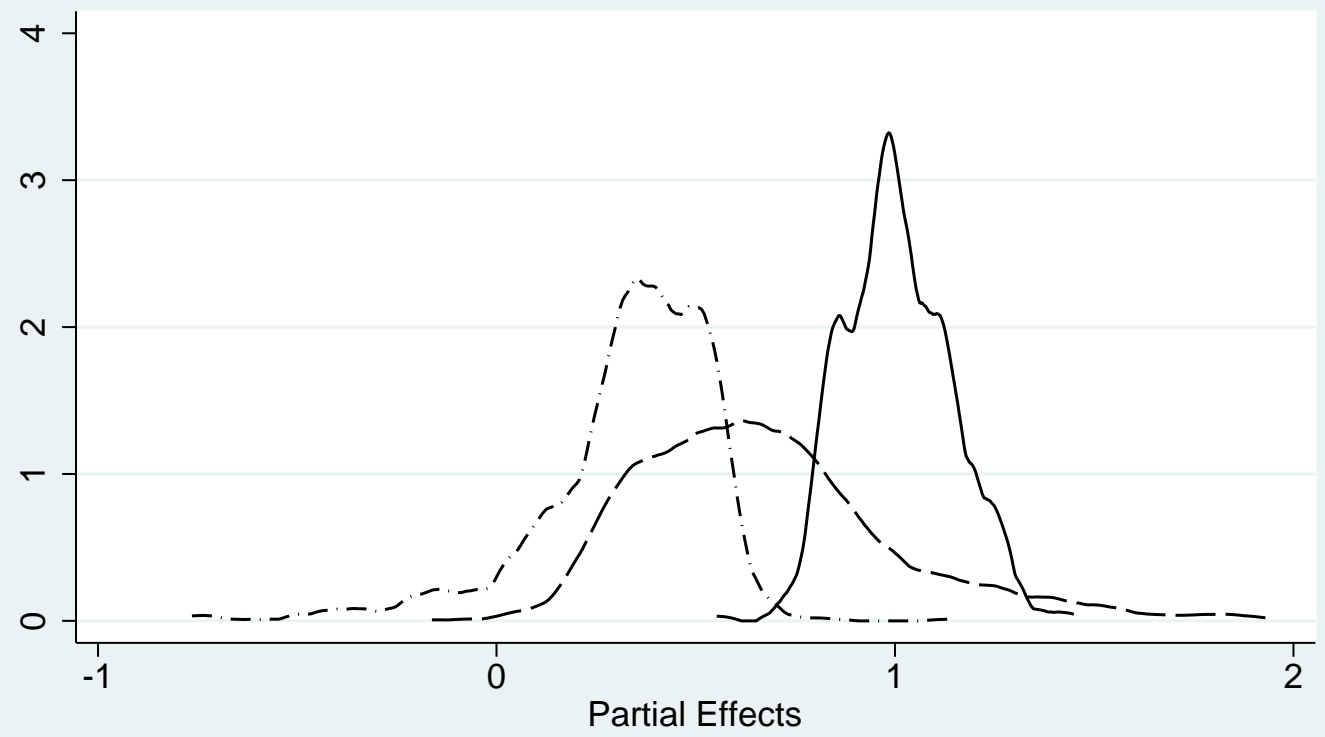

Overall Margin _ - - Extensive Margin _ - - Intensive Margin 


\section{Heterogeneous Economic Union Effects
Econom}

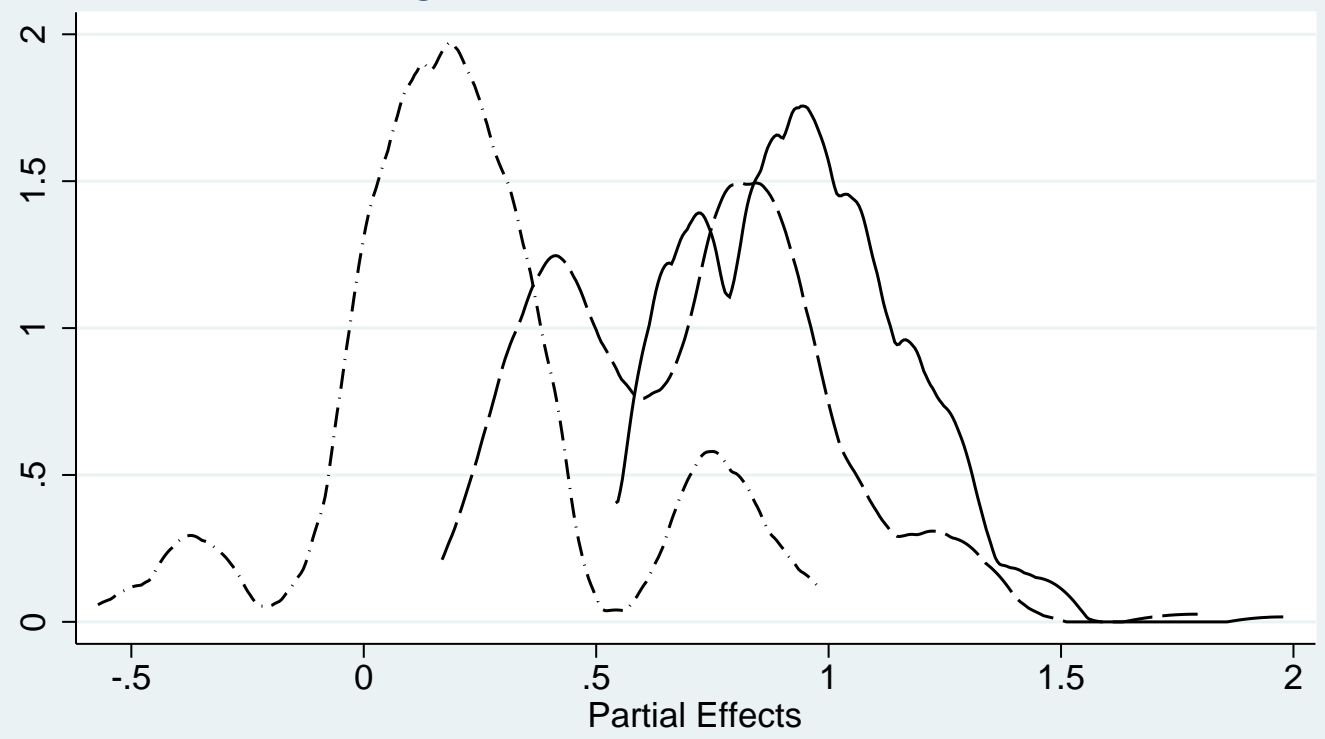

Overall Margin _- - Extensive Margin

- - - Intensive Margin 
Figure 7

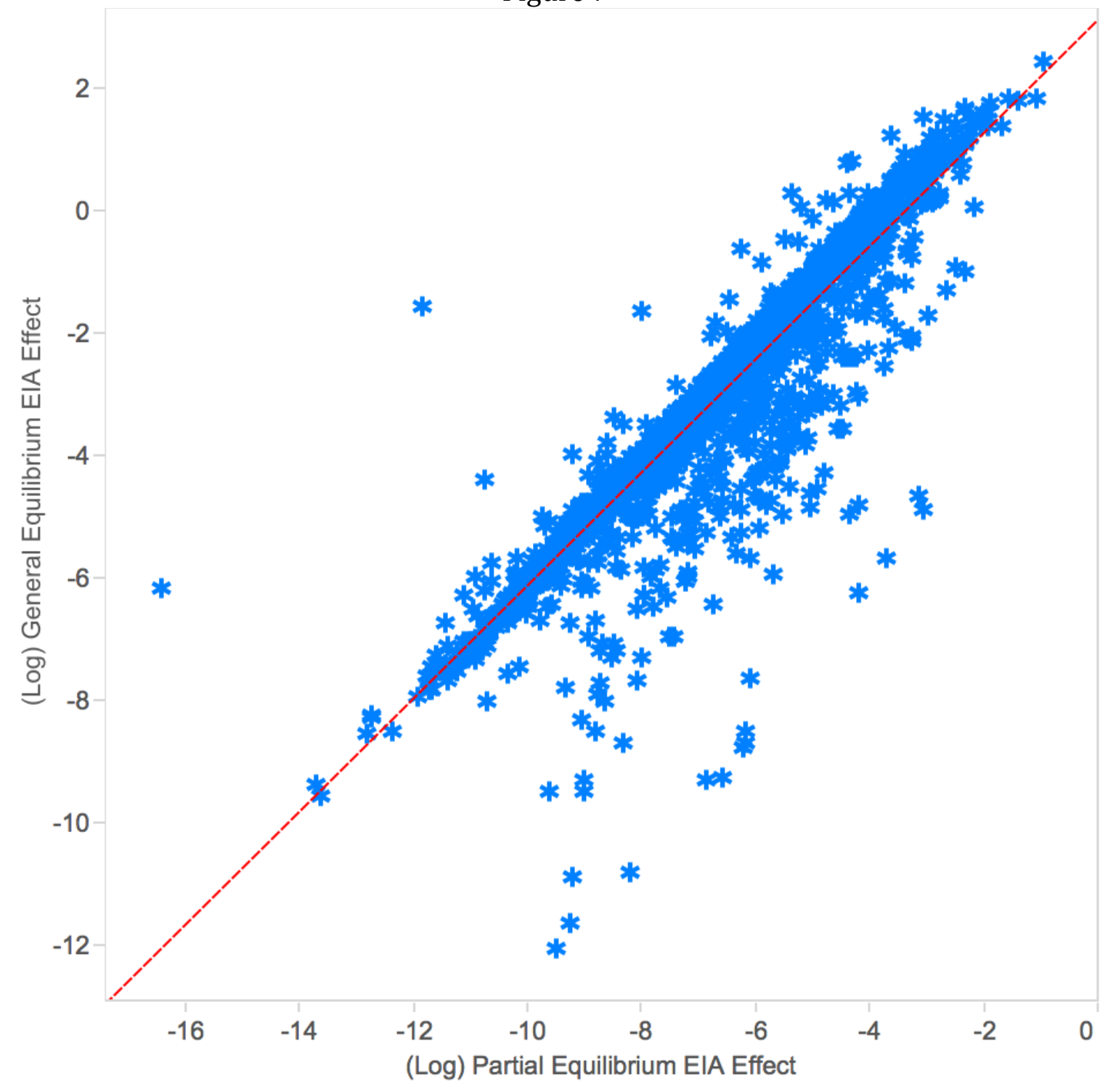


Online Appendix 1: Economic Integration Agreements and Country List ${ }^{1}$

\section{ECONOMIC UNIONS}

Euro Area (1999): Austria, Belgium, Cyprus (2008), Finland, France, Germany, Greece, Ireland, Italy, Luxembourg, Malta (2008), Netherlands, Portugal, Slovak Republic (2008), Slovenia (2008), Spain

West African Economic and Monetary Union (UEMOA/WAEMU) (2000): Benin, Burkina Faso, Guinea-Bissau, Ivory Coast, Mali, Niger, Senegal, Togo

Economic and Monetary Community of Central Africa (CEMAC) (2000): Cameroon, Central African Republic, Chad, Equatorial Guinea, Gabon

\section{COMMON MARKETS}

European Economic Area (EEA) (1993): Austria (1994), Belgium, Bulgaria (2007), Cyprus (2005), Czech Republic (2005), Denmark, Estonia (2005), Finland (1994), France, Germany, Greece, Hungary (2005), Iceland (1994), Ireland, Italy, Latvia (2005), Lithuania (2005), Luxembourg, Malta (2005), Netherlands, Norway (1994), Poland (2005), Portugal, Romania (2007), Slovak Republic (2005), Slovenia (2005), Spain, Sweden (1994), UK

East African Community (EAC) (2001): Burundi (2008), Kenya, Rwanda (2008), Tanzania, Uganda

\section{CUSTOMS UNION}

Andean Community 1 (1995): Bolivia, Colombia, Ecuador, Peru, Venezuela Caribbean Community and Common Market (CARICOM) (1975): Antigua And Barbuda, Bahamas (1984), Barbados, Belize, Dominica, Grenada, Guyana, Haiti (2003), Jamaica, Saint Kitts and Nevis, Saint Lucia, Saint Vincent and the Grenadines, Suriname (1996), Trinidad and Tobago

Central American Common Market (CACM1) (1966-1969): Costa Rica, El Salvador, Guatemala, Honduras, Nicaragua

Eurasian Economic Community (EURASIAN) (2010): Belarus, Kazakhstan, Russia European Economic Community (EEC) (1962-1992): Belgium, Denmark (1973), France, Germany, Greece (1981), Ireland (1973), Italy, Luxembourg, Netherlands, Portugal (1986), Spain (1986), UK (1973)

European Union Customs Union (EUCU): EU-San Marino (1993), EU-Cyprus (1993)

Gulf Cooperation Council Customs Union (GCCCU) (2003): Bahrain, Kuwait, Oman, Qatar, Saudi Arabia, United Arab Emirates

Mercado Comn del Sur (MERCOSUR) (1995): Argentina, Brazil, Paraguay, Uruguay Southern African Customs Union (SACU) (1970): Botswana, Lesotho, Namibia (1990), South Africa, Swaziland

West African Economic and Monetary Union (WAEMU) (1995-1999): Benin, Burkina

\footnotetext{
${ }^{1}$ Only countries in data set are listed.
} 
Faso, Guinea-Bissau (1997), Ivory Coast, Mali, Niger, Senegal, Togo

Czech Republic-Slovak Republic (1993-2004)

\section{FREE TRADE AGREEMENTS}

\section{PLURILATERAL AGREEMENTS}

Andean Community 2 (1993-1994): Bolivia, Colombia, Ecuador, Venezuela Arab Common Market (ACM) (1965): Egypt, Iraq, Syria, Yemen ASEAN-ANZERTA (2010): Australia, New Zealand and ASEAN members Association of Southeast Asian Nations (ASEAN) (2000): Brunei, Cambodia, Indonesia, Laos, Malaysia, Myanmar (Burma), Philippines, Singapore, Thailand, Vietnam Baltic FTA (BAFTA 1999-2004): Estonia, Latvia, Lithuania Caribbean Free Trade Agreement (CARIFTA) (1968-1974): Antigua and Barbuda, Barbados, Belize (1971), Dominica, Grenada, Guyana, Jamaica, Saint Kitts and Nevis, Saint Lucia, Saint Vincent and the Grenadines, Trinidad and Tobago

Central American Common Market (CACM2) (1951-1965): Costa Rica (1963), El Salvador, Guatemala (1955), Honduras (1957), Nicaragua

Central American Common Market (CACM3) (1993): Costa Rica, El Salvador, Guatemala, Honduras, Nicaragua

Central European Free Trade Area (CEFTA) (1993): Albania (2007), Bosnia and Herzegovina (2007), Bulgaria (1999-2006), Croatia (2003), Czech Republic (until 2004), Hungary (19932004), Macedonia (2006), Moldova (2007), Poland (until 2004), Romania (1997-2006), Slovak Republic (1993-2004), Slovenia (1996-2004)

Colombia -Northern Triangle FTA: Colombia, Mexico, El Salvador, Guatemala, Honduras

Common Market for Eastern and Southern Africa (COMESA) (2001): Burundi (2005), Comoros (2006), Congo D.R., Djibouti, Egypt, Eritrea, Ethiopia, Kenya, Libya (2006), Madagascar, Malawi, Mauritius, Rwanda (2005), Seychelles, Swaziland, Uganda, Sudan

Dominican Republic-Central America-United States FTA (2006) (CAFTA-DR): Costa Rica (2009), Dominican Republic (2007), El Salvador, Guatemala (2007), Honduras, Nicaragua, United States

European Free Trade Association (EFTA 1960): Austria (until 1995), Denmark (until 1973), Finland (1986-1995), Iceland (1970), Norway, Portugal (until 1986), Sweden (until 1995), Switzerland, United Kingdom (until 1973)

European Union (EU) (1958): Austria (1995), Belgium, Bulgaria (2007), Cyprus (2004), Czech Republic (2004), Denmark (1973), Estonia (2004), Finland (1995), France, Germany, Greece (1981), Hungary (2004), Ireland (1973), Italy, Latvia (2004), Lithuania (2004), Luxembourg, Malta (2004), Netherlands, Poland (2004), Portugal (1986), Slovak Republic (2004), Slovenia (2004), Spain (1986), Sweden (1995), United Kingdom (1973)

Gulf Cooperation Council (GCCFTA)(1983-2002): Bahrain, Kuwait, Oman, Qatar, Saudi Arabia, United Arab Emirates

NAFTA (North American Free Trade Agreement 1994): Canada, Mexico, US

Pan-Arab Free Trade Area (1998) (PAFTA/GAFTA): Algeria (2009), Bahrain, Egypt, Iraq, Jordan, Kuwait, Lebanon (1999), Libya (1999), Morocco, Oman, Palestine (2005), Qatar, Saudi Arabia, Sudan (2005), Syria, Tunisia, United Arab Emirates, Yemen (2005) 
Pacific Island Countries Trade Agreements (2003) (PICTA): Fiji, Kiribati, Papua New Guinea, Solomon Islands, Tonga, Samoa

South Asian Free Trade Area (SAFTA)(2006): Bangladesh, Bhutan, India, Maldives, Nepal, Pakistan and Sri Lanka

Southern African Development Community (SADC) (2001): Botswana, Congo D.R., Lesotho, Madagascar, Malawi (2009), Mauritius, Mozambique (2009), Namibia, South Africa, Swaziland, Tanzania (2009), Zambia, Zimbabwe

Trans-Pacific Partnership (TPP) (2006): Brunei, Chile, New Zealand, Singapore

West African Monetary Union (WAMU) (1962-1965): Burkina Faso, Mali, Mauritania, Niger, Senegal

\section{BILATERAL AGREEMENTS}

Albania-Bosnia and Herzegovina (2004-2006)

Albania-Croatia (2004-2006)

Albania-Macedonia (2003-2006)

Albania-Macedonia (2003-2006)

Albania-Romania (2004)

Andean Community 1-Chile (2005)

Andean Community 1-MERCOSUR (2005)

Angola-Egypt (2001)

Armenia-Georgia (1999)

Armenia-Kazakhstan (2002)

Armenia-Kyrgyz Republic (1996)

Armenia-Moldova (1996)

Armenia-Russia (1993)

Armenia-Turkmenistan (1997)

Armenia-Ukraine (1997)

ASEAN-China (2006)

ASEAN-India (2010)

ASEAN-Japan (2008)

ASEAN-South Korea (2007)

Australia-Chile (2009)

Australia-New Zealand (1983-2009)

Australia-Papua New Guinea (1977)

Australia-Singapore (2003-2009)

Australia-Thailand (2005-2009)

Australia-USA (2005)

Azerbaijan-Georgia (1997)

Azerbaijan-Russia (1993)

Azerbaijan-Ukraine (1997)

Bahrain-USA (2007)

Belarus-Russia (1993-2009)

Belarus-Ukraine (2007)

Bolivia-Chile (1996-2004)

Bolivia-Mexico (1995) 
Bosnia and Herzegovina-Bulgaria (2005)

Bosnia and Herzegovina-Croatia (2001-2006)

Bosnia and Herzegovina-Macedonia, (2003-2005)

Bosnia and Herzegovina-Moldova (2005-2006)

Bosnia and Herzegovina-Romania (2004-2006)

Bosnia and Herzegovina-Slovenia (2002-2003)

Bulgaria-Israel (2002-2006)

Bulgaria-Macedonia (2000-2006)

Bulgaria-Moldova (2004)

CACM3-Dominican Republic (1998)

CACM3-Mexico (2001)

Cameroon-Gabon (1966-1999)

Canada-Chile (1997)

Canada-Israel (1997)

Canada-Peru (2010)

Canada-USA (1989-1993)

CARICOM-Costa Rica (2004)

CARICOM-Dominican Republic (1998)

CEFTA-Bulgaria (1993-1998)

Chile-China (2007)

Chile-Costa Rica (2002)

Chile-El Salvador (2003)

Chile-Japan (2008)

Chile-Korea (2004)

Chile-Mexico (2000)

Chile-Panama (2008)

Chile-USA (2004)

China-Costa Rica (2010)

China-Hong Kong (2004)

China-Macao (2004)

China-New Zealand (2009)

China-Nicaragua (2007)

China-Pakistan (2008)

China-Peru (2010)

Colombia-Mexico (1995-2009)

COMESA-SADC (2006)

Congo, Republic of-Gabon (1966)

Costa Rica-Mexico (1995-2000)

Croatia-Macedonia (2004)

Czech Republic-Estonia (1997)

Czech Republic-Israel (1997-2004)

Czech Republic-Latvia (1997-2004)

Czech Republic-Lithuania (1997-2004)

Czech Republic-Romania (1997-2006)

EEC-Israel (1975-1992)

EEA-Israel (1993) 
EFTA-Albania (2010)

EFTA-Bulgaria (1994-2006)

EFTA-Canada (2010)

EFTA-Chile (2005)

EFTA-Croatia (2002)

EFTA-Czech Republic (1994-2004)

EFTA-Egypt (2007)

EFTA-Estonia (1997-2004)

EFTA-GCCCU (2009)

EFTA-Hungary (1994-2004)

EFTA-Israel (1993)

EFTA-Jordan (2002)

EFTA-Latvia (1996-2004)

EFTA-Lebanon (2007)

EFTA-Lithuania (1997-2004)

EFTA-Macedonia (2001)

EFTA-Mexico (2002)

EFTA-Morocco (2000)

EFTA-Poland (1994)

EFTA-Romania (1994-2006)

EFTA-SACU (2008)

EFTA-Singapore (2003)

EFTA-Slovak Republic (1993-2004)

EFTA-Slovenia (1995-2004)

EFTA-South Korea (2007)

EFTA-Tunisia (2005)

Egypt-Jordan (1999)

El Salvador-Panama (2003)

Estonia-Hungary (1999-2004)

Estonia-Slovak Republic (1997-2004)

Estonia-Slovenia (1997-2004)

EU-Algeria (2005)

EU-Bulgaria (1994-2006)

EU-Chile (2005)

EU-Croatia (2003)

EU-Cyprus (1988-2004)

EU-Czech Republic (1992-2004)

EU-EFTA (Agreement/European Economic Area 1973/1994)

EU-Egypt (2005)

EU-Estonia (1998-2004)

EU-Faroe Islands (1997)

EU-Hungary (1992-2004)

EU-Israel (2000)

EU-Jordan (2002)

EU-Lativa (1995-2004)

EU-Lebanon (2003) 
EU-Lithuania (1995-2004)

EU-Macedonia (2002)

EU-Mexico (1998)

EU-Morocco (2001)

EU-Poland (1992-2004)

EU-Romania (1993-2006)

EU-Slovak Republic (1993-2004)

EU-Slovenia (1997-2004)

EU-South Africa (2000)

EU-Tunisia (1999)

Faroe Islands-Iceland (1994)

Faroe Islands-Norway (1994)

Faroe Islands-Poland (2000-2004)

Faroe Islands-Switzerland (1996)

Georgia-Kazakhstan (2000)

Georgia-Russia (1993)

Georgia-Turkmenistan (2000)

Georgia-Ukraine (1997)

Hungary-Israel (1998-2004)

Hungary-Latvia (2000-2004)

Hungary-Lithuania (2000-2004)

India-Sri Lanka (1999-2005)

India-Singapore (2006)

India-South Korea (2010)

Ireland-Latvia (1995)

Ireland-Lithuania (1995)

Israel-Mexico (2001)

Israel-Poland (1998-2004)

Israel-Romania (2002-2006)

Israel-Slovak Republic (1997-2004)

Israel-Slovenia (1999-2004)

Israel-USA (1986)

Japan-Switzerland (2010)

Jordan-Singapore (2006)

Jordan-USA (2002)

Kazakhstan-Kyrgyz Republic (1996)

Kazakhstan-Russia (1993-2009)

Kyrgyz Republic-Moldova (1997)

Kyrgyz Republic-Russia (1993)

Kyrgyz Republic-Ukraine (1998)

Kyrgyz Republic-Uzbekistan (1999-2007)

Latvia-Slovak Republic (1997-2004)

Lithuania-Poland (1997-2004)

Lithuania-Slovak Republic (1997-2004)

Lithuania-Slovenia (1997-2003)

Macedonia-Moldova (2005-2006) 
Macedonia-Romania (2004-2006)

Macedonia-Slovenia (1997-2003)

Macedonia-Ukraine (2002-2005)

MERCOSUR-Bolivia (1996-2004)

MERCOSUR-Chile (1996)

MERCOSUR-Israel (2008)

Mexico-Colombia (1995)

Mexico-Japan (2005)

Mexico-Nicaragua (1999)

Mexico-Uruguay (2005)

Mexico-Venezuela (1995)

Moldova-Ukraine (2005)

Morocco-USA (2006)

New Zealand-Singapore (2001-2009)

New Zealand-Thailand (2006-2009)

Oman-USA (2009)

Pakistan-Sri Lanka (2005)

Panama-Singapore (2007)

Peru-Singapore (2010)

Peru-USA (2009)

Poland-Latvia (1999-2004)

Romania-Moldova (1995-2006)

Russia-Tajikistan (1993)

Russia-Turkmenistan (1993)

Russia-Ukraine (1994)

Russia-Uzbekistan (1993)

SADC-SACU (2009)

Slovak Republic-Estonia (1997)

Slovenia-Israel (1999)

Slovenia-Latvia (1997)

Tajikistan-Ukraine (1995)

Turkmenistan-Ukraine (1995)

TPP-China (2007)

Ukraine-Estonia (1997)

Ukraine-Uzbekistan (1996)

USA-Singapore (2004) 
Country List

\begin{tabular}{|c|c|c|c|}
\hline Afghanistan & Djibouti & Kuwait & Qatar \\
\hline Albania & Dominica & Kyrgyz Republic & Romania \\
\hline Algeria & Dominican Republic & Laos & Russian Federation \\
\hline Angola & Ecuador & Latvia & Rwanda \\
\hline Antigua And Barbuda & Egypt, Arab Rep. & Lebanon & Samoa \\
\hline Argentina & El Salvador & Lesotho & San Marino \\
\hline Armenia & Equatorial Guinea & Liberia & Sao Tome and Principe \\
\hline Australia & Eritrea & Libya & Saudi Arabia \\
\hline Austria & Estonia & Lithuania & Senegal \\
\hline Azerbaijan & Ethiopia & Luxembourg & Seychelles \\
\hline Bahamas & Faeroe Islands & Macao & Singapore \\
\hline Bahrain & Fiji & Macedonia, FYR & Slovak Republic \\
\hline Bangladesh & Finland & Madagascar & Slovenia \\
\hline Barbados & France & Malawi & Solomon Islands \\
\hline Belarus & Gabon & Malaysia & Somalia \\
\hline Belgium & Gambia & Maldives & South Africa \\
\hline Belize & Georgia & Mali & Spain \\
\hline Benin & Germany & Malta & Sri Lanka \\
\hline Bermuda & Ghana & Marshall Islands & St. Kitts and Nevis \\
\hline Bhutan & Greece & Mauritania & St. Lucia \\
\hline Bolivia & Greenland & Mauritius & St. Vincent and the Grenadines \\
\hline Bosnia and Herzegovina & Grenada & Mexico & Sudan \\
\hline Botswana & Guatemala & Micronesia & Suriname \\
\hline Brazil & Guinea & Moldova & Swaziland \\
\hline Brunei Darussalam & Guinea-Bissau & Mongolia & Sweden \\
\hline Bulgaria & Guyana & Morocco & Switzerland \\
\hline Burkina Faso & Haiti & Mozambique & Syrian Arab Republic \\
\hline Burundi & Honduras & Myanmar (Burma) & Tajikistan \\
\hline Cambodia & Hong Kong & Namibia & Tanzania \\
\hline Cameroon & Hungary & Nepal & Thailand \\
\hline Canada & Iceland & Netherlands & Togo \\
\hline Cape Verde & India & New Caledonia & Tonga \\
\hline Cayman Islands & Indonesia & New Zealand & Trinidad And Tobago \\
\hline Central African Republic & Iran, Islamic Rep. & Nicaragua & Tunisia \\
\hline Chad & Iraq & Niger & Turkmenistan \\
\hline Chile & Ireland & Nigeria & Uganda \\
\hline China & Israel & Norway & Ukraine \\
\hline Colombia & Italy & Oman & United Arab Emirates \\
\hline Comoros & Ivory Coast & Pakistan & United Kingdom \\
\hline Congo, Dem. Rep. & Jamaica & Panama & United States \\
\hline Costa Rica & Japan & Papua New Guinea & Uruguay \\
\hline Croatia & Jordan & Paraguay & Uzbekistan \\
\hline Cuba & Kazakhstan & Peru & Venezuela \\
\hline Cyprus & Kenya & Philippines & Vietnam \\
\hline Czech Republic & Kiribati & Poland & Yemen \\
\hline Denmark & Korea, Rep. & Portugal & \\
\hline
\end{tabular}




\section{Online Appendix 2: Theoretical Model}

This appendix provides the derivations for our extension of the Melitz-type model in Krautheim (2012, Section 2) to include both endogenous (network-effect) and exogenous export fixed costs, and distinguishing further exogenous policy export fixed costs from exogenous non-policy export fixed costs, in a general equilibrium framework with labormarket clearing and free entry and exit of firms. We provide closed-form solutions for this framework (not provided in Krautheim (2012, Section 4)). We also solve for the associated "structural gravity" model of aggregate trade flows and multilateral resistances, in the spirit of Anderson and van Wincoop (2003) and Helpman, Melitz and Rubinstein (2008). We provide the derivations for several comparative statics discussed in the paper.

\section{A2.1: Consumer Behavior}

Consumer preferences are defined over a continuum of differentiated varieties $\Omega$, taking the form:

$$
U=\left(\int_{\omega \in \Omega} q(\omega)^{\frac{\sigma-1}{\sigma}} d \omega\right)^{\frac{\sigma}{\sigma-1}}
$$

where $q(\omega)$ is quantity of product $\omega$ consumed of available varieties $\Omega$. The elasticity of substitution across varieties is $\sigma$, where $\sigma>1$. Maximizing utility subject to a standard income constraint:

$$
w_{j} L_{j}=\int_{\omega \in \Omega} p(\omega) q(\omega) d \omega
$$

where $w_{j}$ and $L_{j}$ are the wage rate and labor (population) in country $j$, respectively, and $p(\omega)$ is the price paid for variety $\omega$ yields a demand function in country $j$ for country $i$ 's variety:

$$
q_{i j}(\omega)=\left(\frac{p_{i j}(\omega)}{P_{j}}\right)^{-\sigma}\left(\frac{w_{j} L_{j}}{P_{j}}\right),
$$

where $P_{j}$ is the ideal price index of the form:

$$
P_{j}=\left[\int_{\omega \in \Omega} p(\omega)^{1-\sigma} d \omega\right]^{\frac{1}{1-\sigma}} .
$$

\section{A2.2: Producer Behavior}

Firms in country $i$ produce a differentiated variety $\omega$ at a cost with heterogenous productivity, $\varphi$, under monopolistic competition. Potential entrants face a sunk entry cost, $F_{i}^{E}$, and entry into foreign market $j$ entails a further fixed cost, $F_{i j}^{X}$. We assume the cost of exporting good $\omega$ from country $i$ to country $j$ is:

$$
c\left(q_{i j}\right)=\frac{w_{i} q_{i j} \tau_{i j}}{\varphi}+w_{j}\left[F_{i j}^{X N}+F_{i j}^{X P}\right]
$$


where $\tau_{i j}$ represents the variable trade cost of exporting from $i$ to $j, F_{i j}^{X N}$ denotes natural fixed costs associated with exporting from $i$ to $j$ associated with geography and informational barriers, and $F_{i j}^{X P}$ denotes (exogenous) fixed costs of exporting from $i$ to $j$ associated with trade policies (such as regulations). Let $F_{i j}^{X}=F_{i j}^{X N}+F_{i j}^{X P}$. As suggested in the penultimate section of Krautheim (2012), we assume the natural fixed costs, $F_{i j}^{X N}$, can be further decomposed into additively separable exogenous and endogenous components:

$$
F_{i j}^{X N}=A_{i j}^{X N}+n_{i j}^{-\eta}
$$

where $A_{i j}^{X N}$ is the exogenous (spillover insensitive) component, $n_{i j}$ is the number of firms in country $i$ exporting to country $j$, and $\eta$ is the elasticity of fixed costs with respect to the number of domestic firms exporting from country $i$ to country $j$. As noted earlier, Krautheim (2012) did not provide closed-form general equilibrium solutions for such a model.

Using equation (3) and the profit function, the price charged by a firm from country $i$ with productivity $\varphi$ in country $j$ is

$$
p_{i j}(\varphi)=\frac{w_{i} \tau_{i j}}{\rho \varphi}
$$

where $\rho=\frac{\sigma-1}{\sigma}$.

Profits for a firm with productivity $\varphi$ in country $i$ potentially exporting to country $j$ are:

$$
\pi_{i j}(\varphi)=\left(\frac{w_{i} \tau_{i j}}{\rho P_{j} \varphi}\right)^{1-\sigma} w_{j} L_{j}-\left(\frac{w_{i} \tau_{i j}}{\rho P_{j} \varphi}\right)^{-\sigma} \frac{w_{i} \tau_{i j}}{\varphi P_{j}} w_{j} L_{j}-w_{j} F_{i j}^{X}
$$

which can be rewritten as:

$$
\pi_{i j}(\varphi)=\left(\frac{w_{i} \tau_{i j}}{\rho P_{j} \varphi}\right)^{1-\sigma} \frac{w_{j} L_{j}}{\sigma}-w_{j} F_{i j}^{X}
$$

The minimum $\varphi_{i j}^{*}$ that a firm finds profitable to export can be defined using the zero profit condition:

$$
\left(\frac{w_{i} \tau_{i j}}{\rho \varphi_{i j}^{*} P_{j}}\right)^{1-\sigma} \frac{w_{j} L_{j}}{\sigma}=w_{j} F_{i j}^{X}
$$

Solving for $\left(\varphi_{i j}^{*}\right)^{1-\sigma}$ yields:

$$
\left(\varphi_{i j}^{*}\right)^{1-\sigma}=\left(\frac{w_{i} \tau_{i j}}{\rho P_{j}}\right)^{1-\sigma} \frac{L_{j}}{F_{i j}^{X} \sigma}
$$




\section{A2.3: Pareto Distribution}

As is common, we assume the productivity distribution is untruncated Pareto in the form:

$$
g(\varphi)=\gamma \bar{\varphi}^{\gamma} \varphi^{-(\gamma+1)} \text { and } 1-G(\varphi)=\left(\frac{\bar{\varphi}}{\varphi}\right)^{\gamma}
$$

where $g()$ is the probability density function, $G()$ is the cumulative density function, $\bar{\varphi}$ is the lower bound of the support of the productivity distribution $(\bar{\varphi}>0)$, and $\gamma$ is the shape parameter with lower values of $\gamma$ corresponding to greater dispersion in productivity. As discussed in Melitz and Redding (2015), even a small departure from the untruncated Pareto distribution to a truncated Pareto distribution is sufficient to generate an endogenous trade-cost elasticity. ${ }^{1}$ To preclude this channel, we use (as in Krautheim, 2012) an untruncated Pareto distribution to show that our endogenous trade-cost elasticities surface from novel economic channels. A firm in country $i$ must have a productivity level of at least $\varphi_{i j}^{*}$ to have positive profits from exporting to country $j$ :

$$
\pi_{i j}(\varphi)=\max \left\{0,\left(\frac{w_{i} \tau_{i j}}{\rho P_{j} \varphi}\right)^{1-\sigma} \frac{w_{j} L_{j}}{\sigma}-w_{j} F_{i j}^{X}\right\}
$$

Assuming a (untruncated) Pareto distribution, the average profits for firms engaged in exporting goods from country $i$ to country $j$ are given by:

$$
\bar{\pi}_{i j}=\int_{\varphi_{i j}^{*}}^{\infty}\left(\frac{w_{i} \tau_{i j}}{\rho P_{j}}\right)^{1-\sigma} \frac{w_{j} L_{j}}{\sigma} \gamma \varphi^{-(\gamma-\sigma-2)}\left(\varphi_{i j}^{*}\right)^{\gamma} d \varphi-\int_{\varphi_{i j}^{*}}^{\infty} \gamma F_{i j}^{X} w_{j} \varphi^{-(\gamma+1)} \varphi_{i j}^{*} \gamma d \varphi
$$

and simplifying leads to:

$$
\bar{\pi}_{i j}=\left(\frac{w_{i} \tau_{i j}}{\rho P_{j}}\right)^{1-\sigma} \frac{w_{j} L_{j}}{\sigma}\left(\varphi_{i j}^{*}\right)^{\sigma-1}\left(\frac{\gamma}{\gamma-\sigma+1}\right)-w_{j} F_{i j}^{X}
$$

Using equation (6), the expression above can be further simplified to:

$$
\bar{\pi}_{i j}=w_{j} F_{i j}^{X}\left(\frac{\sigma-1}{\gamma-\sigma+1}\right) .
$$

The probability that any firm in country $i$ exports to country $j$ is given by $1-G\left(\varphi_{i j}^{*}\right)$ so that expected profits over all active firms is given by:

$$
\left[1-G\left(\varphi_{i j}^{*}\right)\right] \bar{\pi}_{i j}=\left\{w_{j} F_{i j}^{X}\left(\frac{\sigma-1}{\gamma-\sigma+1}\right)\right\}\left(\frac{\bar{\varphi}}{\varphi_{i j}^{*}}\right)^{\gamma}
$$

\footnotetext{
${ }^{1}$ Helpman, Melitz and Rubinstein (2008) also used a truncated Pareto distribution.
} 
Summing over all importing countries $j$ yields total expected profits of the firm in $i$ :

$$
\bar{\pi}_{i}=\sum_{j}\left[1-G\left(\varphi_{i j}^{*}\right)\right] \bar{\pi}_{i j}=\sum_{j}\left\{w_{j} F_{i j}^{X}\left(\frac{\sigma-1}{\gamma-\sigma+1}\right)\right\}\left(\frac{\bar{\varphi}}{\varphi_{i j}^{*}}\right)^{\gamma}
$$

Multiplying equation (12) by the probability of receiving a productivity draw high enough to cover fixed cost of entry generates the free entry condition:

$$
\left[1-G\left(\varphi_{i i}^{*}\right)\right] \bar{\pi}_{i}=\sum_{j}\left[1-G\left(\varphi_{i j}^{*}\right)\right] \bar{\pi}_{i j}=\sum_{j}\left\{w_{j} F_{i j}^{X}\left(\frac{\sigma-1}{\gamma-\sigma+1}\right)\right\}\left(\frac{\bar{\varphi}}{\varphi_{i j}^{*}}\right)^{\gamma}=w_{i} F_{i}^{E}
$$

which, after rearranging, yields:

$$
\bar{\pi}_{i}=\sum_{j} w_{j} F_{i j}^{X}\left(\frac{\sigma-1}{\gamma-\sigma+1}\right)\left(\frac{\varphi_{i i}^{*}}{\varphi_{i j}^{*}}\right)^{\gamma}=\frac{w_{i} F_{i}^{E}}{\left(\bar{\varphi} / \varphi_{i i}^{*}\right)^{\gamma}}
$$

Equation (13) can be rewritten showing the exogenous and endogenous components of $F_{i j}^{X}$ :

$$
\sum_{j} w_{j}\left(\frac{\sigma-1}{\gamma-\sigma+1}\right)\left(\frac{\varphi_{i i}^{*}}{\varphi_{i j}^{*}}\right)^{\gamma}\left[A_{i j}^{X N}+n_{i j}^{-\eta}+F_{i j}^{X P}\right]=\frac{w_{i} F_{i}^{E}}{\left(\bar{\varphi} / \varphi_{i i}^{*}\right)^{\gamma}}
$$

We can define

$$
\Omega_{i}=\sum_{j} w_{j}\left(\frac{\bar{\varphi}}{\varphi_{i j}^{*}}\right)^{\gamma}\left[A_{i j}^{X N}+n_{i j}^{-\eta}+F_{i j}^{X P}\right]\left(\frac{\sigma \gamma}{\gamma-\sigma+1}\right)
$$

so that:

$$
\left(\frac{\sigma-1}{\sigma \gamma}\right) \Omega_{i}=w_{i} F_{i}^{E}
$$

\section{A2.4: The Price Index and Labor-Market Clearing}

The price index is given by

$$
P_{j}^{1-\sigma}=\left[\sum_{i} n_{i}\left(\frac{\varphi_{i i}^{*}}{\varphi_{i j}^{*}}\right)^{\gamma}\left(\frac{w_{i} \tau_{i j}}{\rho \varphi}\right)^{1-\sigma} \int_{\varphi_{*} i j}^{\infty} \gamma \varphi^{-(\gamma+1)}\left(\varphi_{i j}^{*}\right)^{\gamma} d \varphi\right]
$$

Dividing above equation by $P_{j}^{1-\sigma}$ and multiplying by $w_{j} L_{j}$ yields:

$$
w_{j} L_{j}=\left[\sum_{i} \frac{\gamma \sigma}{\gamma-\sigma+1} n_{i} w_{j} F_{i j}^{X}\left(\frac{\varphi_{i j}^{*}}{\varphi_{i i}^{*}}\right)^{\gamma}\right]
$$


which simplifies to:

$$
L_{j} \frac{\gamma-\sigma+1}{\gamma \sigma}=\left[\sum_{i} n_{i} F_{i j}^{X}\left(\frac{\varphi_{i j}^{*}}{\varphi_{i i}^{*}}\right)^{\gamma}\right]
$$

Rewriting equation (16) for country $i$ yields:

$$
L_{i} \frac{\gamma-\sigma+1}{\gamma \sigma}=\left[\sum_{j} n_{j} F_{j i}^{X}\left(\frac{\bar{\varphi}}{\varphi_{j i}^{*}}\right)^{\gamma}\right]
$$

Define:

$$
\Lambda_{i}=\left[\sum_{j} n_{j} F_{j i}^{X}\left(\frac{\bar{\varphi}}{\varphi_{j i}^{*}}\right)^{\gamma}\right]
$$

so that:

$$
L_{i} / \Lambda_{i}=\frac{\gamma \sigma}{\gamma-\sigma+1}
$$

The wage bill is equal to the labor used in production, labor used to cover fixed export costs, and labor used to cover entry costs:

$$
\begin{aligned}
w_{i} L_{i} & =n_{i} \sum_{j} \int_{\varphi_{i j}^{*}}^{\infty}\left(\frac{w_{i} \tau_{i j}}{\rho P_{j}}\right)^{-\sigma} \frac{w_{j} L_{j}}{P_{j}} \frac{w_{i} \tau_{i j}}{\varphi_{i j}} \varphi^{\sigma} \gamma \varphi^{-(\gamma+1)} \bar{\varphi}^{\gamma} d \varphi \\
& +\sum_{j} n_{j} \int_{\varphi_{i j}^{*}}^{\infty} w_{i} F_{j i}^{X} \gamma \varphi^{-(\gamma+1)} \bar{\varphi}^{\gamma} d \varphi+\frac{w_{i} F_{i}^{E}}{\left(\bar{\varphi} / \varphi_{i i}^{*}\right)^{\gamma}} n_{i}
\end{aligned}
$$

This simplifies to:

$$
w_{i} L_{i}=n_{i} \gamma \frac{w_{i} F_{i}^{E}}{\left(\bar{\varphi} / \varphi_{i i}\right)^{k}}+w_{i} L_{i} \frac{\gamma-\sigma+1}{\sigma \gamma}+\frac{w_{i} F_{i}^{E}}{\left(\bar{\varphi} / \varphi_{i i}\right)^{\gamma}} n_{i}
$$

where we have used:

$$
\frac{\gamma(\sigma-1)}{\gamma-\sigma+1} \sum_{j} w_{j}\left(\frac{\varphi_{i i}^{*}}{\varphi_{i j}^{*}}\right)^{\gamma}\left[A_{i j}^{X N}+n_{i j}^{-\eta}+F_{i j}^{X P}\right]=\frac{\gamma w_{i} F_{i}^{E}}{\left(\bar{\varphi} / \varphi_{i i}\right)^{\gamma}}
$$

Rearranging equation (17), we can solve for the mass of firms:

$$
n_{i}=\frac{\sigma-1}{\sigma \gamma} \frac{L_{i}}{F_{e}}\left(\frac{\bar{\varphi}}{\varphi_{i i}^{*}}\right)^{\gamma}=\left(\frac{w_{i} L_{i}}{\Omega_{i}}\right)\left(\frac{\bar{\varphi}}{\varphi_{i i}^{*}}\right)^{\gamma}
$$

which determines the number of firms in country $i$. 
The probability that a firm in country $i$ exports to $j$ is given by:

$$
\frac{1-G\left(\varphi_{i j}^{*}\right)}{1-G\left(\varphi_{i i}^{*}\right)}=\zeta_{i j} \text { where } 1-G\left(\varphi_{i j}^{*}\right)=\left(\frac{\bar{\varphi}}{\varphi_{i j}^{*}}\right)^{\gamma}
$$

Consequently:

$$
\begin{aligned}
n_{i j} & =\zeta_{i j} n_{i} \\
& =\frac{\left(\frac{\bar{\varphi}}{\varphi_{i j}^{*}}\right)^{\gamma}}{\left(\frac{\bar{\varphi}}{\varphi *_{i i}}\right)^{\gamma}} \frac{\sigma-1}{\sigma \gamma} \frac{L_{i}}{F_{i}^{E}}\left(\frac{\bar{\varphi}}{\varphi_{i i}^{*}}\right)^{\gamma} \\
& =\frac{\sigma-1}{\gamma \sigma F_{i}^{E}} L_{i}\left(\frac{\bar{\varphi}}{\varphi_{i j}^{*}}\right)^{\gamma}
\end{aligned}
$$

Hence, the number of firms in country $i$ exporting to country $j$ depends on the cut-off productivity. We can rewrite equation (19) as:

$$
n_{i j}=\delta_{i}\left(\varphi_{i j}^{*} / \bar{\varphi}\right)^{-\gamma}
$$

where $\delta_{i}$ is a country specific scaling factor:

$$
\delta_{i}=\frac{\sigma-1}{\gamma \sigma F_{i}^{E}} L_{i}
$$

\section{A2.5: Structural Gravity for Trade Flows}

We can provide a structural gravity representation of aggregate trade flows. The trade flow from country $i$ to country $j$ is:

$$
X_{i j}=n_{i j} \int_{\varphi_{i j}^{*}}^{\infty}\left(\frac{w_{i} \tau_{i j}}{\rho P_{j}}\right)^{1-\sigma} \frac{w_{j} L_{j}}{\sigma} \sigma \gamma \varphi^{-(\gamma-\sigma+1)}\left(\varphi_{i j}^{*}\right)^{\gamma} d \varphi
$$

Simplifying the above equation, using equations (13) and (14), yields:

$$
X_{i j}=n_{i j} \underbrace{\left(\frac{w_{i} \tau_{i j}}{\rho P_{j}}\right)^{1-\sigma} \frac{w_{j} L_{j}}{\sigma}\left(\varphi_{i j}^{*} / \bar{\varphi}\right)^{\sigma-1}}_{w_{j}\left(A_{i j}^{X N}+\delta_{i}^{-\eta}\left(\varphi_{i j} / \bar{\varphi}\right)^{\gamma \eta}+F_{i j}^{X P}\right)} \frac{\gamma \sigma}{\gamma-\sigma+1}
$$

so that:

$$
\left.X_{i j}=\frac{\sigma-1}{(\gamma-\sigma+1) F_{i}^{E}} L_{i} w_{j}\left[\left(A_{i j}^{X N}+F_{i j}^{X P}\right)\left(\varphi_{i j}^{*} / \bar{\varphi}\right)^{-\gamma}+\delta_{i}^{-\eta}\left(\varphi_{i j}^{*} / \bar{\varphi}\right)^{\gamma(\eta-1)}\right)\right]
$$


or more succinctly:

$$
X_{i j}=\frac{\sigma-1}{(\gamma-\sigma+1) F_{i}^{E}} L_{i}\left(\frac{\varphi_{i j}^{*}}{\bar{\varphi}}\right)^{-\gamma} w_{j} F_{i j}^{X}
$$

where

$$
F_{i j}^{X}=\left[A_{i j}^{X N}+\delta_{i}\left(\left(\varphi_{i j}^{*} / \bar{\varphi}\right)^{\sigma-1}\right)^{\frac{\eta \gamma}{\sigma-1}}+F_{i j}^{X P}\right]
$$

Summing $X_{i j}$ over all $i$ yields total expenditures for country $j$ :

$$
w_{j} L_{j}=w_{j} \frac{\gamma \sigma}{(\gamma-\sigma+1)} \sum_{i}\left\{\frac{(\sigma-1) L_{i}}{\gamma \sigma F_{i}^{E}}\right\}\left(\frac{\varphi_{i j}^{*}}{\bar{\varphi}}\right)^{-\gamma} F_{i j}^{X}
$$

Given the definition of $\Lambda_{j}$ above, this implies:

$$
L_{j} / \Lambda_{j}=\frac{\gamma \sigma}{(\gamma-\sigma+1)}
$$

Summing trade flows $X_{i j}$ over all $j$ destination markets for $i$ yields:

$$
w_{i} L_{i}=\frac{\sigma-1}{\gamma \sigma F_{i}^{E}} L_{i} \sum_{j}\left[\left(\frac{\varphi_{i j}^{*}}{\bar{\varphi}}\right)^{-\gamma} w_{j} F_{i j}^{X} \frac{\gamma \sigma}{(\gamma-\sigma+1)}\right]
$$

or

$$
w_{i} L_{i} / \Omega_{i}=\frac{\sigma-1}{\gamma \sigma F_{i}^{E}} L_{i}
$$

Making appropriate substitutions into trade equation (22) yields:

$$
X_{i j}=\left(\frac{\sigma-1}{\gamma \sigma F_{i}^{E}} L_{i}\right)\left(w_{j} \frac{\gamma \sigma}{(\gamma-\sigma+1)}\right)\left(\left[\left(A_{i j}^{X N}+F_{i j}^{X P}\right)\left(\varphi_{i j}^{*} / \bar{\varphi}\right)^{-\gamma}+\delta_{i}^{-\eta}\left(\varphi_{i j}^{*} / \bar{\varphi}\right)^{\gamma(\eta-1)}\right]\right)
$$

Appropriate substitutions yields the structural gravity equation:

$$
X_{i j}=\left(\frac{\left(\varphi_{i j}^{*} / \bar{\varphi}\right)^{-\gamma}\left[\left(A_{i j}^{X N}+F_{i j}^{X P}\right)+\delta_{i}^{-\eta}\left(\varphi_{i j}^{*} / \bar{\varphi}\right)^{\gamma \eta}\right]}{\Omega_{i} \Lambda_{j}}\right)\left(w_{i} L_{i}\right)\left(w_{j} L_{j}\right)
$$

or

$$
X_{i j}=\left(\frac{\left(\varphi_{i j}^{*} / \bar{\varphi}\right)^{-\gamma} F_{i j}^{X}}{\Omega_{i} \Lambda_{j}}\right)\left(w_{i} L_{i}\right)\left(w_{j} L_{j}\right)
$$

where

$$
\Omega_{i}=\sum_{j} w_{j}\left(\frac{\varphi_{i j}^{*}}{\bar{\varphi}}\right)^{-\gamma} F_{i j}^{X}\left(\frac{\sigma \gamma}{\gamma-\sigma+1}\right)=\sum_{j} \frac{w_{j} L_{j}}{\Lambda_{j}} F_{i j}^{X}\left(\frac{\varphi_{i j}^{*}}{\bar{\varphi}}\right)^{-\gamma}
$$


and

$$
\Lambda_{j}=\sum_{i} N_{i} F_{i j}^{X}\left(\frac{\varphi_{i j}^{*}}{\bar{\varphi}}\right)^{-\gamma}=\sum_{i} \frac{w_{i} L_{i}}{\Omega_{i}} F_{i j}^{X}\left(\frac{\varphi_{i j}^{*}}{\bar{\varphi}}\right)^{-\gamma}
$$

which is analogous to the structural gravity model in Anderson and van Wincoop (2003).

\section{A2.6: Stability Conditions}

Here we show the conditions for existence of the cut-off productivity for exports from country $i$ to country $j$. The fixed point is given by:

$$
\left(\frac{w_{i} \tau_{i j}}{\rho P_{j}}\right)^{1-\sigma} \frac{w_{j} L_{j}}{\sigma}\left(\varphi_{i j}^{*} / \bar{\varphi}\right)^{\sigma-1}=w_{j}\left[A_{i j}^{X N}+\delta_{i}^{-\eta}\left(\varphi_{i j}^{*} / \bar{\varphi}\right)^{\eta \gamma}+F_{i j}^{X P}\right]
$$

We define:

$$
R_{i j}=\left(\frac{w_{i} \tau_{i j}}{\rho P_{j}}\right)^{1-\sigma} \frac{w_{j} L_{j}}{\sigma}\left(\varphi_{i j}^{*} / \bar{\varphi}\right)^{\sigma-1}
$$

and

$$
C_{i j}=w_{j}\left[A_{i j}^{X N}+\delta_{i}^{-\eta}\left(\left(\varphi_{i j}^{*} / \bar{\varphi}\right)^{\sigma-1}\right)^{\frac{\eta \gamma}{\sigma-1}}+F_{i j}^{X P}\right]
$$

Since $A_{i j}^{X N}+F_{i j}^{X P} \geq 0$ (by assumption), there exists a stable cut-off productivity if $\partial C_{i j} / \partial\left(\varphi_{i j}^{*} / \bar{\varphi}\right)^{\sigma-1}<\partial R_{i j} / \partial\left(\varphi_{i j}^{*} / \bar{\varphi}\right)^{\sigma-1}$ when $C_{i j}=R_{i j}$. This implies:

$\frac{\gamma \eta}{(\sigma-1)} w_{j} \frac{\delta_{i}^{-\eta}\left(\left(\varphi_{i j}^{*} / \bar{\varphi}\right)^{\sigma-1}\right)^{\frac{\gamma \eta}{\sigma-1}}}{\left(\varphi_{i j}^{*} / \bar{\varphi}\right)^{\sigma-1}}<\left(\frac{w_{i} \tau_{i j}}{\rho P_{j}}\right)^{1-\sigma} \frac{w_{j} L_{j}}{\sigma}=\left(\varphi_{i j}^{*} / \bar{\varphi}\right)^{1-\sigma} w_{j}\left[A_{i j}^{X N}+\delta_{i}^{\eta}\left(\left(\varphi_{i j}^{*} / \bar{\varphi}\right)^{\sigma-1}\right)^{\frac{\eta \gamma}{\sigma-1}}+F_{i j}^{X P}\right]$

The above equation simplifies to:

$$
\frac{\gamma \eta}{\sigma-1} \frac{\delta_{i}^{-\eta}\left(\left(\varphi_{i j}^{*} / \bar{\varphi}\right)^{\sigma-1}\right)^{\frac{\gamma \eta}{\sigma-1}}}{\left[A_{i j}^{X N}+\delta_{i}^{-\eta}\left(\left(\varphi_{i j}^{*} / \bar{\varphi}\right)^{\sigma-1}\right)^{\frac{\eta \gamma}{\sigma-1}}+F_{i j}^{X P}\right]}<1
$$

If we define:

$$
s_{i j}=\frac{\delta_{i}^{-\eta}\left(\varphi_{i j}^{*} / \bar{\varphi}\right)^{\gamma \eta}}{A_{i j}^{X N}+\delta_{i}^{-\eta}\left(\varphi_{i j}^{*} / \bar{\varphi}\right)^{\gamma \eta}+F_{i j}^{X P}}
$$

the stability condition reduces to:

$$
1>\frac{\gamma}{\sigma-1} \eta s_{i j}
$$

Throughout the next section of comparative statics, we assume $1-\frac{\gamma}{\sigma-1} \eta s_{i j}>0$. Krautheim (2012) assumed the same condition, where in his model $s_{i j}$ is assumed to be 1 ; in our model, $s_{i j} \leq 1$. 


\section{A2.7: Comparative Statics}

It is important to note that we are primarily interested in this section in the comparative statics associated with "partial effects" of changes in $\tau_{i j}$ and $F_{i j}^{X P}$ on $X_{i j}$. Changes in these variables have direct partial effects, but also work indirectly through changes in the cutoff productivity, $\varphi_{i j}^{*}$. Consequently, it is useful to determine the effects of changes in $\tau_{i j}$ and $F_{i j}^{X P}$ on $\varphi_{i j}^{*}$. Moreover, we ignore general equilibrium effects on wage rates and prices, e.g., $w_{i}$ and $P_{j}$; the effects on these wage rates and prices are addressed in Section 8 of the paper, which discusses general equilibrium effects.

\section{Comparative Static 1a}

The first comparative static in the paper is the effect of changes in (log) variable trade costs $\left(d \ln \tau_{i j}\right)$ on the $(\log )$ cutoff productivity for exporting from $i$ to $j\left(d \ln \varphi_{i j}^{*}\right)$. Starting with the equation determining the cutoff productivity, equation (24) above, we take the logarithms of both sides of equation (24) yielding:

$$
\begin{gathered}
(1-\sigma) \ln w_{i}+(1-\sigma) \ln \tau_{i j}+(\sigma-1) \ln \rho+(\sigma-1) \ln P_{j}+\ln w_{j}+\ln L_{j} \\
-\ln \sigma+(\sigma-1) \ln \left(\varphi_{i j}^{*} / \bar{\varphi}\right)=\ln w_{j}+\ln \left[A_{i j}^{X N}+\delta_{i j}^{-\eta}\left(\varphi_{i j}^{*} / \bar{\varphi}\right)^{\eta \gamma}+F_{i j}^{X P}\right]
\end{gathered}
$$

Differentiating the equation above yields:

$$
(1-\sigma) d \ln \tau_{i j}+(\sigma-1) d \ln \varphi_{i j}^{*}=\left(\frac{\delta_{i}^{-\eta} \eta \gamma\left(\varphi_{i j}^{*} / \bar{\varphi}\right)^{\gamma \eta}}{A_{i j}^{X N}+\delta_{i}^{-\eta}\left(\varphi_{i j}^{*} / \bar{\varphi}\right)^{\gamma \eta}+F_{i j}^{X P}}\right) d \ln \varphi_{i j}^{*}
$$

where $d \ln \rho=d \ln \bar{\varphi}=d \ln L_{j}=d A_{i j}^{X N}=d F_{i j}^{X P}=0$ by assumption and, as discussed above, $d \ln w_{i}=d \ln P_{j}=0$. Simplifying the above equation, using the definition of $s_{i j}$ noted above, yields:

$$
\left[(\sigma-1)-\gamma \eta s_{i j}\right] d \ln \varphi_{i j}^{*}=(\sigma-1) d \ln \tau_{i j}
$$

or

$$
d \ln \varphi_{i j}^{*}=\frac{1}{1-\frac{\gamma}{\sigma-1} \eta s_{i j}} d \ln \tau_{i j}
$$

We note that, in the case of $A_{i j}^{X N}=F_{i j}^{X P}=0, s_{i j}=1$ and consequently this comparative static would be the same as implied by equation (6) in Krautheim (2012).

\section{Comparative Static 1 b}

Start with structural gravity equation (23):

$$
X_{i j}=\left(\frac{\left(\varphi_{i j}^{*} / \bar{\varphi}\right)^{-\gamma}\left[\left(A_{i j}^{X N}+F_{i j}^{X P}\right)+\delta_{i}^{-\eta}\left(\varphi_{i j}^{*} / \bar{\varphi}\right)^{\gamma \eta}\right]}{\Omega_{i} \Lambda_{j}}\right)\left(w_{i} L_{i}\right)\left(w_{j} L_{j}\right)
$$


Taking logarithms:

$$
\ln X_{i j}=\ln \left(w_{i} L_{i} / \Omega_{i}\right)+\ln \left(w_{j} L_{j} / \Lambda_{j}\right)-\gamma \ln \left(\varphi_{i j}^{*} / \bar{\varphi}\right)+\ln \left[\left(A_{i j}^{X N}+F_{i j}^{X P}\right)+\delta_{i}^{-\eta}\left(\varphi_{i j}^{*} / \bar{\varphi}\right)^{\gamma \eta}\right]
$$

Differentiating and solving for the partial (elasticity) effect of a $(\log )$ change in $\varphi_{i j}^{*}$ yields:

$$
\begin{aligned}
d \ln X_{i j} & =-\gamma d \ln \varphi_{i j}^{*}+\frac{\delta_{i}^{-\eta} \gamma \eta\left(\varphi_{i j}^{*} / \bar{\varphi}\right)^{\gamma \eta} d \ln \varphi_{i j}^{*}}{\left[\left(A_{i j}^{X N}+F_{i j}^{X P}\right)+\delta_{i}^{-\eta}\left(\varphi_{i j}^{*} / \bar{\varphi}\right)^{\gamma \eta}\right]} \\
& =-\gamma d \ln \varphi_{i j}^{*}+\gamma \eta s_{i j} d \ln \varphi_{i j}^{*} \\
& =-\gamma\left(1-\eta s_{i j}\right) d \ln \varphi_{i j}^{*}
\end{aligned}
$$

In Comparative Static 1a, we found that:

$$
d \ln \varphi_{i j}^{*}=\frac{1}{1-\frac{\gamma}{\sigma-1} \eta s_{i j}} d \ln \tau_{i j} .
$$

Hence, Comparative Static 1b is:

$$
d \ln X_{i j}=-\gamma\left(\frac{1-\eta s_{i j}}{1-\frac{\gamma}{\sigma-1} \eta s_{i j}}\right) d \ln \tau_{i j}
$$

which, after some algebra, can also be written as:

$$
d \ln X_{i j}=\left[-(\sigma-1)-\left(\frac{\gamma-(\sigma-1)}{1-\frac{\gamma}{\sigma-1} \eta s_{i j}}\right)\right] d \ln \tau_{i j} .
$$

The form of the equation above suggests that the effect of a change in $\tau_{i j}$ can be decomposed into intensive and extensive margin effects, which we address below.

\section{Comparative Statics 1c and 1d}

We can decompose the change in the aggregate trade flow into changes in the intensive and extensive margins. Aggregate trade can be written as:

$$
X_{i j}=w_{i} L_{i} \int_{\varphi_{i j}^{*}}^{\infty} x_{i j}(\varphi) d G(\varphi)
$$

Using Leibniz rule to separate the intensive and extensive margins, differentiation with respect to $\tau_{i j}$ yields:

$$
d X_{i j}=\left[w_{i} L_{i} \int \varphi_{i j}^{*} \frac{\partial x_{i j}(\varphi)}{\partial \tau_{i j}} d G(\varphi)\right] d \tau_{i j}-\left[w_{i} L_{i} x\left(\varphi_{i j}^{*}\right) G \prime\left(\varphi_{i j}^{*}\right) \frac{\partial \varphi_{i j}^{*}}{\partial \tau_{i j}}\right] d \tau_{i j}
$$


The first RHS term is the intensive margin change and the second RHS term is the extensive margin change.

Comparative Static 1c is the intensive margin elasticity of trade to a one percent change in $\tau_{i j}$. At $\partial \varphi_{i j}^{*} / \partial \tau_{i j}=0$, the elasticity of equilibrium individual exports, $x_{i j}$, to $\partial \ln \tau_{i j}$ is:

$$
\frac{\partial \ln x_{i j}}{\partial \ln \tau_{i j}}=\frac{\partial x_{i j} / x_{i j}}{\partial \tau_{i j} / \tau_{i j}}=-(\sigma-1)
$$

Integration over all exporters yields:

$$
\frac{d \ln I M_{i j}}{d \ln \tau_{i j}}=-(\sigma-1)
$$

Comparative Static 1d is the extensive margin elasticity of trade to a one percent change in $\tau_{i j}$. Using the definition of the equilibrium productivity threshold, we have:

$$
\frac{\partial \varphi_{i j}^{*}}{\partial \tau_{i j}}=\frac{\varphi^{*}}{\tau_{i j}}
$$

Using equation (35), the extensive margin elasticity with respect to a one percent change in $\tau_{i j}$ is:

$$
\frac{d \ln E M_{i j}}{d \ln \tau_{i j}}=\frac{-\tau_{i j}}{X_{i j}}\left(w_{i} L_{i} x\left(\varphi_{i j}^{*}\right) G \prime\left(\varphi_{i j}^{*}\right) \frac{\varphi_{i j}^{*}}{\tau_{i j}}\right)
$$

which, after substitutions, yields:

$$
\frac{d \ln E M_{i j}}{d \ln \tau_{i j}}=-\left(\frac{\gamma-(\sigma-1)}{1-\frac{\gamma}{\sigma-1} \eta s_{i j}}\right)
$$

\section{Comparative Static 2a}

The next comparative static in the paper is the effect of changes in exogenous policyoriented export fixed costs, $F_{i j}^{X P}$, on the export cutoff productivity, $d \ln \varphi_{i j}^{*}$. Starting with equation (25) above, differentiating yields:

$$
(\sigma-1) d \ln \varphi_{i j}^{*}=\left(\frac{d F_{i j}^{X P}+\delta_{i}^{-\eta} \eta \gamma\left(\varphi_{i j}^{*} / \bar{\varphi}\right)^{\gamma \eta} d \ln \varphi_{i j}^{*}}{A_{i j}^{X N}+\delta_{i}^{-\eta}\left(\varphi_{i j}^{*} / \bar{\varphi}\right)^{\gamma \eta}+F_{i j}^{X P}}\right)
$$

where $d \ln \rho=d \ln \bar{\varphi}=d \ln L_{j}=d \tau_{i j}=d A_{i j}^{X N}=0$ by assumption and, as discussed above, $d \ln w_{i}=d \ln P_{j}=0$. Simplifying the above equation, using the definition of $s_{i j}$ noted above, yields:

$$
d \ln \varphi_{i j}^{*}=\left(\frac{1}{(\sigma-1)\left(1-\frac{\gamma}{\sigma-1} \eta s_{i j}\right)}\right)\left(\frac{F^{X P_{i j}}}{A_{i j}^{X N}+\delta_{i}^{-\eta}\left(\varphi_{i j}^{*} / \bar{\varphi}\right)^{\gamma \eta}+F_{i j}^{X P}}\right) d \ln F_{i j}^{X P}
$$


Given the stability condition for the export cutoff productivity, the first term in large parentheses on the RHS is positive. Given the second term in large parentheses on the RHS is also positive, it follows that the relationship between $d \ln \varphi_{i j}^{*}$ and $d F_{i j}^{X P}$ is positive. Note that there is no such comparative static in Krautheim (2012); this also holds for the remaining comparative statics below.

\section{Comparative Static $2 \mathrm{~b}$}

We now solve explicitly for the effect of a (log) change in policy-based fixed export costs on the aggregate trade flow, Start with structural gravity equation (23):

$$
X_{i j}=\left(\frac{\left(\varphi_{i j}^{*} / \bar{\varphi}\right)^{-\gamma}\left[\left(A_{i j}^{X N}+F_{i j}^{X P}\right)+\delta_{i}^{-\eta}\left(\varphi_{i j}^{*} / \bar{\varphi}\right)^{\gamma \eta}\right]}{\Omega_{i} \Lambda_{j}}\right)\left(w_{i} L_{i}\right)\left(w_{j} L_{j}\right)
$$

Take the logarithms of both sides of the equation above and differentiate with respect to $\ln \varphi_{i j}^{*}$ and with respect to $\ln F_{i j}^{X}$. Incorporating results from (analogous) Comparative Static $1 b$ above, we find:

$$
d \ln X_{i j}=-\gamma\left(1-\eta s_{i j}\right) d \ln \varphi_{i j}^{*}+\frac{F_{i j}^{X P}}{A_{i j}^{X N}+\delta_{i}^{-\eta}\left(\varphi_{i j}^{*} / \bar{\varphi}\right)^{\gamma \eta}+F_{i j}^{X P}} d \ln F_{i j}^{X P} .
$$

In Comparative Static 2a, we found:

$$
d \ln \varphi_{i j}^{*}=\left(\frac{1}{(\sigma-1)\left(1-\frac{\gamma}{\sigma-1} \eta s_{i j}\right)}\right)\left(\frac{F^{X P_{i j}}}{A_{i j}^{X N}+\delta_{i}^{-\eta}\left(\varphi_{i j}^{*} / \bar{\varphi}\right)^{\gamma \eta}+F_{i j}^{X P}}\right) d \ln F_{i j}^{X P}
$$

Substitution of the equation above into equation (39) yields:

$$
d \ln X_{i j}=\left[-\frac{\gamma}{\sigma-1}\left(\frac{1-\eta s_{i j}}{1-\frac{\gamma}{\sigma-1} \eta s_{i j}}\right)\left(\frac{F^{X P_{i j}}}{A_{i j}^{X N}+\delta_{i}^{-\eta}\left(\varphi_{i j}^{*} / \bar{\varphi}\right)^{\gamma \eta}+F_{i j}^{X P}}\right)+1\right] d \ln F_{i j}^{X P}
$$

With some algebra, this equation can be rewritten as:

$d \ln X_{i j}=\left(\left[\frac{1}{\sigma-1}\left(-(\sigma-1)-\frac{\gamma-(\sigma-1)}{1-\frac{\gamma}{\sigma-1} \eta s_{i j}}\right)\right]+1\right)\left(\frac{F^{X P_{i j}}}{A_{i j}^{X N}+\delta_{i}^{-\eta}\left(\varphi_{i j}^{*} / \bar{\varphi}\right)^{\gamma \eta}+F_{i j}^{X P}}\right) d \ln F_{i j}^{X P}$

which simplifies to:

$$
d \ln X_{i j}=-\left(\frac{\frac{\gamma}{\sigma-1}-1}{1-\frac{\gamma}{\sigma-1} \eta s_{i j}}\right)\left(\frac{F^{X P_{i j}}}{A_{i j}^{X N}+\delta_{i}^{-\eta}\left(\varphi_{i j}^{*} / \bar{\varphi}\right)^{\gamma \eta}+F_{i j}^{X P}}\right) d \ln F_{i j}^{X P}
$$

which is the same as the comparative static in the main paper, since $n_{i j}^{-\eta}=\delta_{i}^{-\eta}\left(\varphi_{i j}^{*} / \bar{\varphi}\right)^{\gamma \eta}$. 


\section{Comparative Statics 2c and 2d}

Similar to Comparative Static 1c, we can decompose the change in the aggregate trade flows into changes in the intensive and extensive margins using Leibniz rule.

Using the definition of the equilibrium firm-level exports, $\partial x_{i j}(\varphi) / \partial F_{i j}^{X P}=0$. Consequently, the elasticity of the intensive margin with respect to a one percent change in $F_{i j}^{X P}$ is:

$$
\frac{d \ln I M_{i j}}{d \ln F_{i j}^{X P}}=0
$$

Using the definition of the equilibrium productivity threshold and the same procedure as in Comparative Static 1d, the elasticity of the extensive margin with respect to a one percent change in $F_{i j}^{X P}$ is:

$$
d \ln E M_{i j}=-\left(\frac{\frac{\gamma}{\sigma-1}-1}{1-\frac{\gamma}{\sigma-1} \eta s_{i j}}\right)\left(\frac{F^{X P_{i j}}}{A_{i j}^{X N}+\delta_{i}^{-\eta}\left(\varphi_{i j}^{*} / \bar{\varphi}\right)^{\gamma \eta}+F_{i j}^{X P}}\right) d \ln F_{i j}^{X P}
$$

which is the same as $d \ln X_{i j} / d \ln F_{i j}^{X P}$.

\section{Proof}

The following derivation proves that $d \ln \left(-\frac{d \ln E M_{i j}}{d \ln F_{i j}^{X P}}\right) / d F_{i j}^{X P}$ is positive.

$$
\begin{aligned}
\ln \left(-\frac{d \ln E M_{i j}}{d \ln F_{i j}^{X P}}\right)= & \ln \left(\frac{\gamma}{\sigma-1}-1\right)-\ln \left(1-\frac{\gamma}{\sigma-1} \eta s_{i j}\right)+\ln F_{i j}^{X P}-\ln \left(A_{i j}^{X N}+F_{i j}^{X P}+n_{i j}^{-\eta}\right) \\
= & 0-\left(\frac{1}{1-\frac{\gamma}{\sigma-1} \eta s_{i j}}\right)\left(-\frac{\gamma}{\sigma-1} \eta\right) \frac{d s_{i j}}{d F_{i j}^{X P}}+\frac{1}{F_{i j}^{X P}} \frac{d F_{i j}^{X P}}{d F_{i j}^{X P}} \\
& -\left(\frac{1}{A_{i j}^{X N}+F_{i j}^{X P}+n_{i j}^{-\eta}}\right) \frac{d F_{i j}^{X P}}{d F_{i j}^{X P}} \\
= & \frac{\frac{\gamma}{\sigma-1} \eta}{1-\frac{\gamma}{\sigma-1} \eta s_{i j}} \frac{d s_{i j}}{d F_{i j}^{X P}}+\frac{1}{F_{i j}^{X P}}-\frac{1}{A_{i j}^{X N}+F_{i j}^{X P}+n_{i j}^{-\eta}}
\end{aligned}
$$

Remember that:

$$
\begin{aligned}
\frac{d s_{i j}}{d F_{i j}^{X P}} & =\frac{\left(A_{i j}^{X N}+F_{i j}^{X P}+n_{i j}^{-\eta}\right)(0)-n_{i j}^{-\eta}(1)}{\left(A_{i j}^{X N}+F_{i j}^{X P}+n_{i j}^{-\eta}\right)^{2}} \\
& =\frac{-n_{i j}^{-\eta}}{\left(A_{i j}^{X N}+F_{i j}^{X P}+n_{i j}^{-\eta}\right)^{2}}
\end{aligned}
$$


Substituting (43) into (42):

$$
\begin{aligned}
\frac{d \ln \left(-\frac{d \ln E M_{i j}}{d \ln F_{i j}^{X P}}\right)}{d F_{i j}^{X P}} & =\left(\frac{\frac{\gamma}{\sigma-1} \eta}{1-\frac{\gamma}{\sigma-1} \eta s_{i j}}\right)\left(-\frac{n_{i j}^{-\eta}}{\left(A_{i j}^{X N}+F_{i j}^{X P}+n_{i j}^{-\eta}\right)^{2}}\right)+\frac{1}{F_{i j}^{X P}}-\frac{1}{A_{i j}^{X N}+F_{i j}^{X P}+n_{i j}^{-\eta}} \\
& =\frac{1}{F_{i j}^{X P}}+\frac{\frac{\gamma}{\sigma-1} \eta}{1-\frac{\gamma}{\sigma-1} \eta s_{i j}}(-1) s_{i j} \frac{1}{A_{i j}^{X N}+F_{i j}^{X P}+n_{i j}^{-\eta}}-\frac{1}{A_{i j}^{X N}+F_{i j}^{X P}+n_{i j}^{-\eta}} \\
& =\frac{1}{F_{i j}^{X P}}+\frac{1}{A_{i j}^{X N}+F_{i j}^{X P}+n_{i j}^{-\eta}}\left[\frac{-\frac{\gamma}{\sigma-1} \eta s_{i j}}{1-\frac{\gamma}{\sigma-1} \eta s_{i j}}-1\right] \\
& =\frac{1}{F_{i j}^{X P}}+\frac{1}{A_{i j}^{X N}+F_{i j}^{X P}+n_{i j}^{-\eta}}\left[\frac{-\frac{\gamma}{\sigma-1} \eta s_{i j}-1+\frac{\gamma}{\sigma-1} \eta s_{i j}}{1-\frac{\gamma}{\sigma-1} \eta s_{i j}}\right] \\
& =\frac{1}{F_{i j}^{X P}}-\frac{1}{\left[A_{i j}^{X N}+F_{i j}^{X P}+n_{i j}^{-\eta}\right]\left[1-\frac{\gamma}{\sigma-1} \eta s_{i j}\right]}
\end{aligned}
$$

The necessary condition for the RHS to be positive is:

$$
\begin{aligned}
& \frac{1}{F_{i j}^{X P}}-\frac{1}{\left[A_{i j}^{X N}+F_{i j}^{X P}+n_{i j}^{-\eta}\right]\left[1-\frac{\gamma}{\sigma-1} \eta s_{i j}\right]}>0 \\
\Rightarrow & \left(A_{i j}^{X N}+F_{i j}^{X P}+n_{i j}^{-\eta}\right)\left[1-\frac{\gamma}{\sigma-1} \eta s_{i j}\right]>F_{i j}^{X P} \\
\Rightarrow & 1-\frac{\gamma}{\sigma-1} \eta s_{i j}>\frac{F_{i j}^{X P}}{A_{i j}^{X N}+F_{i j}^{X P}+n_{i j}^{-\eta}} \\
\Rightarrow & 1>\frac{F_{i j}^{X P}+\frac{\gamma}{\sigma-1} \eta\left(n_{i j}^{-\eta}\right)}{A_{i j}^{X N}+F_{i j}^{X P}+n_{i j}^{-\eta}} \\
\Rightarrow & A_{i j}^{X N}+n_{i j}^{-\eta}>\frac{\gamma}{\sigma-1} \eta n_{i j}^{-\eta} \\
\Rightarrow & \frac{A_{i j}^{X N}}{n_{i j}^{-\eta}}+1>\frac{\gamma \eta}{\sigma-1}
\end{aligned}
$$

Krautheim assumes that

$$
\frac{\gamma}{\sigma-1} \eta<1
$$

Therefore

$$
\frac{d\left[-\frac{\delta \ln E M_{i j}}{\delta \ln F_{i j}^{X P}}\right]}{d F_{i j}^{X P}}>0
$$




\section{A2.8: Theoretical Considerations for Combining our Models in Sections 3 and 4}

We have not explicitly combined the insights of our Armington and Melitz models in Sections 3 and 4, respectively. The reason is the mathematical intractability of such a model. Basically, replacing $\tau_{i j}$ with an ad valorem tariff $t_{i j}\left(t_{i j}>1\right)$ and then adding freight costs per unit of output $f r_{i j}$ (denoted freight $t_{i j}$ in Section 3 of the paper) is not a trivial extension of our Melitz model in Section 4. For instance, the modified average profits condition has no obvious solution as in a standard Melitz model; also, the free entry condition has no clear solution. Nevertheless, we provide some derivations below to show a direction that an extension of our paper to merge the two features of each model might follow.

For brevity, the key considerations that are derived below are that the profits for any firm must be finite and that the average profits also need to be finite. In the derivations below, we show that the profits of any firm are finite when the RHS in the following equation is finite:

$$
\pi_{i j}(\varphi)=\left(\frac{w_{i} t_{i j}}{\rho P_{j} \varphi}\right)^{1-\sigma} \frac{w_{j} L_{j}}{\sigma}\left\{\sum_{m=0}^{\infty}(-1)^{m} \frac{(\sigma-2+m) !}{((\sigma-2) !) m !}\left(\frac{\varphi f r_{i j}}{w_{i} t_{i j}}\right)^{m}\right\}
$$

The necessary condition for the RHS of this equation to be finite is that $\frac{\varphi f r_{i j}}{w_{i} t_{i j}}<1$. However, the numerator in this fraction is the freight costs per worker of firm with productivity $\varphi$. The denominator of this fraction is the wage rate per worker in the production of the good (scaled up by $t_{i j}$, where $t_{i j}>1$ ). This ratio will likely be below unity as empirically freight costs are a small percentage of marginal costs relative to labor costs.

Average profits will be finite when the RHS in the following equation is finite:

$$
\bar{\pi}_{i j}=\left(\frac{w_{i} t_{i j}}{\rho P_{j} \varphi_{i j}^{*}}\right)^{1-\sigma} \frac{w_{j} L_{j}}{\sigma}\left\{\sum_{m=0}^{\infty}(-1)^{m} \frac{(\sigma-2+m) !}{((\sigma-2) !) m !}\left(\frac{\varphi_{i j}^{*} f r_{i j}}{w_{i} t_{i j}}\right)^{m}\left(\frac{k}{k-\sigma-1+m}\right)\right\}
$$

The necessary condition for the second equation to be finite is that $\frac{\varphi_{i j}^{*} f r_{i j}}{w_{i} t_{i j}}<1$. As above, this fraction is likely below unity. Hence, an extension of this paper in this direction may be fruitful for future research.

\section{Derivations for Above}

Profits for a firm with productivity $\varphi$ are:

$$
\pi_{i j}(\varphi)=\left(\frac{w_{i} t_{i j}+f r_{i j}}{\rho P_{j} \varphi}\right)^{1-\sigma} \frac{w_{j} L_{j}}{\sigma}-w_{i} F_{i j}^{X}
$$

where $t_{i j}$ is an ad valorem tariff and $f r_{i j}$ is a specific (freight) cost per unit of output. 
We can take an infinite Taylor series around $f r_{i j}=0$ to obtain:

$$
\begin{gathered}
\pi_{i j}(\varphi)=\left(\frac{w_{i} t_{i j}}{\rho P_{j} \varphi}\right)^{1-\sigma} \frac{w_{j} L_{j}}{\sigma}-w_{i} F_{i j}^{X}-(\sigma-1)\left(\frac{w_{i} t_{i j}}{\rho P_{j} \varphi}\right)^{1-\sigma} \frac{w_{j} L_{j}}{\sigma} *\left(\frac{f r_{i j} \varphi}{w_{i} t_{i j}}\right) \\
+\frac{\sigma(\sigma-1)}{2 !}\left(\frac{w_{i} t_{i j}}{\rho P_{j} \varphi}\right)^{1-\sigma} \frac{w_{j} L_{j}}{\sigma} *\left(\frac{f r_{i j} \varphi}{w_{i} t_{i j}}\right)^{2} \\
-\frac{\sigma(\sigma-1)(\sigma+1)}{3 !}\left(\frac{w_{i} t_{i j}}{\rho P_{j} \varphi}\right)^{1-\sigma} \frac{w_{j} L_{j}}{\sigma} *\left(\frac{f r_{i j} \varphi}{w_{i} t_{i j}}\right)^{3} \\
-\frac{\sigma(\sigma-1)(\sigma+1)(\sigma+2)}{4 !}\left(\frac{w_{i} t_{i j}}{\rho P_{j} \varphi}\right)^{1-\sigma} \frac{w_{j} L_{j}}{\sigma} *\left(\frac{f r_{i j} \varphi}{w_{i} t_{i j}}\right)^{4}+\ldots
\end{gathered}
$$

which can be rewritten as:

$$
\begin{gathered}
\pi_{i j}(\varphi)=\left(\frac{w_{i} t_{i j}}{\rho P_{j} \varphi}\right)^{1-\sigma} \frac{w_{j} L_{j}}{\sigma}\left\{1-(\sigma-1)\left(\frac{f r_{i j} \varphi}{w_{i} t_{i j}}\right)+\frac{\sigma(\sigma-1)}{2 !}\left(\frac{f r_{i j} \varphi}{w_{i} t_{i j}}\right)^{2}\right. \\
-\frac{\sigma(\sigma-1)(\sigma+1)}{3 !}\left(\frac{f r_{i j} \varphi}{w_{i} t_{i j}}\right)^{3}+\frac{\sigma(\sigma-1)(\sigma+1)(\sigma+2)}{4 !}\left(\frac{f r_{i j} \varphi}{w_{i} t_{i j}}\right)^{4}+\ldots \\
-w_{i} F_{i j}^{X}
\end{gathered}
$$

or

$$
\pi_{i j}(\varphi)=\left(\frac{w_{i} t_{i j}}{\rho P_{j} \varphi}\right)^{1-\sigma} \frac{w_{j} L_{j}}{\sigma}\left\{\sum_{m=0}^{\infty}(-1)^{m} \frac{(\sigma-2+m) !}{((\sigma-2) !) m !}\left(\frac{\varphi f r_{i j}}{w_{i} t_{i j}}\right)^{m}\right\}
$$

The RHS will converge if $\frac{\varphi f r_{i j}}{w_{i} t_{i j}}<1$. The ratio is likely less than one because empirically freight costs per worker are less than labor costs per worker.

If this series converges, we can see if the expected value of profits also converges. Expected profits are given by:

$$
\bar{\pi}_{i j}=\int_{\varphi_{*} i j}^{\infty}\left(\frac{w_{i} t_{i j}+f r_{i j}}{\rho P_{j} \varphi}\right)^{1-\sigma} \frac{w_{j} L_{j}}{\sigma} \gamma \varphi^{-(\gamma+1)}\left(\varphi_{i j}^{*}\right)^{\gamma} d \varphi-w_{i} F_{i j}^{X}
$$

Again, taking a Taylor series expansion:

$$
\begin{gathered}
\bar{\pi}_{i j}=\int_{\varphi *_{i j}}^{\infty}\left(\frac{w_{i} t_{i j}}{\rho P_{j} \varphi}\right)^{1-\sigma} \frac{w_{j} L_{j}}{\sigma} \gamma \varphi^{-(\gamma+1)}\left(\varphi_{i j}^{*}\right)^{\gamma} d \varphi \\
-(\sigma-1) \int_{\varphi_{* i j}}^{\infty}\left(\frac{w_{i} t_{i j}}{\rho P_{j} \varphi}\right)^{1-\sigma} \frac{w_{j} L_{j}}{\sigma} \gamma \varphi^{-(\gamma+1)}\left(\frac{\varphi f r_{i j}}{w_{i} t_{i j}}\right)\left(\varphi_{i j}^{*}\right)^{\gamma} d \varphi
\end{gathered}
$$




$$
\begin{gathered}
+\frac{\sigma(\sigma-1)}{2 !} \int_{\varphi_{* i j}}^{\infty}\left(\frac{w_{i} t_{i j}}{\rho P_{j} \varphi}\right)^{1-\sigma} \frac{w_{j} L_{j}}{\sigma} \gamma \varphi^{-(\gamma+1)}\left(\frac{\varphi f r_{i j}}{w_{i} t_{i j}}\right)^{2}\left(\varphi_{i j}^{*}\right)^{\gamma} d \varphi+\ldots \\
-w_{i} F_{i j}^{X}
\end{gathered}
$$

Collecting the $\varphi$ terms:

$$
\begin{gathered}
\bar{\pi}_{i j}=\int_{\varphi *_{i j}}^{\infty}\left(\frac{w_{i} t_{i j}}{\rho P_{j}}\right)^{1-\sigma} \frac{w_{j} L_{j}}{\sigma} \gamma \varphi^{-(\gamma-\sigma+2)}\left(\varphi_{i j}^{*}\right)^{\gamma} d \varphi \\
-(\sigma-1) \int_{\varphi_{*} i j}^{\infty}\left(\frac{w_{i} t_{i j}}{\rho P_{j}}\right)^{1-\sigma} \frac{w_{j} L_{j}}{\sigma} \gamma \varphi^{-(\gamma-\sigma-1)}\left(\frac{f r_{i j}}{w_{i} t_{i j}}\right)\left(\varphi_{i j}^{*}\right)^{\gamma} d \varphi \\
+\frac{\sigma(\sigma-1)}{2 !} \int_{\varphi *_{i j}}^{\infty}\left(\frac{w_{i} t_{i j}}{\rho P_{j}}\right)^{1-\sigma} \frac{w_{j} L_{j}}{\sigma} \gamma \varphi^{-(\gamma-\sigma)}\left(\frac{f r_{i j}}{w_{i} t_{i j}}\right)^{2}\left(\varphi_{i j}^{*}\right)^{\gamma} d \varphi+\ldots \\
-w_{i} F_{i j}^{X}
\end{gathered}
$$

Rearranging terms yields:

$$
\begin{gathered}
\bar{\pi}_{i j}=\left(\frac{w_{i} t_{i j}}{\rho P_{j}}\right)^{1-\sigma} \frac{w_{j} L_{j}}{\sigma} \int_{\varphi *_{i j}}^{\infty} \gamma \varphi^{-(\gamma-\sigma+2)}\left(\varphi_{i j}^{*}\right)^{\gamma} d \varphi \\
-(\sigma-1)\left(\frac{w_{i} t_{i j}}{\rho P_{j}}\right)^{1-\sigma} \int_{\varphi *_{i j}}^{\infty} \gamma \varphi^{-(\gamma-\sigma-1)}\left(\frac{f r_{i j}}{w_{i} t_{i j}}\right)\left(\varphi_{i j}^{*}\right)^{\gamma} d \varphi \\
+\frac{\sigma(\sigma-1)}{2 !}\left(\frac{w_{i} t_{i j}}{\rho P_{j}}\right)^{1-\sigma} \frac{w_{j} L_{j}}{\sigma} \int_{\varphi_{* i j}}^{\infty} \gamma \varphi^{-(\gamma-\sigma)}\left(\frac{f r_{i j}}{w_{i} t_{i j}}\right)^{2}\left(\varphi_{i j}^{*}\right)^{\gamma} d \varphi+\ldots \\
-w_{i} F_{i j}^{X}
\end{gathered}
$$

Integrating yields:

$$
\begin{gathered}
\bar{\pi}_{i j}=\left(\frac{w_{i} t_{i j}}{\rho P_{j}}\right)^{1-\sigma} \frac{w_{j} L_{j}}{\sigma} \frac{\gamma}{(\gamma-\sigma-1)}\left(\varphi_{i j}^{*}\right)^{-(\gamma-\sigma+1)}\left(\varphi_{i j}^{*}\right)^{\gamma} \\
-(\sigma-1)\left(\frac{w_{i} t_{i j}}{\rho P_{j}}\right)^{1-\sigma} \frac{\gamma}{\gamma-\sigma}\left(\varphi_{i j}^{*}\right)^{-(\gamma-\sigma)}\left(\frac{f r_{i j}}{w_{i} t_{i j}}\right)\left(\varphi_{i j}^{*}\right)^{\gamma} \\
+\frac{\sigma(\sigma-1)}{2 !}\left(\frac{w_{i} t_{i j}}{\rho P_{j}}\right)^{1-\sigma} \frac{w_{j} L_{j}}{\sigma} \frac{\gamma}{\gamma-\sigma+1}\left(\varphi_{i j}^{*}\right)^{-(\gamma-\sigma+1)}\left(\frac{f r_{i j}}{w_{i} t_{i j}}\right)^{2}\left(\varphi_{i j}^{*}\right)^{\gamma}+\ldots \\
-w_{i} F_{i j}^{X}
\end{gathered}
$$


Rearranging terms again yields:

$$
\begin{gathered}
\bar{\pi}_{i j}=\left(\frac{w_{i} t_{i j}}{\rho P_{j} \varphi_{i j}^{*}}\right)^{1-\sigma} \frac{w_{j} L_{j}}{\sigma}\left\{\frac{\gamma}{(\gamma-\sigma+1}-\frac{\gamma(\sigma-1)}{\gamma-\sigma}\left(\frac{\varphi_{i j}^{*} f r_{i j}}{w_{i} t_{i j}}\right)\right. \\
+\frac{\gamma \sigma(\sigma-1)}{(\gamma-\sigma) 2 !}\left(\frac{\varphi_{i j}^{*} f r_{i j}}{w_{i} t_{i j}}\right)^{2}-\frac{\gamma \sigma(\sigma-1)(\sigma+1)}{(\gamma-\sigma+1) 3 !}\left(\frac{\varphi_{i j}^{*} f r_{i j}}{w_{i} t_{i j}}\right)^{3}+\ldots \\
-w_{i} F_{i j}^{X}
\end{gathered}
$$

This can be succinctly written as:

$$
\bar{\pi}_{i j}=\left(\frac{w_{i} t_{i j}}{\rho P_{j} \varphi_{i j}^{*}}\right)^{1-\sigma} \frac{w_{j} L_{j}}{\sigma}\left\{\sum_{m=0}^{\infty}(-1)^{m} \frac{(\sigma-2+m) !}{((\sigma-2) !) m !}\left(\frac{\varphi_{i j}^{*} f r_{i j}}{w_{i} t_{i j}}\right)^{m}\left(\frac{\gamma}{\gamma-\sigma-1+m}\right)\right\}
$$

The RHS will converge if $\frac{\varphi_{i j}^{*} f r_{i j}}{w_{i} t_{i j}}<1$. Analogously to above, the ratio is likely less than one because empirically freight costs per worker are less than labor costs per worker. 


\section{Online Appendix 3}

Table 1

\begin{tabular}{|c|c|c|c|c|c|c|}
\hline $\begin{array}{c}(1) \\
\text { Variables }\end{array}$ & $\begin{array}{c}(2) \\
\text { Expected Sign } \\
\text { Trade }\end{array}$ & $\begin{array}{c}\text { (3) } \\
\text { Trade }\end{array}$ & $\begin{array}{c}(4) \\
\text { Expected Sign } \\
\text { Intensive }\end{array}$ & $\begin{array}{c}\text { (5) } \\
\text { Intensive }\end{array}$ & $\begin{array}{c}(6) \\
\text { Expected Sign } \\
\text { Extensive }\end{array}$ & $\begin{array}{c}\text { (7) } \\
\text { Extensive }\end{array}$ \\
\hline$\overline{O W P T A_{t}}$ & + & $\begin{array}{l}-0.11^{* * *} \\
(-3.75)\end{array}$ & + & $\begin{array}{l}-0.07^{* *} \\
(-2.56)\end{array}$ & + & $\begin{array}{l}-0.04 \\
(-1.13)\end{array}$ \\
\hline$O W P T A_{t} * \ln$ DIST & - & $\begin{array}{l}-0.11^{* * *} \\
(-3.44)\end{array}$ & - & $\begin{array}{c}-0.12^{* * *} \\
(3.84)\end{array}$ & - & $\begin{array}{c}0.01 \\
(0.22)\end{array}$ \\
\hline$O W P T A_{t} * \mathrm{ADJ}$ & ? & $\begin{array}{c}0.17 \\
(0.80)\end{array}$ & + & $\begin{array}{l}-0.15 \\
(-0.73)\end{array}$ & - & $\begin{array}{c}0.31 \\
(1.30)\end{array}$ \\
\hline$O W P T A_{t} * \mathrm{LANG}$ & + & $\begin{array}{l}-0.01 \\
(-0.18)\end{array}$ & 0 & $\begin{array}{l}-0.21^{* * *} \\
(-2.71)\end{array}$ & + & $\begin{array}{l}0.20 * * * \\
(2.12)\end{array}$ \\
\hline$O W P T A_{t} *$ RELIG & + & $\begin{array}{l}-0.04 \\
(-0.65)\end{array}$ & 0 & $\begin{array}{c}0.05 \\
(0.78)\end{array}$ & + & $\begin{array}{l}-0.09 \\
(-1.21)\end{array}$ \\
\hline$O W P T A_{t} *$ LEGAL & $?$ & $\begin{array}{c}0.00 \\
(0.00)\end{array}$ & 0 & $\begin{array}{l}0.15^{* * *} \\
(3.17)\end{array}$ & $?$ & $\begin{array}{l}-0.15^{* * *} \\
(-2.65)\end{array}$ \\
\hline$O W P T A_{t} *$ COLONY & $?$ & $\begin{array}{c}0.06 \\
(0.52)\end{array}$ & 0 & $\begin{array}{c}0.14 \\
(11.41)\end{array}$ & $?$ & $\begin{array}{l}-0.09 \\
(-0.72)\end{array}$ \\
\hline$T W P T A_{t}$ & + & $\begin{array}{c}0.01 \\
(0.25)\end{array}$ & + & $\begin{array}{c}0.02 \\
(0.43)\end{array}$ & + & $\begin{array}{l}-0.01 \\
(-0.14)\end{array}$ \\
\hline$T W P T A_{t} * \ln$ DIST & - & $\begin{array}{l}-0.14^{* * *} \\
(-3.55)\end{array}$ & - & $\begin{array}{l}-0.13^{* * *} \\
(-3.57)\end{array}$ & - & $\begin{array}{l}-0.00 \\
(-0.07)\end{array}$ \\
\hline$T W P T A_{t} * \mathrm{ADJ}$ & $?$ & $\begin{array}{c}0.09 \\
(0.96)\end{array}$ & + & $\begin{array}{c}0.11 \\
(1.25)\end{array}$ & - & $\begin{array}{l}-0.02 \\
(-0.22)\end{array}$ \\
\hline$T W P T A_{t} * \mathrm{LANG}$ & + & $\begin{array}{c}0.00 \\
(0.00)\end{array}$ & 0 & $\begin{array}{l}-0.10 \\
(-1.47)\end{array}$ & + & $\begin{array}{c}0.10 \\
(1.24)\end{array}$ \\
\hline$T W P T A_{t} *$ RELIG & + & $\begin{array}{c}0.04 \\
(0.59)\end{array}$ & 0 & $\begin{array}{l}-0.12^{*} \\
(-1.72)\end{array}$ & + & $\begin{array}{r}0.17^{*} \\
(1.95)\end{array}$ \\
\hline$T W P T A_{t} *$ LEGAL & $?$ & $\begin{array}{l}-0.04 \\
(-0.77)\end{array}$ & 0 & $\begin{array}{c}0.03 \\
(0.56)\end{array}$ & $?$ & $\begin{array}{l}-0.08 \\
(-1.14)\end{array}$ \\
\hline$T W P T A_{t} *$ COLONY & $?$ & $\begin{array}{l}-0.04 \\
(-0.36)\end{array}$ & 0 & $\begin{array}{l}-0.11 \\
(-1.11)\end{array}$ & $?$ & $\begin{array}{c}0.07 \\
(0.62)\end{array}$ \\
\hline$F T A_{t}$ & + & $\begin{array}{l}0.20^{* * *} \\
(5.94)\end{array}$ & + & $\begin{array}{l}0.11^{* * *} \\
(3.30)\end{array}$ & + & $\begin{array}{c}0.09 \\
(2.33)\end{array}$ \\
\hline$F T A_{t} * \ln$ DIST & - & $\begin{array}{l}-0.21^{* * *} \\
(-8.12)\end{array}$ & - & $\begin{array}{l}-0.04^{*} \\
(-1.76)\end{array}$ & - & $\begin{array}{l}-0.17^{* * *} \\
(-5.57)\end{array}$ \\
\hline$F T A_{t} * \mathrm{ADJ}$ & $?$ & $\begin{array}{c}0.12^{* * *} \\
(16.76)\end{array}$ & + & $\begin{array}{c}0.30^{* * *} \\
(14.46)\end{array}$ & - & $\begin{array}{l}-0.19^{* *} \\
(-2.24)\end{array}$ \\
\hline$F T A_{t} * \mathrm{LANG}$ & + & $\begin{array}{l}0.19^{* * *} \\
(3.31)\end{array}$ & 0 & $\begin{array}{c}0.04 \\
(0.79)\end{array}$ & + & $\begin{array}{l}0.15^{* *} \\
(2.21)\end{array}$ \\
\hline$F T A_{t} *$ RELIG & + & $\begin{array}{l}0.20^{* * *} \\
(3.45)\end{array}$ & 0 & $\begin{array}{l}-0.06 \\
(-1.07)\end{array}$ & + & $\begin{array}{l}0.26^{* * *} \\
(3.88)\end{array}$ \\
\hline$F T A_{t} * \mathrm{LEGAL}$ & $?$ & $\begin{array}{l}-0.10^{* *} \\
(-2.13)\end{array}$ & 0 & $\begin{array}{c}0.07 \\
(1.55)\end{array}$ & $?$ & $\begin{array}{l}-0.17^{* * *} \\
(-3.13)\end{array}$ \\
\hline$F T A_{t} *$ COLONY & $?$ & $\begin{array}{l}-0.21^{*} \\
(-1.89)\end{array}$ & 0 & $\begin{array}{c}0.10 \\
(0.94)\end{array}$ & $?$ & $\begin{array}{l}-0.31^{* *} \\
(-2.41)\end{array}$ \\
\hline
\end{tabular}


Table 1

\begin{tabular}{|c|c|c|c|c|c|c|}
\hline $\begin{array}{c}(1) \\
\text { Variables }\end{array}$ & $\begin{array}{c}(2) \\
\text { Expected Sign } \\
\text { Trade }\end{array}$ & $\begin{array}{c}(3) \\
\text { Trade }\end{array}$ & $\begin{array}{l}(4) \\
\text { Expected Sign } \\
\text { Intensive }\end{array}$ & $\begin{array}{c}(5) \\
\text { Intensive }\end{array}$ & $\begin{array}{c}(6) \\
\text { Expected Sign } \\
\text { Extensive }\end{array}$ & $\begin{array}{c}(7) \\
\text { Extensive }\end{array}$ \\
\hline$\overline{C U_{t}}$ & + & $\begin{array}{l}0.61^{* * *} \\
(3.46)\end{array}$ & + & $\begin{array}{c}0.51^{* * *} \\
(2.99)\end{array}$ & + & $\begin{array}{c}0.10 \\
(0.49)\end{array}$ \\
\hline$C U_{t} * \ln \mathrm{DIST}$ & - & $\begin{array}{c}-0.13 \\
(-1.36)\end{array}$ & - & $\begin{array}{c}0.10 \\
(1.03)\end{array}$ & - & $\begin{array}{l}-0.23^{* *} \\
(-2.04)\end{array}$ \\
\hline$C U_{t} * \mathrm{ADJ}$ & $?$ & $\begin{array}{c}0.08 \\
(0.57)\end{array}$ & + & $\begin{array}{c}0.28^{* *} \\
(2.11)\end{array}$ & - & $\begin{array}{c}-0.20 \\
(-1.27)\end{array}$ \\
\hline$C U_{t} * \mathrm{LANG}$ & + & $\begin{array}{l}0.64^{* * *} \\
(4.62)\end{array}$ & 0 & $\begin{array}{c}0.06 \\
(0.45)\end{array}$ & + & $\begin{array}{l}0.58^{* * *} \\
(3.61)\end{array}$ \\
\hline$C U_{t} *$ RELIG & + & $\begin{array}{c}0.27^{*} \\
(1.72)\end{array}$ & 0 & $\begin{array}{c}0.03 \\
(0.18)\end{array}$ & + & $\begin{array}{c}0.25 \\
(1.34)\end{array}$ \\
\hline$C U_{t} *$ LEGAL & $?$ & $\begin{array}{c}0.09 \\
(0.69)\end{array}$ & 0 & $\begin{array}{c}0.04 \\
(0.32)\end{array}$ & $?$ & $\begin{array}{c}0.05 \\
(0.32)\end{array}$ \\
\hline$C U_{t} * \mathrm{COLONY}$ & $?$ & $\begin{array}{l}-1.17^{* * *} \\
(-3.31)\end{array}$ & 0 & $\begin{array}{c}-0.14 \\
(-0.41)\end{array}$ & $?$ & $\begin{array}{l}-1.03^{* *} \\
(-2.51)\end{array}$ \\
\hline$C M_{t}$ & + & $\begin{array}{l}0.69^{* * *} \\
(5.95)\end{array}$ & + & $\begin{array}{c}-0.17 \\
(-1.51)\end{array}$ & + & $\begin{array}{l}0.86^{* * *} \\
(6.42)\end{array}$ \\
\hline$C M_{t} * \ln$ DIST & - & $\begin{array}{l}-0.20^{\text {*** }} \\
(-2.86)\end{array}$ & - & $\begin{array}{l}-0.49^{* * *} \\
(-7.25)\end{array}$ & - & $\begin{array}{l}0.29^{* * *} \\
(3.62)\end{array}$ \\
\hline$C M_{t} * \mathrm{ADJ}$ & $?$ & $\begin{array}{c}-0.02 \\
(-0.16)\end{array}$ & + & $\begin{array}{c}0.20 \\
(1.45)\end{array}$ & - & $\begin{array}{c}-0.22 \\
(-1.36)\end{array}$ \\
\hline$C M_{t} * \mathrm{LANG}$ & + & $\begin{array}{c}0.02 \\
(0.09)\end{array}$ & 0 & $\begin{array}{l}-0.50^{* * *} \\
(-2.63)\end{array}$ & + & $\begin{array}{c}0.52^{* *} \\
(2.27)\end{array}$ \\
\hline$C M_{t} *$ RELIG & + & $\begin{array}{c}0.13 \\
(1.33)\end{array}$ & 0 & $\begin{array}{c}0.00 \\
(0.03)\end{array}$ & + & $\begin{array}{c}0.12 \\
(1.13)\end{array}$ \\
\hline$C M_{t} * \mathrm{LEGAL}$ & $?$ & $\begin{array}{c}-0.03 \\
(-0.32)\end{array}$ & 0 & $\begin{array}{c}0.02 \\
(0.20)\end{array}$ & $?$ & $\begin{array}{c}-0.05 \\
(-0.45)\end{array}$ \\
\hline$C M_{t} *$ COLONY & $?$ & $\begin{array}{c}-0.21 \\
(-1.12)\end{array}$ & 0 & $\begin{array}{c}0.24 \\
(1.31)\end{array}$ & $?$ & $\begin{array}{l}-0.45^{* *} \\
(-2.07)\end{array}$ \\
\hline$E C U_{t}$ & + & $\begin{array}{l}0.80^{* * *} \\
(4.37)\end{array}$ & + & $\begin{array}{c}0.20 \\
(1.16)\end{array}$ & + & $\begin{array}{c}0.59 \\
(2.82)\end{array}$ \\
\hline$E C U_{t} * \ln$ DIST & - & $\begin{array}{c}0.00 \\
(0.01)\end{array}$ & - & $\begin{array}{c}-0.24^{*} \\
(-1.93)\end{array}$ & - & $\begin{array}{c}0.24 \\
(1.63)\end{array}$ \\
\hline$E C U_{t} * \mathrm{ADJ}$ & $?$ & $\begin{array}{c}-0.08 \\
(-0.45)\end{array}$ & + & $\begin{array}{c}0.22 \\
(1.28)\end{array}$ & - & $\begin{array}{c}-0.30 \\
(-1.46)\end{array}$ \\
\hline$E C U_{t} * \mathrm{LANG}$ & + & $\begin{array}{l}0.42^{* * *} \\
(2.57)\end{array}$ & 0 & $\begin{array}{c}-0.30^{*} \\
(-1.94)\end{array}$ & + & $\begin{array}{l}0.72^{* * *} \\
(3.85)\end{array}$ \\
\hline$E C U_{t} *$ RELIG & + & $\begin{array}{l}0.37^{* * *} \\
(2.61)\end{array}$ & 0 & $\begin{array}{l}0.43^{* * *} \\
(3.14)\end{array}$ & + & $\begin{array}{c}-0.06 \\
(-0.36)\end{array}$ \\
\hline$E C U_{t} * \mathrm{LEGAL}$ & $?$ & $\begin{array}{c}-0.12 \\
(-1.08)\end{array}$ & 0 & $\begin{array}{c}-0.05 \\
(-0.41)\end{array}$ & $?$ & $\begin{array}{c}-0.08 \\
(-0.59)\end{array}$ \\
\hline$E C U_{t} * \mathrm{COLONY}$ & $?$ & $\begin{array}{c}0.53 \\
(1.26)\end{array}$ & 0 & $\begin{array}{c}0.32 \\
(0.77)\end{array}$ & $?$ & $\begin{array}{c}0.22 \\
(0.44)\end{array}$ \\
\hline
\end{tabular}


Table 1

\begin{tabular}{|c|c|c|c|c|c|c|}
\hline Variables & $\begin{array}{c}(2) \\
\text { Expected Sign } \\
\text { Trade }\end{array}$ & Trade & $\begin{array}{c}(4) \\
\text { Expected Sign } \\
\text { Intensive }\end{array}$ & Intensive & $\begin{array}{c}(6) \\
\text { Expected Sign } \\
\text { Extensive }\end{array}$ & Extensive \\
\hline \multicolumn{7}{|l|}{ Fixed Effects: } \\
\hline Exporter-Year & & Yes & & Yes & & Yes \\
\hline Importer-Year & & Yes & & Yes & & Yes \\
\hline Country-Pair & & Yes & & Yes & & Yes \\
\hline$\overline{R^{2}}$ & & 0.912 & & 0.822 & & 0.824 \\
\hline$N$ & & 70,173 & & 70,173 & & 70,173 \\
\hline
\end{tabular}

Notes: ${ }^{*},{ }^{* *}$, and ${ }^{* * *}$ denote $p<0.10, p<0.05$, and $p<0.01$, respectively. Cutoff for nontraded goods is $\$ 1,000,000$; this affects the sample size. 
Table 2

\begin{tabular}{|c|c|c|c|c|c|c|}
\hline $\begin{array}{c}(1) \\
\text { Variables }\end{array}$ & $\begin{array}{c}(2) \\
\text { Expected Sign } \\
\text { Trade }\end{array}$ & $\begin{array}{c}(3) \\
\text { Trade }\end{array}$ & $\begin{array}{c}(4) \\
\text { Expected Sign } \\
\text { Intensive }\end{array}$ & Intensive & $\begin{array}{c}(6) \\
\text { Expected Sign } \\
\text { Extensive }\end{array}$ & $\begin{array}{c}(7) \\
\text { Extensive }\end{array}$ \\
\hline$\overline{O W P T A_{t}}$ & + & $\begin{array}{l}-0.08^{* * *} \\
(-2.81)\end{array}$ & + & $\begin{array}{c}-0.05^{*} \\
(-1.73)\end{array}$ & + & $\begin{array}{c}-0.03 \\
(-1.11)\end{array}$ \\
\hline$O W P T A_{t} * \ln \mathrm{DIST}$ & - & $\begin{array}{l}-0.09^{* * *} \\
(-2.81)\end{array}$ & - & $\begin{array}{l}-0.10^{* * *} \\
(-3.30)\end{array}$ & - & $\begin{array}{c}0.01 \\
(0.28)\end{array}$ \\
\hline$O W P T A_{t} * \mathrm{ADJ}$ & $?$ & $\begin{array}{c}0.09 \\
(0.39)\end{array}$ & + & $\begin{array}{l}-0.13^{* *} \\
(-0.58)\end{array}$ & - & $\begin{array}{c}0.23 \\
(0.92)\end{array}$ \\
\hline$O W P T A_{t} * \mathrm{LANG}$ & + & $\begin{array}{c}-0.10 \\
(-1.31)\end{array}$ & 0 & $\begin{array}{c}-0.13^{*} \\
(-1.87)\end{array}$ & + & $\begin{array}{c}0.04 \\
(0.47)\end{array}$ \\
\hline$O W P T A_{t} *$ RELIG & + & $\begin{array}{c}0.01 \\
(0.11)\end{array}$ & 0 & $\begin{array}{l}0.13^{* *} \\
(2.12)\end{array}$ & + & $\begin{array}{c}-0.12^{*} \\
(-1.87)\end{array}$ \\
\hline$O W P T A_{t} *$ LEGAL & $?$ & $\begin{array}{c}-0.05 \\
(-1.11)\end{array}$ & 0 & $\begin{array}{l}0.20^{* * *} \\
(4.51)\end{array}$ & $?$ & $\begin{array}{l}-0.25^{* * *} \\
(-5.29)\end{array}$ \\
\hline$O W P T A_{t} *$ COLONY & $?$ & $\begin{array}{c}0.10 \\
(0.96)\end{array}$ & 0 & $\begin{array}{c}0.03 \\
(0.32)\end{array}$ & $?$ & $\begin{array}{c}0.07 \\
(0.62)\end{array}$ \\
\hline$T W P T A_{t}$ & + & $\begin{array}{c}0.04 \\
(1.21)\end{array}$ & + & $\begin{array}{c}-0.02 \\
(-0.48)\end{array}$ & + & $\begin{array}{c}0.06 \\
(1.63)\end{array}$ \\
\hline$T W P T A_{t} * \ln$ DIST & - & $\begin{array}{l}-0.12^{\text {*** }} \\
(-3.37)\end{array}$ & - & $\begin{array}{l}-0.13^{* * *} \\
(-3.94)\end{array}$ & - & $\begin{array}{c}0.02 \\
(0.44)\end{array}$ \\
\hline$T W P T A_{t} * \mathrm{ADJ}$ & $?$ & $\begin{array}{l}0.25^{* * *} \\
(2.82)\end{array}$ & + & $\begin{array}{c}0.09 \\
(1.06)\end{array}$ & - & $\begin{array}{c}0.16^{*} \\
(1.76)\end{array}$ \\
\hline$T W P T A_{t} * \mathrm{LANG}$ & + & $\begin{array}{c}0.01 \\
(0.08)\end{array}$ & 0 & $\begin{array}{c}-0.04 \\
(-0.60)\end{array}$ & + & $\begin{array}{c}0.04 \\
(0.64)\end{array}$ \\
\hline$T W P T A_{t} *$ RELIG & + & $\begin{array}{c}0.05 \\
(0.69)\end{array}$ & 0 & $\begin{array}{c}-0.08 \\
(-1.13)\end{array}$ & + & $\begin{array}{c}0.12^{*} \\
(1.75)\end{array}$ \\
\hline$T W P T A_{t} *$ LEGAL & $?$ & $\begin{array}{c}-0.02 \\
(-0.36)\end{array}$ & 0 & $\begin{array}{c}0.11^{* *} \\
(2.04)\end{array}$ & $?$ & $\begin{array}{l}-0.13^{* *} \\
(-2.25)\end{array}$ \\
\hline$T W P T A_{t} * \mathrm{COLONY}$ & $?$ & $\begin{array}{l}-0.27^{* *} \\
(-2.42)\end{array}$ & 0 & $\begin{array}{c}-0.16 \\
(-1.50)\end{array}$ & $?$ & $\begin{array}{c}-0.11 \\
(-0.96)\end{array}$ \\
\hline$F T A_{t}$ & + & $\begin{array}{l}0.21^{* * *} \\
(5.78)\end{array}$ & + & $\begin{array}{l}0.23^{* * *} \\
(6.68)\end{array}$ & + & $\begin{array}{c}-0.02 \\
(-0.54)\end{array}$ \\
\hline$F T A_{t} * \ln \mathrm{DIST}$ & - & $\begin{array}{l}-0.15^{* * *} \\
(-5.67)\end{array}$ & - & $\begin{array}{l}-0.07^{* * *} \\
(-2.81)\end{array}$ & - & $\begin{array}{l}-0.08^{* * *} \\
(-2.86)\end{array}$ \\
\hline$F T A_{t} * \mathrm{ADJ}$ & $?$ & $\begin{array}{c}0.05 \\
(0.65)\end{array}$ & + & $\begin{array}{l}0.32^{* * *} \\
(4.36)\end{array}$ & - & $\begin{array}{l}-0.27^{* * *} \\
(-3.39)\end{array}$ \\
\hline$F T A_{t} * \mathrm{LANG}$ & + & $\begin{array}{l}0.19^{* * *} \\
(3.08)\end{array}$ & 0 & $\begin{array}{c}0.09 \\
(1.53)\end{array}$ & + & $\begin{array}{c}0.10 \\
(1.61)\end{array}$ \\
\hline$F T A_{t} *$ RELIG & + & $\begin{array}{l}0.29^{* * *} \\
(4.77)\end{array}$ & 0 & $\begin{array}{c}0.10 \\
(1.76)\end{array}$ & + & $\begin{array}{l}0.18^{* * *} \\
(2.95)\end{array}$ \\
\hline$F T A_{t} * \mathrm{LEGAL}$ & $?$ & $\begin{array}{l}-0.11^{* *} \\
(-2.19)\end{array}$ & 0 & $\begin{array}{c}0.04 \\
(0.78)\end{array}$ & $?$ & $\begin{array}{l}-0.14^{* * *} \\
(-2.86)\end{array}$ \\
\hline$F T A_{t} * \mathrm{COLONY}$ & $?$ & $\begin{array}{l}-0.37^{* * *} \\
(-2.93)\end{array}$ & 0 & $\begin{array}{c}0.14 \\
(1.12)\end{array}$ & $?$ & $\begin{array}{l}-0.51^{\text {*** }} \\
(-3.91)\end{array}$ \\
\hline
\end{tabular}


Table 2

\begin{tabular}{|c|c|c|c|c|c|c|}
\hline $\begin{array}{c}(1) \\
\text { Variables }\end{array}$ & $\begin{array}{c}(2) \\
\text { Expected Sign } \\
\text { Trade }\end{array}$ & $\begin{array}{c}(3) \\
\text { Trade }\end{array}$ & $\begin{array}{l}(4) \\
\text { Expected Sign } \\
\text { Intensive }\end{array}$ & Intensive & $\begin{array}{c}6) \\
\text { Expected Sign } \\
\text { Extensive }\end{array}$ & $\begin{array}{c}(7) \\
\text { Extensive }\end{array}$ \\
\hline$\overline{C U_{t}}$ & + & $\begin{array}{c}0.53^{* * *} \\
(2.85)\end{array}$ & + & $\begin{array}{c}0.55^{* * *} \\
(3.07)\end{array}$ & + & $\begin{array}{c}-0.02 \\
(-0.09)\end{array}$ \\
\hline$C U_{t} * \ln$ DIST & - & $\begin{array}{c}-0.08 \\
(-0.76)\end{array}$ & - & $\begin{array}{c}0.00 \\
(0.04)\end{array}$ & - & $\begin{array}{c}-0.08 \\
(-0.77)\end{array}$ \\
\hline$C U_{t} * \mathrm{ADJ}$ & $?$ & $\begin{array}{c}0.03 \\
(0.18)\end{array}$ & + & $\begin{array}{c}0.27^{*} \\
(1.91)\end{array}$ & - & $\begin{array}{c}-0.24 \\
(-1.60)\end{array}$ \\
\hline$C U_{t} * \mathrm{LANG}$ & + & $\begin{array}{l}0.65^{* * *} \\
(4.38)\end{array}$ & 0 & $\begin{array}{c}0.15 \\
(1.07)\end{array}$ & + & $\begin{array}{l}0.50^{* * *} \\
(3.26)\end{array}$ \\
\hline$C U_{t} *$ RELIG & + & $\begin{array}{c}0.30^{*} \\
(1.74)\end{array}$ & 0 & $\begin{array}{c}0.20 \\
(1.22)\end{array}$ & + & $\begin{array}{c}0.10 \\
(0.56)\end{array}$ \\
\hline$C U_{t} * \mathrm{LEGAL}$ & $?$ & $\begin{array}{c}0.04 \\
(0.25)\end{array}$ & 0 & $\begin{array}{c}-0.08 \\
(-0.57)\end{array}$ & $?$ & $\begin{array}{r}-0.11 \\
(0.78)\end{array}$ \\
\hline$C U_{t} *$ COLONY & $?$ & $\begin{array}{l}-1.27^{\text {*** }} \\
(-3.07)\end{array}$ & 0 & $\begin{array}{c}-0.14 \\
(-0.35)\end{array}$ & $?$ & $\begin{array}{l}-1.13^{* * *} \\
(-2.67)\end{array}$ \\
\hline$C M_{t}$ & + & $\begin{array}{l}0.54^{* * *} \\
(4.29)\end{array}$ & + & $\begin{array}{c}0.01 \\
(0.12)\end{array}$ & + & $\begin{array}{l}0.53^{* * *} \\
(4.09)\end{array}$ \\
\hline$C M_{t} * \ln \mathrm{DIST}$ & - & $\begin{array}{l}-0.23^{\text {*** }} \\
(-2.94)\end{array}$ & - & $\begin{array}{l}-0.50^{* * *} \\
(-6.80)\end{array}$ & - & $\begin{array}{l}0.28^{* * *} \\
(3.52)\end{array}$ \\
\hline$C M_{t} * \mathrm{ADJ}$ & $?$ & $\begin{array}{c}-0.03 \\
(-0.02)\end{array}$ & + & $\begin{array}{c}0.11 \\
(0.72)\end{array}$ & - & $\begin{array}{c}-0.11 \\
(-0.70)\end{array}$ \\
\hline$C M_{t} * \mathrm{LANG}$ & + & $\begin{array}{c}0.01 \\
(0.04)\end{array}$ & 0 & $\begin{array}{c}-0.35^{*} \\
(-1.65)\end{array}$ & + & $\begin{array}{c}0.35 \\
(1.58)\end{array}$ \\
\hline$C M_{t} *$ RELIG & + & $\begin{array}{l}0.21^{* *} \\
(2.03)\end{array}$ & 0 & $\begin{array}{c}0.15 \\
(1.49)\end{array}$ & + & $\begin{array}{c}0.06 \\
(0.58)\end{array}$ \\
\hline$C M_{t} * \mathrm{LEGAL}$ & $?$ & $\begin{array}{c}-0.10 \\
(-1.03)\end{array}$ & 0 & $\begin{array}{c}-0.12 \\
(-1.33)\end{array}$ & $?$ & $\begin{array}{c}0.02 \\
(0.24)\end{array}$ \\
\hline$C M_{t} * \mathrm{COLONY}$ & $?$ & $\begin{array}{c}-0.44^{* *} \\
(-2.01)\end{array}$ & 0 & $\begin{array}{c}0.27 \\
(1.31)\end{array}$ & $?$ & $\begin{array}{l}-0.71^{\text {*** }} \\
(-3.19)\end{array}$ \\
\hline$E C U_{t}$ & + & $\begin{array}{l}0.40^{* *} \\
(2.06)\end{array}$ & + & $\begin{array}{c}0.42^{* *} \\
(2.29)\end{array}$ & + & $\begin{array}{c}-0.03 \\
(-0.13)\end{array}$ \\
\hline$E C U_{t} * \ln \mathrm{DIST}$ & - & $\begin{array}{l}-0.27^{* *} \\
(-1.99)\end{array}$ & - & $\begin{array}{c}-0.25^{*} \\
(-1.93)\end{array}$ & - & $\begin{array}{c}-0.02 \\
(-0.15)\end{array}$ \\
\hline$E C U_{t} * \mathrm{ADJ}$ & $?$ & $\begin{array}{c}-0.09 \\
(-0.05)\end{array}$ & + & $\begin{array}{c}-0.07 \\
(-0.37)\end{array}$ & - & $\begin{array}{c}-0.03 \\
(-0.14)\end{array}$ \\
\hline$E C U_{t} * \mathrm{LANG}$ & + & $\begin{array}{c}0.40^{* *} \\
(2.39)\end{array}$ & 0 & $\begin{array}{c}-0.00^{*} \\
(-0.03)\end{array}$ & + & $\begin{array}{c}0.40^{* *} \\
(2.35)\end{array}$ \\
\hline$E C U_{t} *$ RELIG & + & $\begin{array}{c}0.34^{* *} \\
(2.22)\end{array}$ & 0 & $\begin{array}{l}0.64^{* * *} \\
(4.41)\end{array}$ & + & $\begin{array}{c}-0.30^{*} \\
(-1.94)\end{array}$ \\
\hline$E C U_{t} * \mathrm{LEGAL}$ & $?$ & $\begin{array}{c}-0.18 \\
(-1.37)\end{array}$ & 0 & $\begin{array}{c}-0.15 \\
(-1.23)\end{array}$ & $?$ & $\begin{array}{c}-0.02 \\
(-0.18)\end{array}$ \\
\hline$E C U_{t} * \mathrm{COLONY}$ & $?$ & $\begin{array}{c}-0.11 \\
(-0.22)\end{array}$ & 0 & $\begin{array}{c}0.45 \\
(0.96)\end{array}$ & $?$ & $\begin{array}{c}-0.57 \\
(-1.11)\end{array}$ \\
\hline
\end{tabular}


Table 2

\begin{tabular}{|c|c|c|c|c|c|c|}
\hline $\begin{array}{c}(1) \\
\text { Variables }\end{array}$ & $\begin{array}{c}(2) \\
\text { Expected Sign } \\
\text { Trade }\end{array}$ & Trade & $\begin{array}{c}(4) \\
\text { Expected Sign } \\
\text { Intensive }\end{array}$ & Intensive & $\begin{array}{c}(6) \\
\text { Expected Sign } \\
\text { Extensive }\end{array}$ & Extensive \\
\hline \multicolumn{7}{|l|}{ Fixed Effects: } \\
\hline Exporter-Year & & Yes & & Yes & & Yes \\
\hline Importer-Year & & Yes & & Yes & & Yes \\
\hline Country-Pair & & Yes & & Yes & & Yes \\
\hline$\overline{\overline{R^{2}}}$ & & 0.897 & & 0.800 & & 0.821 \\
\hline$N$ & & 103,147 & & 103,147 & & 103,147 \\
\hline
\end{tabular}

Notes: ${ }^{*},{ }^{* *}$, and ${ }^{* * *}$ denote $p<0.10, p<0.05$, and $p<0.01$, respectively. Cutoff for nontraded goods is $\$ 100,000$; this affects the sample size. 
Online Appendix 4

Table 1: Probit Results: 1970-1990

\begin{tabular}{|c|c|c|c|c|c|}
\hline & $\begin{array}{c}(1) \\
\text { EIA }(1970)\end{array}$ & $\begin{array}{c}(2) \\
\text { EIA }(1975)\end{array}$ & $\begin{array}{c}(3) \\
\text { EIA }(1980)\end{array}$ & $\begin{array}{c}(4) \\
\text { EIA }(1985)\end{array}$ & $\begin{array}{c}(5) \\
\text { EIA }(1990)\end{array}$ \\
\hline $\ln$ DIST & $\begin{array}{c}-0.944^{* * *} \\
(-14.51)\end{array}$ & $\begin{array}{c}-1.101^{* * *} \\
(-22.72)\end{array}$ & $\begin{array}{c}-1.117^{* * *} \\
(-23.10)\end{array}$ & $\begin{array}{c}-1.123^{* * *} \\
(-24.90)\end{array}$ & $\begin{array}{c}-1.185^{* * *} \\
(-27.23)\end{array}$ \\
\hline ADJ & $\begin{array}{c}-0.874^{* * *} \\
(-4.82)\end{array}$ & $\begin{array}{c}-1.031^{* * *} \\
(-7.25)\end{array}$ & $\begin{array}{c}-1.073^{* * *} \\
(-7.34)\end{array}$ & $\begin{array}{c}-1.029^{* * *} \\
(-7.44)\end{array}$ & $\begin{array}{c}-0.916^{* * *} \\
(-7.21)\end{array}$ \\
\hline LANG & $\begin{array}{c}0.00290 \\
(0.02)\end{array}$ & $\begin{array}{l}0.242^{*} \\
(2.44)\end{array}$ & $\begin{array}{l}0.195^{*} \\
(1.98)\end{array}$ & $\begin{array}{c}0.371^{* * *} \\
(4.03)\end{array}$ & $\begin{array}{c}0.317^{* * *} \\
(3.62)\end{array}$ \\
\hline LEGAL & $\begin{array}{l}0.229 \\
(1.94)\end{array}$ & $\begin{array}{c}0.0592 \\
(0.69)\end{array}$ & $\begin{array}{c}0.0621 \\
(0.74)\end{array}$ & $\begin{array}{c}0.0489 \\
(0.63)\end{array}$ & $\begin{array}{c}-0.00484 \\
(-0.07)\end{array}$ \\
\hline COLONY & $\begin{array}{l}-0.269 \\
(-0.83)\end{array}$ & $\begin{array}{l}-0.287 \\
(-1.31)\end{array}$ & $\begin{array}{c}-0.0562 \\
(-0.28)\end{array}$ & $\begin{array}{l}-0.248 \\
(-1.26)\end{array}$ & $\begin{array}{c}-0.0560 \\
(-0.33)\end{array}$ \\
\hline RELIG & $\begin{array}{c}0.497^{* * *} \\
(3.59)\end{array}$ & $\begin{array}{c}0.308^{* *} \\
(3.03)\end{array}$ & $\begin{array}{c}0.308^{* *} \\
(3.04)\end{array}$ & $\begin{array}{l}0.215^{*} \\
(2.25)\end{array}$ & $\begin{array}{c}0.0686 \\
(0.76)\end{array}$ \\
\hline Sum GDP & $\begin{array}{c}0.290^{* * *} \\
(4.56)\end{array}$ & $\begin{array}{c}0.383^{* * *} \\
(7.80)\end{array}$ & $\begin{array}{c}0.340^{* * *} \\
(6.99)\end{array}$ & $\begin{array}{c}0.330^{* * *} \\
(6.97)\end{array}$ & $\begin{array}{c}0.452^{* * *} \\
(10.64)\end{array}$ \\
\hline$|D i f f G D P|$ & $\begin{array}{c}-0.136^{* * *} \\
(-2.69)\end{array}$ & $\begin{array}{c}-0.153^{* *} \\
(-3.89)\end{array}$ & $\begin{array}{c}-0.126^{* * *} \\
(-3.22)\end{array}$ & $\begin{array}{c}-0.151 \text { *** } \\
(-3.96)\end{array}$ & $\begin{array}{c}-0.190 * * * \\
(-5.83)\end{array}$ \\
\hline Constant & $\begin{array}{l}0.917 \\
(1.13)\end{array}$ & $\begin{array}{l}0.672 \\
(1.17)\end{array}$ & $\begin{array}{l}1.180^{*} \\
(2.07)\end{array}$ & $\begin{array}{c}2.287^{* * *} \\
(4.08)\end{array}$ & $\begin{array}{l}0.742 \\
(1.42)\end{array}$ \\
\hline$N$ & 9912 & 11530 & 11604 & 10700 & 11552 \\
\hline PseudoR ${ }^{2}$ & 0.354 & 0.398 & 0.403 & 0.402 & 0.418 \\
\hline
\end{tabular}


Probit Tables

1995-2010

Table 2: Probit Results: 1995-2010

\begin{tabular}{|c|c|c|c|c|}
\hline & $\begin{array}{c}(1) \\
\text { EIA (1995) }\end{array}$ & $\begin{array}{c}(2) \\
\text { EIA }^{(2000)}\end{array}$ & $\begin{array}{c}(3) \\
\text { EIA }(2005)\end{array}$ & $\begin{array}{c}(4) \\
\text { EIA }(2010)\end{array}$ \\
\hline $\ln$ DIST & $\begin{array}{c}-1.165^{* * *} \\
(-36.89)\end{array}$ & $\begin{array}{c}-1.214^{* * *} \\
(-48.58)\end{array}$ & $\begin{array}{c}-1.177^{* * *} \\
(-58.47)\end{array}$ & $\begin{array}{c}-1.098^{* * *} \\
(-59.28)\end{array}$ \\
\hline ADJ & $\begin{array}{c}-0.572^{\text {*** }} \\
(-6.49)\end{array}$ & $\begin{array}{c}-0.352^{* * *} \\
(-4.71)\end{array}$ & $\begin{array}{c}-0.400^{* * *} \\
(-5.50)\end{array}$ & $\begin{array}{c}-0.226^{* *} \\
(-3.16)\end{array}$ \\
\hline LANG & $\begin{array}{c}0.677^{* * *} \\
(10.64)\end{array}$ & $\begin{array}{c}0.535^{* * *} \\
(11.17)\end{array}$ & $\begin{array}{c}0.451^{* * *} \\
(11.25)\end{array}$ & $\begin{array}{c}0.451^{* * *} \\
(11.86)\end{array}$ \\
\hline LEGAL & $\begin{array}{c}-0.221^{* * *} \\
(-4.00)\end{array}$ & $\begin{array}{c}-0.0636 \\
(-1.54)\end{array}$ & $\begin{array}{c}-0.0221 \\
(-0.66)\end{array}$ & $\begin{array}{c}-0.0243 \\
(-0.78)\end{array}$ \\
\hline COLONY & $\begin{array}{c}-0.353^{*} \\
(-2.46)\end{array}$ & $\begin{array}{c}0.000277 \\
(0.00)\end{array}$ & $\begin{array}{c}-0.0896 \\
(-0.94)\end{array}$ & $\begin{array}{c}-0.217^{*} \\
(-2.32)\end{array}$ \\
\hline RELIG & $\begin{array}{c}0.207^{* *} \\
(3.14)\end{array}$ & $\begin{array}{c}0.300^{* * *} \\
(5.98)\end{array}$ & $\begin{array}{c}0.241^{* * *} \\
(5.75)\end{array}$ & $\begin{array}{c}0.206^{* * *} \\
(5.21)\end{array}$ \\
\hline Sum GDP & $\begin{array}{c}0.505^{* * *} \\
(15.59)\end{array}$ & $\begin{array}{c}0.537^{* * *} \\
(20.27)\end{array}$ & $\begin{array}{c}0.426^{* * *} \\
(20.08)\end{array}$ & $\begin{array}{c}0.420^{* * *} \\
(20.79)\end{array}$ \\
\hline$|\operatorname{Diff} G D P|$ & $\begin{array}{c}-0.239^{* * *} \\
(-9.61)\end{array}$ & $\begin{array}{c}-0.275^{* * *} \\
(-13.40)\end{array}$ & $\begin{array}{c}-0.209^{* *} \\
(-12.69)\end{array}$ & $\begin{array}{c}-0.198^{* * *} \\
(-12.55)\end{array}$ \\
\hline Constant & $\begin{array}{l}0.559 \\
(1.48)\end{array}$ & $\begin{array}{c}1.275^{* * *} \\
(4.28)\end{array}$ & $\begin{array}{c}2.603^{* * *} \\
(10.36)\end{array}$ & $\begin{array}{c}1.955^{* * *} \\
(8.23)\end{array}$ \\
\hline$N$ & 16904 & 21724 & 23196 & 22805 \\
\hline PseudoR ${ }^{2}$ & 0.421 & 0.443 & 0.401 & 0.360 \\
\hline
\end{tabular}

